\title{
Algoritmos Evolutivos Aplicados na Investigação da Adaptabilidade do Código Genético
}

\author{
Lariza Laura de Oliveira
}

Tese apresentada ao programa Interunidades em Bioinformática para a obtenção do grau de Doutor em Ciências

Departamento de ComputaÇão e Matemática DA

Faculdade de Filosofia, Ciências e Letras de

\author{
RIBEIRÃo PRETO \\ $\mathrm{DA}$ \\ Universidade De SÃo Paulo
}

Programa Interunidades de Pós-Graduação em Bioinformática

Orientador: Prof. Dr. Renato Tinós

Coorientador: Prof. Dr. Paulo Sérgio Lopes de Oliveira 


\section{Algoritmos Evolutivos Aplicados na Investigação da Adaptabilidade do Codigo Genético}

Esta versão corresponde à tese

de Lariza Laura de Oliveira a ser apresentada para a Comissão Julgadora. 
Dedicatória

Dedico esta tese às minhas raízes 


\section{Agradecimentos}

"People think dreams aren't real just because they aren't made of matter, of particles. Dreams are real. But they are made of viewpoints, of images, of memories and puns and lost hopes."

- Neil Gaiman

"Dreams shape the world."

- Neil Gaiman, The Sandman, Vol. 3: Dream Country

- A todos os professores que passaram pela minha vida, que me motivaram a seguir o caminho acadêmico. Em especial aos da Informática Biomédica.

- Ao meu orientador prof. Renato Tinós pela orientação, dedicação e incentivo que veio desde a minha primeira iniciação cientifica, ainda durante a graduação, em 2006. Por ter depositado em mim a confiança que permitiu com que esse trabalho fosse concluído.

- Ao prof. Paulo Sérgio pelas importantes sugestões durante o desenvolvimento deste trabalho.

- Ao prof. Alex Freitas pelas contribuições, acolhida e aprendizado durante minha estádia na Universidade de Kent.

- A todos os amigos que me receberam durante o estágio no exterior e que hoje continuam presentes na minha vida.

- Aos meus colegas de laboratório, que durante a pós-graduação cederam seu precioso tempo as minhas discussões e cafés. 
- A todos os funcionários do Departamento de Computação e Matemática pela amizade, pelos cafezinhos e por tornar a rotina de trabalho mais leve e agradável.

- A Patrícia Martorelli por me ajudar nos assuntos burocráticos do programa de pósgraduação, durante o mestrado e doutorado.

- A todos os meus amigos por me apoiarem e incentivarem nos momentos de desilusão, por não permitirem que eu desistisse, por não me abandonarem mesmo quando eu não tinha tempo para cultivar nossa amizade.

- Aos amigos Daniane e André, em especial, pelos longos anos de amizade, presença e companheirismo.

- A amiga Luciana pelas preciosas conversas nem sempre científicas que muito me ajudaram nos últimos meses de escrita.

- A meus pais Walter e Elizabeth e a minha irmã Nadia por permitirem que tudo isso fosse possível, por terem me apoiado durante toda a minha trajetória de estudante.

- À Fundação de Amparo a Pesquisa do Estado de São Paulo (FAPESP) pelo auxílio financeiro a este projeto.

- A Deus por me amparar nos momentos mais difíceis. 


\section{Resumo}

O código genético é altamente conservado e está presente na maior parte dos organismos vivos. Uma questão que tem intrigado os cientistas é se o código genético é fruto do acaso ou de um processo evolutivo. Se qualquer associação entre aminoácidos e códons é possível, então existem cerca de $1,51 \times 10^{84}$ códigos possíveis. A hipótese de que o código genético evoluiu é suportada por sua robustez frente a mutações. Duas metodologias tem sido utilizadas para estudar esta hipótese: a abordagem estatística, que estima o número de códigos aleatórios melhores que o código genético padrão, e a abordagem por engenharia, que compara o código padrão com os melhores códigos hipotéticos obtidos por meio de um algoritmo de otimização. A utilização de ambas abordagens têm sido feita considerando-se apenas uma função objetivo, baseada na robustez frente a mutações quando uma determinada propriedade dos aminoácidos é considerada. Neste trabalho, propõe-se considerar mais de um objetivo simultaneamente para a avaliação dos códigos genéticos. Para isso, três abordagens multiobjetivo utilizando Algoritmos Genéticos são empregadas. São elas: abordagem lexicográfica, ponderada e de Pareto. Os resultados indicam que a utilização de mais de um objetivo é promissor, sendo os códigos hipotéticos gerados mais similares ao código genético padrão, quando comparados com os resultados obtidos por outros autores.

Palavras-chave: Algoritmos Genéticos, Bioinformática, Adaptabilidade do Código Genético. 


\section{Abstract}

The genetic code is highly preserved and it is present in most living organisms. If we consider all codes mapping the 64 codes into 20 amino acids and one stop codon, there are more than $1.51 \times 10^{84}$ possible genetic codes. The main question related to the organization of the genetic code is why exactly the standard code was selected among this huge number of possible genetic codes. The hypothesis that the genetic code has evolved is supported by its robustness against mutations. Many researchers argue that the organization of the standard code is a product of natural selection and that the code's robustness against mutations would support this hypothesis. Two methodologies have been used to investigate this hypothesis: the first one is the statistical approach which estimates the number of random codes which are better than the standard genetic code. The second is the engineering approach, which compare the standard code with the best hypothetical codes obtained by an optimization algorithm. Both approaches have been used considering only one objective function, which is usually based on the robustness against changes using the polar requirement. In this research, we propose to consider more than one objective simultaneously for the evaluation of genetic codes. For this purpose, three approaches using multi-objective genetic algorithms were employed, are they: lexicographic, weighted, and Pareto-based. The results indicate that considering more than one objective function is promising: the hypothetical codes generated are more similar to the standard genetic code, when compared with the results obtained by the monoobjective approach.

key words: Genetic algorithms, Bioinformatics, Genetic code adaptability. 


\section{Conteúdo}

$\begin{array}{ll}\text { Dedicatória } & \text { i }\end{array}$

Lista de Abreviaturas $\quad$ ix

Lista de Símbolos $\quad$ x

Lista de Figuras $\quad$ xi

Lista de Tabelas $\quad$ xiv

1 Introdução $\quad 1$

1.1 Objetivos e contribuições . . . . . . . . . . . . . . . . . . . 3

1.2 Organização do documento . . . . . . . . . . . . . . . . . . . . . . 4

2 O código genético $\quad 5$

2.1 Ácidos nucleicos e proteínas: características básicas . . . . . . . . . . . 6

2.1 .1 Ácidos nucleicos . . . . . . . . . . . . . . . . . . . . . . 6

2.1.2 Proteínas . . . . . . . . . . . . . . . . 6

2.2 Do DNA às proteínas . . . . . . . . . . . . . . . . . 8

2.3 Alguns conceitos básicos de evolução . . . . . . . . . . . . . . . . . 9

2.4 A origem do código genético . . . . . . . . . . . . . . . . . . . . 11

2.5 Características do código genético e sua descoberta . . . . . . . . . . . . . 12

2.6 Avaliação de códigos genéticos . . . . . . . . . . . . . . . . . . . . . . . . . . . . . . . . . .

2.6.1 Função de Avaliação Baseada na Robustez . . . . . . . . . . . . . . . 13 
2.6.2 Erros de tradução e em função da posição da base . . . . . . . . . . . 15

2.6.3 Medidas para validação de códigos . . . . . . . . . . . . . . . 16

2.7 Trabalhos relacionados . . . . . . . . . . . . . . . . . . . . . 18

3 Algoritmos Genéticos $\quad 20$

3.1 Algoritmos Genéticos . . . . . . . . . . . . . . . . . . 20

3.1 .1 O Algoritmo Genético Padrão . . . . . . . . . . . . . . . . . . . 21

3.1.2 Codificação, Operadores de Seleção e Reprodução Empregados . . . 24

3.1.3 Algoritmos Genéticos Multiobjetivo . . . . . . . . . . . . . . 27

4 Abordagem Monoobjetivo $\quad 29$

5 Abordagem Ponderada 34

6 Abordagem Lexicográfica 39

7 Abordagem de Pareto $\quad 43$

7.1 NSGA-II . . . . . . . . . . . . . . . . . . . . . . 43

7.1.1 Abordagem de Pareto utilizando dois objetivos: Polaridade e Hidropatia 46

7.1.2 Abordagem de Pareto utilizando dois objetivos: Polaridade e Volume Molecular . . . . . . . . . . . . . . . . . . . . . . . 49

7.1.3 Abordagem de Pareto utilizando três objetivos: Polaridade, Hidropatia e Volume Molecular . . . . . . . . . . . . . . . . . . . . . . . 52

8 Discussão e Conclusões $\quad 56$

8.1 Comparação das abordagens . . . . . . . . . . . . . . . . . . 56

8.2 Conclusões . . . . . . . . . . . . . . . . . . . . . . 62

A Abordagem de Pareto e por pesos considerando uma função de robustez $\begin{array}{ll}\text { baseada em entropia } & 64\end{array}$

A.1 Função de avaliação baseada na entropia . . . . . . . . . . . . . . . . . . . . 67

A.2 Abordagem por pesos considerando entropia . . . . . . . . . . . . . 67

A.3 Abordagem de Pareto . . . . . . . . . . . . . . . . . . . . . . . . . . 68

A.4 Avaliação dos resultados . . . . . . . . . . . . . . . . . . . . 68

A.5 Resultados e Discussão . . . . . . . . . . . . . . . . . . . . . . . 68

A.5.1 Abordagem 1: ponderada baseada em entropia . . . . . . . . . . . 68

A.5.2 Abordagem 2: Pareto baseada em entropia . . . . . . . . . . . . . . 71

A.6 Considerações finais . . . . . . . . . . . . . . . . . . . . 74

B Apêndice: Abordagem de Pareto considerando a codificação restritiva 76 B.1 Abordagem de Pareto utilizando dois objetivos: Polaridade e Volume Molecular 77 
B.1.1 Abordagem de Pareto utilizando dois objetivos: Polaridade e Volume Molecular . . . . . . . . . . . . . . . . . 79

B.2 Abordagem estatística . . . . . . . . . . . . . . . . 81

B.3 Conclusões . . . . . . . . . . . . . . . . . . . . . . . . . . . . . 82

$\begin{array}{lr}\text { Bibliografia } & 83\end{array}$ 


\section{Lista de Abreviaturas}

$\begin{array}{ll}\text { AG } & \text { Algoritmo Genético } \\ \text { CGP } & \text { Código Genético Padrão } \\ p d m & \text { Porcentagem de distância de minimização } \\ \text { DNA } & \text { ácido desoxirribonucleico } \\ \text { RNA } & \text { ácido ribonucleico } \\ \text { mRNA } & \text { RNA mensageiro } \\ \text { tRNA } & \text { RNA transportador } \\ \text { A } & \text { Adenina } \\ \text { C } & \text { Citosina } \\ \text { T } & \text { Timina } \\ \text { G } & \text { Guanina } \\ \text { U } & \text { Uracila } \\ \text { NSGA-II } & \text { Fast Nondominated Sorting Approach II } \\ \text { AEs } & \text { Algoritmos evolutivos } \\ \text { ATP } & \text { Trifosfato de adenosina } \\ \text { GTP } & \text { Trifosfato de guanosina } \\ \text { ADP } & \text { Difostato de adenosina } \\ \text { GDP } & \text { Difostato de guanosina } \\ \text { CDP } & \text { Difostato de citidina } \\ \text { UDP } & \text { Difostato de uridina } \\ & \end{array}$




\section{Lista de Símbolos}

$M_{s} \quad$ Medida de robustez

$M_{s t} \quad$ Medida de robustez considerando pesos

$C \quad$ Código genético hipotético

$w(i, j) \quad$ Peso entre dois aminoácidos

$N(i, j, C)$ Número de possíveis substituições de um códon

$\bar{f}_{i} \quad$ Avaliação média de códigos gerados aleatoriamente

$f_{i}(C) \quad$ Avaliação do $i$-ésimo objetivo do código hipotético

$C_{\mathrm{C}} \quad$ Valor de avaliação do código genético padrão 


\section{Lista de Figuras}

1.1 O código genético padrão adaptada de (Lehninger et al., 2005). . . . . . . . 2

2.1 A tradução. . . . . . . . . . . . . . . . . . . . . . . . 9

3.1 Funcionamento básico do AG. . . . . . . . . . . . . . . . . . . . . . 22

3.2 Funcionamento básico do crossover. . . . . . . . . . . . . . . . . . . 23

3.3 Funcionamento básico da mutação. . . . . . . . . . . . . . . . . . . . . . . . 23

3.4 Fragmento de um indivíduo na codificação não restritiva. Cada posição corresponde a 1 dos 61 códons (exceto códons de parada) associada a um dos 20 possíveis aminoácidos. . . . . . . . . . . . . . . . . . . . . 24

3.5 Codificação restritiva. Nesta codificação um indivíduo é composto por 20 posições referentes aos aminoácidos, sendo cada uma associada a um grupo de códons. . . . . . . . . . . . . . . . . . . . . . . 25

3.6 O operador de swap. . . . . . . . . . . . . . . . . 26

3.7 O operador de mutação. . . . . . . . . . . . . . . . . . 26

3.8 Exemplo de problema multiobjetivo. . . . . . . . . . . . . . . . . . 28

4.1 Frequência de códons associados a cada aminoácido para o código hipotético de maior $p d m$ e para o código padrão. . . . . . . . . . . . . . . . . . . . 32

5.1 Frequência de códons associados a cada aminoácido para o código hipotético de maior $p d m$ e para o código padrão para a combinação de pesos $w_{1}=0,4$, $w_{2}=0,35, w_{3}=0,25 \ldots \ldots \ldots \ldots \ldots$ 
5.2 Frequência de códons associados a cada aminoácido para o código hipotético de maior $p d m$ e para o código padrão para a combinação de pesos $w_{1}=0,6$, $w_{2}=0,3, w_{3}=0,1 \ldots \ldots \ldots \ldots \ldots \ldots \ldots \ldots \ldots \ldots \ldots \ldots \ldots \ldots \ldots$

5.3 Frequência de códons associados a cada aminoácido para o código hipotético de maior $p d m$ e para o código padrão para a combinação de pesos $w_{1}=0,8$, $w_{2}=0,15$ e $w_{3}=0,05 \ldots \ldots \ldots \ldots \ldots$

6.1 Frequência de códons associados a cada aminoácido para o código hipotético de maior $p d m$ e para o código padrão. . . . . . . . . . . . . . . . . .

7.1 Fronteira de Pareto para o experimento utilizando polaridade e hidropatia. .

7.2 Frequência de códons associados a cada aminoácido para o código hipotético de maior $p d m$ e para o código genético padrão,utilizando a abordagem de Pareto com dois objetivos: polaridade e hidropatia. . . . . . . . . . . . . . . 49

7.3 Fronteira de pareto para o experimento utilizando polaridade e volume. . . . 50

7.4 Frequência de códons associados a cada aminoácido para o código hipotético de maior $p d m$ e para o código genético padrão para a abordagem de Pareto com dois objetivos: polaridade e volume molecular. . . . . . . . . . . . . 52

7.5 Fronteira de Pareto para o experimento utilizando polaridade e volume. . . .

7.6 Frequência de códons associados a cada aminoácido para o código hipotético de maior $p d m$ e para o código genético padrão, considerando a abordagem de Pareto com 3 objetivos (polaridade, hidropatia e volume molecular). . . . . .

8.1 Fronteira considerando todas as soluções obtidas pelas abordagens de Pareto .

A.1 Frequências de códons associados a aminoácidos para o melhor indivíduo em comparação com o código genético padrão. . . . . . . . . . . . . . . . . . .

A.2 Valor de avaliação do melhor individuo para 10 execuções do AG e diferentes tabelas de conversão.

A.3 Frequências de códons associados a aminoácidos no código genético padrão e no melhor código hipotético obtido no experimento com a abordagem 1 e com $a=0.7$ usando $M_{s}$.

A.4 Frequências de códons associados a aminoácidos no código genético padrão e no melhor código hipotético obtido no experimento com a abordagem 1 e com $a=0.8$ usando $M_{s t} \ldots \ldots \ldots \ldots \ldots \ldots$

A.5 Frequências de códons associados a aminoácidos no código genético padrão e no melhor código hipotético não dominado com a abordagem 1 e usando $M_{s}$.

A.6 Frequências de códons associados a aminoácidos no código genético padrão e no melhor código hipotético não dominado com a abordagem 1 e usando $M_{s t}$.

B.1 Fronteira de Pareto para o experimento utilizando polaridade e hidropatia com a codificação restritiva. 
B.2 Fronteira de Pareto para o experimento utilizando polaridade e hidropatia com a codificação restritiva e $M_{s t} \ldots \ldots \ldots \ldots$. . . . . . . . 78

B.3 Fronteira de Pareto para o experimento utilizando polaridade e hidropatia com a codificação restritiva. . . . . . . . . . . . . . . . . . 80

B.4 Fronteira de Pareto para o experimento utilizando polaridade e volume com a codificação restritiva e $M_{s t} \ldots \ldots \ldots$. . . . . . . . . . . . . 81 


\section{Lista de Tabelas}

2.1 Propriedades dos aminoácidos (Haig e Hurst, 1991): polaridade (Woese, 1965), hidropatia (Kyte e Doolittle, 1982) e volume (Grantham, 1974). . . . . . . .

2.2 Pesos usados no cálculo do $M_{s t}$. Os pesos representam a quantificação de erros na tradução usados para ponderar o erro como função da posição da base.

4.1 Média, desvio padrão e mínimo dos valores de avaliação $\left(M_{s t}\right.$ considerando a polaridade dos aminoácidos) calculados para o melhor código obtido pelo AG monoobjetivo na ultima geração (para 30 sementes aleatórias). . . . . . . . .

4.2 P-valores obtidos usando o teste Wilcoxon signed-rank para comparação entre as taxas de swap e mutação. Os valores de robustez utilizados no cálculo foram obtidos para o melhores códigos hipotéticos retornados pelo AG monoobjetivo. 30

4.3 Média, desvio padrão e melhores valores dos valores de avaliação, $p d m$ (considerando a polaridade), melhora, número de coincidências e entropia calculados para os melhores códigos obtidos pelo AG monoobjetivo na última geração (para 30 sementes aleatórias). $M_{s t}(\mathrm{P})$ é o valor do erro para a polaridade, as demais medidas são indicadas como $(\mathrm{H})$ para hidropatia e (VM) para o volume. 31

4.4 Polaridade dos aminoácidos. . . . . . . . . . . . . . . . . . . . . . . 32

4.5 Código genético padrão e melhores códigos hipotéticos obtidos pelo AG Monoobjetivo (os códigos de parada foram omitidos) . . . . . . . . . . . .

5.1 Resultados de avaliação, $M_{s t}, p d m$, melhora, número de coindiciências e entropia para os melhores códigos obtidos pelo AG ponderado. . . . . . . . . . 
5.2 Código genético padrão e melhores códigos hipotéticos obtidos pelo AG Ponderado (os códigos de parada foram omitidos) . . . . . . . . . . . . . .

6.1 Resultados de avaliação para os três objetivos, $p d m$, melhora (para a polaridade) and número de coincidências para os melhores códigos obtidos pelo AG lexicográfico. . . . . . . . . . . . . . . . . . . .

6.2 Código genético padrão e melhores códigos hipotéticos obtidos pelo AG Lexicografico (os códigos de parada foram omitidos) . . . . . . . . . . . . . .

7.1 Resultados de avaliação para os objetivos $\left(M_{s t}\right.$ considerando polaridade e hidropatia), $p d m$ e melhora para as soluções não dominadas obtidas pelo NSGA-II. . . . . . . . . . . . . . . . . . . . . .

7.2 Resultados de avaliação para os dois objetivos considerados, $p d m$, melhora (para a polaridade), número de coincidências e entropia para os melhores códigos obtidos pelo AG com Pareto para Polaridade e Hidropatia (para 30 sementes aleatórias).

7.3 Código genético padrão e melhores códigos hipotéticos obtidos pelo AG multiobjetivo com dois objetivos: polaridade e hidropatia. . . . . . . . . . . . . .

7.4 Resultados de avaliação para os objetivos $\left(M_{s t}\right.$ considerando polaridade e hidropatia), $p d m$ e melhora para as soluções não dominadas obtidas pelo NSGA-II (em 30 execuções do AG) . . . . . . . . . . . . . . . . . .

7.5 Resultados de avaliação para os dois objetivos considerados, pdm, melhora (para a polaridade) and número de coincidências para os melhores códigos obtidos pela abordagem de Pareto com dois objetivos: Polaridade e o Volume Molecular. . . . . . . . . . . . . . . . . . . .

7.6 Código genético padrão e melhores códigos hipotéticos obtidos pelo AG multiobjetivo na abordagem de Pareto com dois objetivos: polaridade e volume

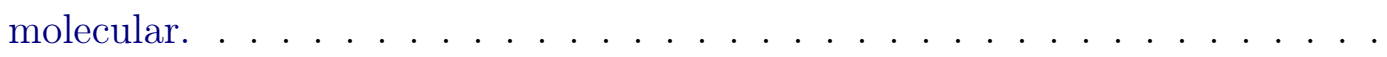

7.7 Resultados de avaliação para os objetivos $\left(M_{s t}\right.$ considerando polaridade, hidropatia e volume molecular), $p d m$ e melhora para as soluções não dominadas obtidas pelo NSGA-II (em 30 execuções do AG). . . . . . . . . . . . . . .

7.8 Resultados de avaliação para os três objetivos considerados, $p d m$, melhora (para a polaridade), número de coincidências e entropia para os melhores códigos obtidos pelo AG com Pareto considerando polaridade, hidropatia e volume molecular. . . . . . . . . . . . . . . . . . .

7.9 Código genético padrão e melhores códigos hipotéticos obtidos pelo AG multiobjetivo na abordagem de Pareto com três objetivos: polaridade, hidropatia e volume molecular. . . . . . . . . . . . . . . . . . . . . . . . . 
8.1 Comparação dos resultados de avaliação $\left(M_{s t}\right)$ para os três objetivos do CGC e de todas as abordagens testadas. O melhor valor de cada objetivo também é apresentado. Neste caso, ele não corresponde necessariamente a mesma solução. 57

8.2 Comparação dos resultados de avaliação $\left(M_{s t}\right)$ para os três objetivos do CGC e dos melhores indivíduos de todas as abordagens testadas. . . . . . . . . . 59

8.3 Comparação dos valores de $p d m$ de todas as abordagens testadas. . . . . . . 60

8.4 Comparação dos valores de melhora para a polaridade de todas as abordagens testadas. . . . . . . . . . . . . . . . . . . 61

8.5 Comparação dos valores de coincidências para a polaridade de todas as abordagens testadas. . . . . . . . . . . . . . . . . . . . .

8.6 Comparação dos valores de entropia para a polaridade de todas as abordagens testadas. . . . . . . . . . . . . . . . . . .

8.7 Tabela Resumo: indica qual abordagem obteve o melhor valor médio da medida indicada. . . . . . . . . . . . . . . . . . . . . . .

A.1 Valores de $p d m$ e melhora no experimento com a abordagem 1, utilizando $M_{s} .69$

A.2 Valores de $p d m$ e melhora no experimento com a abordagem 1, utilizando $M_{s t}$. 69

A.3 Resultados da avaliação dos objetivos 1 e 2, pdm e melhora para as soluções não dominadas e dominância em relação ao código padrão, considerando $M_{s}$.

A.4 Resultados da avaliação dos objetivos 1 e 2, pdm e melhora para as soluções não dominadas e dominância em relação ao código padrão, considerando $M_{s t}$.

A.5 Número de coindências para os experimentos com $M_{s}$ e $M_{s}$ para abordagem 1 (ponderada) e 2 (Pareto).

A.6 Código genético padrão e os código hipotéticos de maior valor de $p d m$ em ambas as abordagens. . . . . . . . . . . . . . .

B.1 Resultados de avaliação para os objetivos $\left(M_{t}\right.$ considerando polaridade $(\mathrm{P})$ e hidropatia $(\mathrm{H}))$, pdm e melhora para as soluções não dominadas obtidas pelo NSGA-II. Os valores de $M_{s}$ para o código padrão são 5,19 para a polaridade e 9,39 para a hidropatia.

B.2 Resultados de avaliação para os objetivos $\left(M_{s t}\right.$ considerando polaridade e hidropatia), $p d m$ e melhora para as soluções não dominadas obtidas pelo NSGA-II. Os valores de $M_{s t}$ para o código padrão são 2,63 para a polaridade e 4,6 para a hidropatia.

B.3 Resultados de avaliação para os objetivos $\left(M_{s}\right.$ considerando polaridade e o volume molecular), $p d m$ e melhora para as soluções não dominadas obtidas pelo NSGA-II. Os valores de $M_{s}$ para o código padrão são 5,19 para a polaridade e 2266,13 para o volume. 
B.4 Resultados de avaliação para os objetivos $\left(M_{s t}\right.$ considerando polaridade e o volume molecular), $p d m$ e melhora para as soluções não dominadas obtidas pelo NSGA-II. Os valores de $M_{s t}$ para o código padrão são 2,63 para a polaridade e 1766,7 para o volume. . . . . . . . . . . . . . . . . .

B.5 Numero de códigos aleatórios melhores que o padrão. Foram gerados 10 milhões de códigos. . . . . . . . . . . . . . . . . . . . . . . 


\section{CAPÍTULO 1}

\section{Introdução}

"I'm fascinated by the idea that genetics is digital. A gene is a long sequence of coded letters, like computer information. Modern biology is becoming very much a branch of information technology."

- Richard Dawkins

Proteínas são macromoléculas vitais para a maioria dos processos biológicos em organismos vivos, sendo responsáveis por tarefas relacionadas à catálise, ao transporte, ao armazenamento, à motilidade, à defesa e à regulação. Proteínas são compostas por aminoácidos unidos por ligações covalentes formando séries com diferentes tamanhos e constituições (Lehninger et al., 2005). Os aminoácidos diferem entre si de acordo com as propriedades de suas cadeias laterais, tais como polaridade, tamanho, entre outras. A complexidade estrutural e a diversidade de funções biológicas das proteínas são produtos do grande número de possibilidades de composição e sequências de aminoácidos. A sequência de aminoácidos de uma proteína é ditada pelo RNA mensageiro de acordo com o código genético. Cada trinca de nucleotídeos, conhecida como códon, é mapeada em um aminoácido.

Durante algum tempo pensou-se que o código genético padrão fosse universal e imutável desde o seu surgimento, ou seja, que o código não houvesse evoluído desde então. O fato é que o código genético padrão é o mesmo na maioria dos organismos vivos, sendo chamado, portanto, de universal. O termo "frozen accident" foi empregado por Crick para se referir a hipótese de que a estrutura do código tivesse surgido a partir de um evento aleatório (Crick, 
1968). A complexa maquinaria proteica previamente descrita suportava essa hipótese, já que qualquer alteração do código implicaria em mudanças nas proteínas codificadas, o que seria biologicamente inviável, podendo causar sérias consequências nos organismos vivos, desde doenças até mesmo sendo incompatível com a vida.

A descoberta da existência de códigos genéticos alternativos, ou seja, que divergiam do padrão, mostrou que o código é capaz de evoluir sim e não é universal como se pensava. Um exemplo de código divergente do padrão é o código mitocondrial. A observação de que o código mitocondrial divergia do nuclear iniciou a busca por outros códigos alternativos. Atualmente, cerca de 20 códigos alternativos são conhecidos (Koonin e Novozhilov, 2009). Acredita-se que esses códigos alternativos sejam oriundos do código genético padrão (Knight et al., 2001).

O código genético padrão, portanto, está presente em grande parte dos organismos vivos, salvo as exceções acima referidas. Uma pergunta que tem intrigado os cientistas há várias décadas é o porquê exatamente esse código foi escolhido (Crick, 1968; Di Giulio, 2005, 1989; Freeland e Hurst, 1998; Maddox, 1994; Monteagudo e Santos, 2007; Parker, 1989; Vetsigian et al., 2006; Woese, 1965). Se todos as combinações de 64 códons e 21 aminoácidos forem consideradas, então teria-se mais de 1,51×10 ${ }^{84}$ códigos possíveis (Schoenauer e Clote, 1997). A Figura 1.1 mostra o código genético padrão.

\begin{tabular}{|c|c|c|c|c|c|c|c|}
\hline \multirow{18}{*}{ 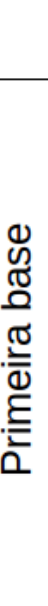 } & & \multicolumn{4}{|c|}{ Segunda base } & & \multirow{18}{*}{ 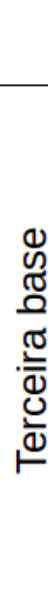 } \\
\hline & & $\mathrm{U}$ & $\mathrm{C}$ & A & G & & \\
\hline & \multirow{4}{*}{$\mathrm{U}$} & Fenilalanina (PHE) & Serina (SER) & Tirosina (TYR) & Cisteína (CYS) & $\mathrm{U}$ & \\
\hline & & Fenilalanina (PHE) & Serina (SER) & Tirosina (TYR) & Cisteína (CYS) & $\mathrm{C}$ & \\
\hline & & Leucina (LEU) & Serina (SER) & Códon de Parada & Códon de Parada & $A$ & \\
\hline & & Leucina (LEU) & Serina (SER) & Códon de Parada & Triptofano (TRP) & G & \\
\hline & \multirow{4}{*}{ C } & Leucina (LEU) & Prolina (PRO) & Histidina (HIS) & Arginina (ARG) & $\mathrm{U}$ & \\
\hline & & Leucina (LEU) & Prolina (PRO) & Histidina (HIS) & Arginina (ARG) & $\mathrm{C}$ & \\
\hline & & Leucina (LEU) & Prolina (PRO) & Glutamina (GLN) & Arginina (ARG) & $A$ & \\
\hline & & Leucina (LEU) & Prolina (PRO) & Glutamina (GLN) & Arginina (ARG) & G & \\
\hline & \multirow{4}{*}{ A } & Isoleucina (ILE) & Treonina (THR) & Asparagina (ASN) & Serina (SER) & $\mathrm{U}$ & \\
\hline & & Isoleucina (ILE) & Treonina (THR) & Asparagina (ASN) & Serina (SER) & $\mathrm{C}$ & \\
\hline & & Isoleucina (ILE) & Treonina (THR) & Lisina (LYS) & Arginina (ARG) & A & \\
\hline & & Metionina (MET) & Treonina (THR) & Lisina (LYS) & Arginina (ARG) & G & \\
\hline & \multirow{4}{*}{ G } & Valina (VAL) & Alanina (ALA) & Ácido Aspático (ASP) & Glicina (GLY) & $\mathrm{U}$ & \\
\hline & & Valina (VAL) & Alanina (ALA) & Ácido Aspático (ASP) & Glicina (GLY) & $\mathrm{C}$ & \\
\hline & & Valina (VAL) & Alanina (ALA) & Ácido Glutâmico (GLU) & Glicina (GLY) & $\mathrm{A}$ & \\
\hline & & Valina (VAL) & Alanina (ALA) & Ácido Glutâmico (GLU) & Glicina (GLY) & G & \\
\hline
\end{tabular}

Figura 1.1: O código genético padrão adaptada de (Lehninger et al., 2005).

Existem algumas principais teorias que tentam explicar a origem do código genético padrão, dentre elas destacam-se três: a teoria estereoquímica, teoria adaptativa e co-evolução (as teorias são detalhas no Capítulo 2).

A organização do código genético padrão permanece sob discussão, porém muitos pesquisadores argumentam que o código genético é produto da seleção natural. A hipótese de que o código genético tenha evoluído é sustentada por sua robustez contra mutações quando propriedades como polaridade são consideradas (Woese, 1965). Haig and Hurst (Haig e Hurst , 1991), e outros autores depois deles (Freeland e Hurst, 1998; Knight et al., 1999), mostra- 
ram que uma pequena porcentagem de códigos aleatórios são melhores que o código genético padrão, quando a minimização de efeitos deletérios no processo de tradução é considerada.

De acordo com (Knight et al., 1999), seguindo a hipótese de que o código genético é produto da seleção natural, duas abordagens têm sido utilizadas para analisar o problema de adaptabilidade do código genético: a abordagem estatística e a abordagem por engenharia. A abordagem estatística estima o número de códigos gerados aleatoriamente melhores que o código genético padrão (Alff-Steinberger, 1969). O problema da abordagem estatística é que se apenas uma parte muito pequena dos possíveis códigos aleatórios é melhor que o código padrão, então é muito difícil identificar códigos ótimos. Já a abordagem por engenharia permite identificar regiões do espaço de busca onde os melhores códigos, de acordo com uma dada função de avaliação, podem ser encontrados.

Seguindo a abordagem por engenharia, Santos e Monteagudo (Santos e Monteagudo , 2010) empregaram um Algoritmo Genético (AG) para otimizar os códigos de acordo com uma função de robustez considerando a polaridade. AGs pertencem à classe dos Algoritmos Evolutivos (AEs), i.e., meta-heurísticas populacionais inspiradas em mecanismos encontrados em evolução natural e genética. AEs, devido às suas características intrínsecas, como uso de operadores estocásticos e de populações de soluções candidatas, podem ser vistos, aparentemente, como extremamente interessantes para problemas complexos nos quais técnicas tradicionais de otimização não apresentam bom desempenho. Vale salientar, entretanto, que outros algoritmos de otimização poderiam ser utilizados na abordagem por engenharia (Buhrman et al., 2011).

\subsection{Objetivos e contribuições}

Tanto na abordagem estatística como na abordagem por engenharia, os trabalhos encontrados na literatura têm sempre empregado um único objetivo durante a otimização, que é geralmente uma função da robustez perante erros quando uma única medida, como a polaridade dos aminoácidos, é considerada. A hipótese deste trabalho é que o uso simultâneo de mais de um objetivo é útil para o estudo do código genético padrão.

Neste trabalho, pela primeira vez, mais de um objetivo é utilizado para comparar a qualidade dos códigos genéticos hipotéticos e padrão. Para isso, seguindo a abordagem por engenharia, um Algoritmo Genético multiobjetivo é empregado para levar em consideração mais de um objetivo simultaneamente. Dessa forma, consideramos a hipótese de que mais de um fator foi importante durante o processo de evolução que deu origem ao código genético.

Nas simulações apresentadas nessa tese de doutorado, as medidas de robustez frente a propriedades distintas dos aminoácidos são consideradas simultaneamente. Dessa forma, é possível estudar combinações de funções e propriedades durante o processo de otimização e como elas afetam a geração de códigos hipotéticos. Os códigos gerados podem então ser comparados ao código genético padrão, fornecendo indícios sobre quais fatores podem ter 
sido importantes para o surgimento do código genético padrão.

Um algoritmo genético foi implementado "in house"e três abordagens multiobjetivo foram testadas: ponderada, lexicográfica e por Pareto. Vale ressaltar que este é o primeiro trabalho na literatura que considera mais de um objetivo simultaneamente no processo de otimização para gerar códigos hipotéticos ótimos. Os resultados indicam que considerar outras propriedades além da polaridade na função de robustez pode produzir códigos hipotéticos mais próximos do código genético padrão, em comparação com aqueles gerados com apenas um objetivo. Os experimentos realizados até aqui abrem margem para um estudo mais aprofundado das funções de avaliação utilizadas neste problema, indicando que a utilização da abordagem multiobjetivo é promissora.

\subsection{Organização do documento}

Esta tese está organizada em: Capítulo 2, no qual conceitos básicos sobre o código genético são apresentados; Capítulo 3, no qual conceitos básicos sobre Algoritmos Genéticos são apresentados; Capítulo 4, apresenta a metodologia e resultados obtidos com a abordagem monoobjetivo; Capítulo 5, apresenta a metodoloria e resultados obtidos com a abordagem ponderada; Capítulo 6, apresenta a metologia e resultados obtidos com a abordagem lexicográfica, Capítulo 7, apresenta a metodologia e resultados obtidos para a abordagem de pareto. Capítulo 8, apresenta uma discussão e conclusões obtidas. 


\section{CAPÍTULO 2}

\section{O código genético}

"The undreamt-of breakthrough of molecular biology has made the problem of the origin of life a greater riddle than it was before: we have acquired new and deeper problems."

- Karl R. Popper, Studies in the Philosophy of Biology, 1974

O código genético exerceu um grande fascínio na ciência, mesmo antes de ter sido completamente descoberto. O código padrão é comum à esmagadora maioria dos organismos vivos e esse fato evidencia a existência de um ancestral comum a todos os organismos. Além disso o código padrão possui características peculiares, as quais tem intrigado pesquisadores ao longo do tempo. O fato é que não se sabe se essas características emergiram por terem realmente sido "selecionadas" diretamente ao longo do tempo ou se emergiram de algum outro processo, não sendo diretamente selecionadas e o quanto o acaso influenciou no surgimento do código (Crick, 1968; Di Giulio, 2005, 1989; Freeland e Hurst, 1998; Woese, 1965).

Neste capítulo, conceitos biológicos necessários para o entendimento das propriedades do código genético serão revistos. O capítulo fornece uma revisão sobre a estrutura físicoquímica dos ácidos nucleicos e proteínas, sobre os processos de transcrição, tradução, replicação de DNA, sobre conceitos básicos de evolução molecular e por fim trata das características do código genético e sua importância. 


\section{1 Ácidos nucleicos e proteínas: características básicas}

As seções seguintes tratam de algumas características básicas dos ácidos nucleicos e das proteínas, necessários para a compreensão da importância dessas moléculas.

\subsection{1 Ácidos nucleicos}

Os ácidos nucleicos são macromoléculas de grande importância para os organismos vivos, pois são responsáveis pelo armazenamento da informação genética necessária para o desenvolvimento e funcionamento dos seres vivos (Alberts et al., 2010; Lodish et al., 2007).

A estrutura de um ácido nucleico é composta de cadeias de nucleotídeos, os quais, por sua vez, são formados por 3 componentes: uma pentose, sendo mais conhecidas a ribose (RNA) e a desoxirribose (DNA), um radical fosfato e uma base nitrogenada.

A estrutura do DNA difere da estrutura do RNA por conter uma desoxirribose no lugar na ribose, ou seja, o grupo hidroxila $(\mathrm{OH})$ presente na ribose dá lugar a um hidrogênio $(\mathrm{H})$ na desoxirribose.

As bases nitrogenadas presentes nas moléculas de DNA e RNA podem ser de cinco tipos e dividem-se em duas categorias: púricas e pirimídicas. As bases chamadas púricas são aquelas que possuem um anel duplo em sua constituição. São elas: adenina (A) e guanina (G). Já as bases pirimidicas possuem um anel simples. São elas: timina (T), citosina (C) e uracila (U). O DNA e o RNA possuem 4 bases em sua constituição. No DNA as bases são A, C, T e G, enquanto que no RNA a uracila (U) aparece no lugar da timina (T). A estrutura da uracila é similar à da timina, porém na uracila o grupo metil (CH3) não está presente (Abrantes, 2011; Alberts et al., 2010).

O DNA é usualmente encontrado na forma de dupla hélice. As fitas de DNA são mantidas unidas por ligações de hidrogênio entre as bases nitrogenadas A e T e entre C e G. O RNA, por sua vez, é frequentemente encontrado na forma de uma hélice simples e é capaz de formar uma grande variedade de estruturas através do pareamento de pequenas regiões.

\subsubsection{Proteínas}

Proteínas são macromoléculas vitais para o funcionamento da maioria dos processos biológicos. Elas são responsáveis por executar importantes atividades nas células (Lodish et al., 2007). Essas atividades, muitas vezes, exigem a ação conjunta de várias proteínas. Ao longo de bilhões de anos de evolução, as proteínas passaram por um processo de desenvolvimento e refinamento, tanto estrutural, quanto funcional (Alberts et al., 2010; Branden et al., 1991). Essa evolução proporcionou a aquisição de atividades especializadas. Entre as principais funções biológicas das proteínas (Alberts et al., 2010), destacam-se: catálise, transporte, armazenamento, motilidade, defesa e regulação. A atividade funcional proteica é diretamente dependente de sua estrutura tridimensional. 
A organização espacial de proteínas é chamada de conformação Lehninger et al. (2005). Uma proteína pode ter várias conformações. Essa propriedade reflete características funcionais, por exemplo, a participação em reações e a interação com ligantes. Normalmente, as conformações predominantes são as termodinamicamente mais estáveis e isso depende das propriedades físico-químicas dos aminoácidos constituintes da proteína, como a polaridade, por exemplo. Quando encontradas em alguma de suas conformações funcionais, as proteínas são chamadas de nativas. As proteínas são compostas por aminoácidos unidos por ligações covalentes, chamadas ligações peptídicas.

Proteínas são organizadas nos níveis estruturais: primário, secundário, terciário e quartenário. A formação dos níveis estruturais é dependente da sequência de aminoácidos que representa a estrutura primária.

Os aminoácidos diferem entre si pelas suas cadeias laterais, ou grupos R, que podem variar conforme carga, tamanho, estrutura e polaridade. As diferentes propriedades das cadeias laterais dos aminoácidos são responsáveis por produzir uma diversa variedade de proteínas funcionalmente distintas (Leach, 2001). Os aminoácidos podem ser classificados, em função da cadeia lateral, em 5 grupos:

- Alifáticos e apolares: glicina (Gly), alanina (Ala), prolina (Pro), valina (Val), leucina (Leu), isoleucina (Ile) e metionina (Met);

- Aromáticos: fenilalanina (Phe), tirosina (Tyr) e triptofano (Trp);

- Polares e não-carregados: serina (Ser), treonina (Thr), cisteína (Cys), asparagina (Asp) e glutamina $(\mathrm{Gln})$;

- Positivamente carregados: lisina (Lys), histidina (His) e arginina (Arg);

- Negativamente carregados: aspartato (Asp) e glutamato (Glu).

A classificação acima apresentada é apenas um agrupamento possível, já que os aminoácidos possuem inúmeras propriedades que influem diretamente na demais estruturas secundária, terciária e quaternária, o que determina a função da proteína. Dessa forma, um erro de tradução, ou mesmo uma mutação que ocasione a troca de um aminoácido por outro, pode alterar completamente a proteína em questão. Um exemplo bastante conhecido de doença ocasionada por esse tipo de mutação é o da anemia falciforme. Essa doença é caracterizada pela presença de hemácias com formato de foice o que ocasiona um transporte deficiente de gases. O problema ocorre devido a uma troca de aminoácido na proteína globina (Glu é trocado por Val através da mutação que transforma GAA em GUA) Lehninger et al. (2005). Esse exemplo mostra que uma única mutação em uma base do códon é capaz de alterações drásticas na proteína e suas funções. 


\subsection{Do DNA às proteínas}

O fluxo de informação genética, ou seja, o modo como a informação contida no DNA é convertida para RNA e posteriormente para proteína é conhecido como Dogma Central da biologia molecular Crick (1968).

O DNA da células encontra-se normalmente em longos fragmentos. Nos humanos, o DNA é encontrado na forma de 23 pares de cromossomos, enquanto que nas bactérias ele pode aparecer como um fragmento circular. Os genes são as regiões do DNA "de interesse", ou seja, regiões que contem a informação necessária para a síntese de RNA e proteínas. O DNA é capaz de fazer cópias de si mesmo através do processo chamado replicação. Durante o processo de replicação a dupla hélice da molécula de DNA é aberta com auxílio da proteína helicase e cada fita gera uma fita complementar idêntica em um processo semi-conservativo, que preserva uma fita "antiga"juntamente com uma fita "nova"(Lehninger et al., 2005).

Além de realizar cópias de si próprio o DNA também é capaz de guiar a síntese de outras moléculas. O processo de síntese proteica que compreende o fluxo de informação do DNA até as proteínas ocorre em duas fases: transcrição e tradução. Durante a transcrição, uma fita de DNA serve como modelo para determinar a ordem na qual os monômeros de ribonucleosídeos trifosfato (rNTP) irão se polimeralizar formando uma fita de RNA complementar. A reação de polimerização é catalizada pela proteína RNA polimerase. A RNA polimerase se liga a uma das duas fitas de DNA temporariamente separadas durante o processo de transcrição e a fita de RNA complementar vai sendo formada à medida que a proteína se move ao longo da fita de DNA, quando o processo está completo, as duas fitas de DNA voltam a se parear (Abrantes, 2011; Alberts et al., 2010).

A tradução é o nome dado ao processo de síntese de proteínas. Nele o alfabeto de 4 letras do RNA mensageiro (mRNA) é "traduzido"para o alfabeto de 20 letras das proteínas (20 aminoácidos). O processo é o mesmo em praticamente todos os organismos, com raras exceções. A fita de mRNA é lida em grupos de três nucleotídeos (códon), sendo cada códon responsável por codificar um aminoácido na proteína correspondente. Uma vez que existem 64 códons possíveis ( 4 × 4 x 4) e apenas 20 aminoácidos, um aminoácido pode ser codificado por 1 ou mais códons. Essa correspondência entre códon-aminoácido é dada pelo código genético. O código é lido por um tipo de RNA chamado de RNA transportador (tRNA). Os tRNAs ligam-se a um aminoácido específico e possuem uma extremidade com a sequência específica de 3 nucleotídeos, chamada de anticódon. O anticódon realiza o reconhecimento de um códon específico pelo pareamento de suas bases. Assim, a síntese de um peptídeo se dá a medida que as moléculas de tRNAs carregadas de aminoácidos (são chamados de aminoacil-tRNA) vão se pareando com os códons da molécula de mRNA (Abrantes, 2011; Alberts et al., 2010).

A tradução ocorre nos ribossomos. Os ribossomos são estruturas complexas compostas por ribonucleoproteínas. São compostos por duas subunidades ribossomais uma maior e outra menor. Na tradução o mRNA se liga na subunidade ribossomal menor. O códon de início 
da tradução (AUG) é reconhecido pelo tRNA iniciador e se liga ao sítio $\mathrm{P}$ do ribossomo. A subunidade ribossômica maior é então adicionada formando o complexo de iniciação ribossômico. A fase seguinte é chamada de fase de alongamento e os tRNAs carregados com seus respectivos aminoácidos se ligam aos códons através do pareamento de bases. Os novos aminoácidos vão sendo ligados ao sítio A do ribossomo. A ligação covalente que une o aminoácido e o tRNA situados no sítio P é rompida e uma ligação covalente é formada entre os dois aminoácidos, o tRNA agora vazio é liberado e o ribossomo se move. A síntese procede até que um códon de parada seja alcançado (UAA, UAG, ou UGA). O códon de parada não possui anticódon e desse modo nenhum aminoácido é adicionado, porém ele é reconhecido por uma proteína de liberação ( $\mathrm{RF}$ - do inglês "release factor") que se liga ao códon de parada e inicia a sequência de eventos que conduz ao término da tradução e liberação do peptídeo sintetizado (Lehninger et al., 2005). A Figura 2.1 ilustra o processo de tradução acima descrito.

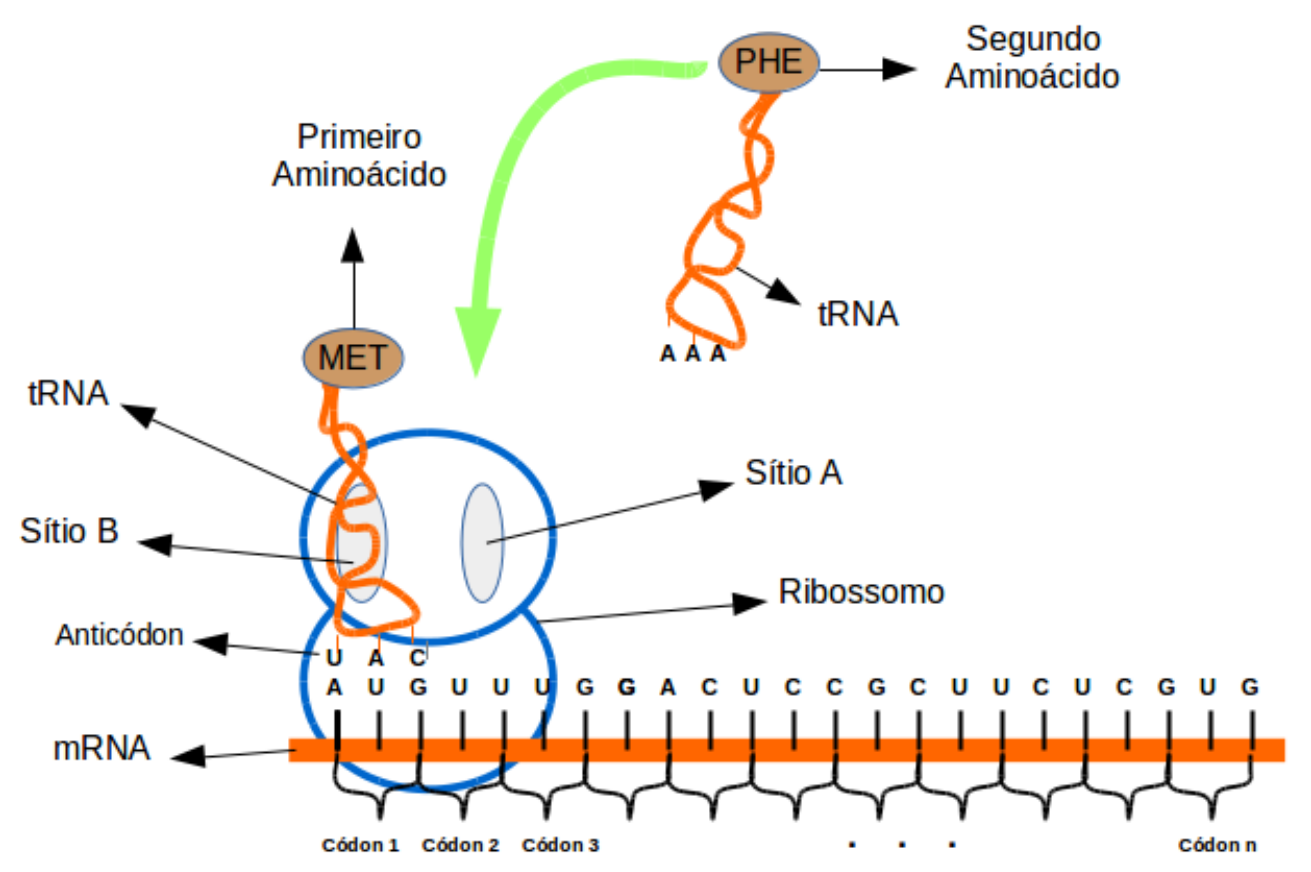

Figura 2.1: A tradução.

\subsection{Alguns conceitos básicos de evolução}

Em 1859, o naturalista Charles Darwin revolucionou a ciência publicando o seu livro intitulado: "On the Origin of Species by Means of Natural Selection", cujo título mais tarde seria resumido para "A origem das espécies". O trabalho de Darwin trouxe a ideia de que a diversidade das espécies atuais é produto de um processo de evolução, que ocorre por meio da descendência com alterações. Os rumos desses descendentes modificados, ou seja, se eles sobreviverão ou não, são definidos pela chamada seleção natural (Klug et al., 2010). 
Na época em que Darwin publicou seu trabalho, pouco se sabia sobre os mecanismos de hereditariedade, que foram descritos bem mais tarde por Gregor Mendel. Unindo os dois conhecimentos temos a teoria da evolução moderna, que leva em conta os mecanismo de transmissão genética e mutação.

De uma maneira geral, pode-se pensar na vasta variedade de espécies atuais como sendo ramos de uma árvore. Os ramos menores descendem de ramos maiores, ou seja, os ramos maiores são ancestrais comuns dos ramos que descendem deles e assim por diante. A medida que vamos descendo pelos galhos, chegaremos ao tronco que representaria um suposto ancestral comum de todas as espécies. Essa representação em forma de árvore é chamada de árvore filogenética. LUCA é o nome que se dá a esse suposto último ancestral universal comum ("last universal commum ancestor") que acredita-se ter sido similar a uma bacteria. A existência de um único ancestral comum vai de encontro ao fato de que o código genético é praticamente o mesmo em todos os organismos vivos, com poucas exceções. Dessa maneira, o código teria se fixado antes do surgimento de outras espécies e a pressão seletiva teria tornado o surgimento de variações extremamente difícil.

Um pouco depois de Darwin, em 1865, Gregor Mendel publicou seu trabalho sobre a hereditariedade, baseando-se em seus experimentos com ervilhas. Observando os fenótipos das ervilhas Mendel conseguiu estudar como a herança genética acontecia nas gerações filiais. Ele também definiu os conceitos de dominância e recessividade. Posteriormente, descobriu-se que os padrões de hereditariedade descobertos por Mendel faziam sentido quando do ponto de vista do comportamento dos cromossomos durante a meiose (Bowler, 2000; Zaha et al. , 2014).

Do ponto de vista da evolução um conceito importante é o conceito de alelo. Os alelos são variações de um gene. Por exemplo, consideremos um gene $B$ responsável por uma determinada característica em humanos com dois alelos $B$ e $b$. O alelo $B$ determina a presença da característica, enquanto que $b$ determina sua ausência. A característica possui uma dominância completa, pois se um determinado indivíduo apresentar os dois alelos no mesmo locus $(B b)$ ele apresentará a característica, assim como se ele apresentar o par $(B B)$. No caso, a ausência da característica ocorrerá apenas na presença de dois alelos recessivos $(b b)$.

Sob as lentes da genética, uma definição satisfatória de evolução é a alteração das frequências alélicas ao longo do tempo (Hartl et al., 1997). A seleção natural certamente é um dos causadores dessas mudanças de frequências. Contudo, outros mecanismos também podem explicar essas variações, sendo um deles a deriva genética. A deriva genética é um processo que muda as frequências alélicas estocasticamente. O processo ocorre como resultado da amostragem de gametas ${ }^{1}$, no qual a frequência de determinado alelo pode aumentar por acaso, sem que este ocasione alguma vantagem evolutiva, por exemplo. Em populações pequenas, poucos gametas são sorteados para compor os indivíduos das próximas gerações, dessa forma

\footnotetext{
${ }^{1}$ Gametas: celular reprodutivas, ou sexuais, que durante a fecundação se fundem formando o zigoto. São células haploides, ou seja, possuem apenas um cromossomo de cada tipo, diferente das células somáticas (não reprodutivas) que possuem um par de cromossomos de cada tipo.
} 
uma mudança de frequências pode ocorrer mais facilmente. A deriva é estocástica e imprevisível e mais pronunciada quanto menor for o tamanho da população (Crow et al., 1970).

Um importante fato que veio a propor uma ruptura com a teoria de que qualquer mudança alélica fosse ocasionada pela seleção natural foi a proposição da teoria neutralista da evolução molecular por Mooto Kimura. Kimura defendeu que a maior parte das mutações seriam neutras e portanto não estariam sujeitas a seleção natural, de forma que as variações alélicas seriam governadas principalmente por deriva genética (Kimura, 1984).

\subsection{A origem do código genético}

Várias teorias tentam explicar o surgimento do código genético com suas características atuais. As principais são: teoria estereoquímica, teoria adaptativa e coevolução, as quais são apresentadas a seguir.

- Teoria estereoquímica

A teoria estereoquímica propõe que a estrutura do código genético padrão é um produto da afinidade físico-química existente entre os aminoácidos e seus respectivos códons ou anti-códons. O primeiro modelo estereoquímico foi proposta por Gamow em 1954, antes do código genético ser decifrado. Gamow propôs que haveria uma relação entre os aminoácidos e "rhomb-shaped holes" que seriam formados por sequências de nucleotídeos do DNA (Gamow, 1954). Posteriormente, após a descoberta do código genético padrão, novos modelos estereoquímicos mais complexos foram propostos (Dunnill, 1966; Pelc e Welton, 1966).

- Teoria adaptativa

A segunda é a teoria adaptativa, o que sugere que o código genético é um produto da minimização dos efeitos dos erros nos processos de síntese de proteínas, sendo moldada por forças seletivas (Novozhilov et al., 2007), no sentido de um estado congelado (ou, na terminologia da otimização, no sentido de um ótimo local ou global) (Epstein , 1966; Goldberg e Wittes, 1966; Sonneborn, 1965). Nessa teoria, é possivel distinguir duas linhas: a hipótese da mutação letal, na qual o código evoluiu para minimizar o efeito de mutações pontuais e a hipótese da minimização dos erros de tradução, que postula que o código teria evoluído devido a pressão evolutiva de minimizar o efeito de leituras erradas na tradução.

- Teoria da Co-evolução

A terceira teoria, chamada de co-evolução (Wong, 1975), afirma que o código padrão evoluiu sob influência das vias de biossíntese de aminoácidos, juntamente com a primeira espécie. Dessa forma, o código genético co-evoluiu juntamente com a biossíntese dos aminoácidos, de forma que os grupos de códons eram associados inicialmente a 
aminoácidos precursores e posteriormente foram realocados para os aminoácidos tal qual conhecemos atualmente (Wong, 2005).

\subsection{Características do código genético e sua descoberta}

Na década de 1960, Francis Crick descobriu o mecanismo segundo o qual a informação genética, codificada através de um alfabeto de 4 letras de ácidos nucleicos, é traduzida para a linguagem de 20 letras das proteínas. Segundo a hipótese de Crick, um ácido nucleico, talvez RNA, serviria como adaptador. Uma parte desse adaptador seria responsável por se ligar a um aminoácido específico e outra parte por reconhecer uma sequência de aminoácidos e traduzi-lo em mRNA (Lehninger et al., 2005).

Estudos anteriores já haviam revelado a existência de códons formados por triplas de nucleotídeos. Outra informação importante foi a descoberta de como os códons são lidos. Descobriu-se que a leitura é feita de forma sucessiva e não sobreposta, ou seja, o primeiro códon constitui o primeiro quadro de leitura e o próximos códons se iniciam a cada 3 resíduos de nucleotídeos. Contudo, desconhecia-se quais códons codificavam quais aminoácidos no processo de tradução.

Em 1961, Marshall Nirenberg e Heinrich Matthaei incubaram o polinucleotídeo poli(U), extrato de Escherichia coli (E. coli), GTP (Guanosina trifosfato), ATP (Adenosina trifosfato) em uma mistura de 20 aminoácidos em 20 tubos diferentes, cada um com um diferente aminoácido radioativamente marcado (Lehninger et al., 2005). Devido ao fato de que o poli(U) é composto por triplas de UUU, deveria ocorrer a síntese de um polipeptídeo formado pelo aminoácido codificado por UUU. Verificou-se então que em um dos tubos se formou um peptídeo composto apenas por fenilalanina radioativa, indicando então que o códon UUU codifica esse aminoácido. A mesma estratégia revelou que o códon CCC codifica a prolina e que o AAA codifica lisina. Além disso, os polinucleotídios sintéticos foram preparados na presença de fosforilase que catalisa a formação de RNA a partir de ADP, UDP, CDP e GDP. Na presença de UDP, a fosforilase codifica apenas poli(U), porém na presença de todos (ADP, UDP, CDP e GDP $)^{2}$ codifica diferentes triplas formadas por A, U, C e G. Esse experimento permitiu conhecer quais aminoácidos eram codificados por algumas triplas, contudo, apesar de saber a composição de cada tripla, ainda não era possível saber a ordem de cada base dentro da tripla.

Em 1964, Nirenberg e Philip Leder conseguiram identificar os aminoácidos codificados por cerca de 50 triplas. Em seguida, diversos experimentos foram realizados por diversos grupos, até que em 1966, foram identificadas todas as triplas e aminoácidos codificados, inclusive as que codificam os códons de parada (Lehninger et al., 2005).

Uma importante característica do código genético, e que pode se verificada na Figura 1.1, é que um aminoácido pode ser codificado por mais de um códon. Por essa razão o

\footnotetext{
${ }^{2}$ ADP: Adenosina difostato; UDP: Uridina difosfato; CDP: Citidina difosfato e GDP: Guanosina difosfato
} 
código é chamado degenerado, ou seja, redundante. Isto ocorre porque, com sequências de 3 nucleotídeos, existem 64 combinações para os códons, os quais codificam apenas 20 aminoácidos e sinalizam 3 pontos de parada para a tradução. A degeneração do código não é uniforme, por exemplo, a metionina e o triptofano são codificados por um único códon. Já três dos aminoácidos (Leu, Ser, Arg) são codificados por seis, cinco aminoácidos por quatro, a isoleucina por três, e nove aminoácidos por dois códons. Essa propriedade confere robustez ao código perante determinadas mutações, já que uma mutação em um códon não necessariamente acarretará uma troca de aminoácido; pois a mudança pode resultar em um códon que codifica aquele mesmo aminoácido. Além disso, devido à disposição dos aminoácidos no código genético padrão, muitas vezes a mutação em um nucleotídeo gera uma aminoácido com propriedades físico-químicas semelhantes ao aminoácido anteriormente codificado Ardell e Sella (2001); Lehninger et al. (2005).

Alguns pesquisadores têm sugerido que o código genético evoluiu para sua forma presente de tal forma a torná-lo mais robusto frente a diversos tipos de mutação (Freeland e Hurst , 1998). De fato, diversos experimentos têm demonstrado que o código genético utilizado pelos seres vivos é mais robusto que a imensa maioria dos códigos gerados aleatoriamente (o número de códigos aleatórios piores que o código genético varia conforme a definição da função de estabilidade, mas em geral este número fica acima de 99,9 \%) (Freeland e Hurst, 1998; Gilis et al., 2001; Haig e Hurst, 1991).

\subsection{Avaliação de códigos genéticos}

Esta seção descreve algumas medidas descritas na literatura e/ou criadas aqui para avaliar a qualidade dos códigos genéticos hipotéticos gerados. A primeira delas é a função de avaliação baseada em robustez, que é empregada nas abordagens estatística e por engenharia (ou seja, é utilizada pelo algoritmo de otimização como objetivo a ser otimizado).

As demais medidas foram utilizadas para avaliar os códigos hipotéticos obtidos após o processo de otimização. A porcentagem de distância de minimização ( $p d m$ ) (Di Giulio, 1989) e a melhora (Santos e Monteagudo, 2009) são medidas usualmente empregadas na literatura para a avaliação de códigos. A entropia para avaliação de códigos hipotéticos foi proposta durante esta pesquisa.

\subsubsection{Função de Avaliação Baseada na Robustez}

A função de avaliação frequentemente empregada na literatura é a média quadrática $\left(M_{s}(C)\right)$ da variação de uma propriedade dos aminoácidos, que computa todas as possíveis mudanças para cada base de todos os códons de um dado código genético $C$ (Di Giulio et al. , 1994; Freeland e Hurst, 1998; Goldman, 1993; Haig e Hurst, 1991; Santos e Monteagudo, 2010). A polaridade dos aminoácidos é geralmente considerada a propriedade mais substan- 
cial quando o $M_{s}(C)$ é calculado (Santos e Monteagudo, 2010). O $M_{s}(C)$ é definido como:

$$
M_{s}(C)=\frac{\sum_{i j}(X(i, C)-X(j, C))^{2}}{\sum_{i j} N(i, j, C)}
$$

sendo que $X(i, C)$ é o valor da propriedade para o $i$-ésimo aminoácido (neste caso, uma das propriedades mostradas na Tabela 2.1) e $N(i, j, C)$ é o número de possíveis substituições de um códon, não considerando as mudanças para e de códons de parada. Vale ressaltar que quanto menor o $M_{s}(C)$ mais robusto é o código.

Os aminoácidos possuem várias outras propriedades além da polaridade. Neste trabalho, o $M_{s}(C)$ foi calculado também para a hidropatia e para o volume molecular. Os valores de polaridades aqui utilizados foram definidos por Woese em 1965 a partir de experimentos de cromatografia (Woese, 1965) ${ }^{3}$. A hidropatia é baseada na transferência de energia livre dos aminoácidos em vapor e da distribuição das cadeias laterais e seus valores foram definidos em (Kyte e Doolittle, 1982). Já o volume molecular é calculado como o volume do resíduo de aminoácido menos o volume do peptídeo e foi definido em (Grantham, 1974). Os valores das três propriedades utilizadas são mostrados na Tabela 2.1. Todos os valores são adimensionais.

\footnotetext{
3 Em 2008, Mathew e Luthey-Schulten, utilizando mecânica estatística, realizaram algumas correções computacionais nos experimentos de Woese e atualizaram os valores de polaridade (Butler et al., 2009). Os valores atualizados foram também testados nesta pesquisa, porém não foi verificada diferença estatística nos resultados. Desse modo, os valores primeiramente obtidos por Woese (Woese, 1965) foram mantidos a fim que fosse possível comparar com outros trabalhos da literatura, por se tratar dos valores mais frequentemente utilizados.
} 
Tabela 2.1: Propriedades dos aminoácidos (Haig e Hurst, 1991): polaridade (Woese, 1965), hidropatia (Kyte e Doolittle, 1982) e volume (Grantham, 1974).

\begin{tabular}{c|c|c|c} 
Aminoácido & Polaridade & Hidropatia & Volume molecular \\
\hline \hline Ala & 7 & 1,8 & 31 \\
\hline Arg & 9,1 & $-4,5$ & 124 \\
\hline Asp & 13 & $-3,5$ & 54 \\
\hline Asn & 10 & $-3,5$ & 56 \\
\hline Cys & 4,8 & 2,5 & 55 \\
\hline Glu & 12,5 & $-3,5$ & 83 \\
\hline Gln & 8,6 & $-3,5$ & 85 \\
\hline Gly & 7,9 & $-0,4$ & 3 \\
\hline His & 8,4 & $-3,2$ & 96 \\
\hline Ile & 4,9 & 4,5 & 111 \\
\hline Leu & 4,9 & 3,8 & 111 \\
\hline Lys & 10,1 & $-3,9$ & 119 \\
\hline Met & 5,3 & 1,9 & 105 \\
\hline Phe & 5 & 2,8 & 132 \\
\hline Pro & 6,6 & $-1,6$ & 32,5 \\
\hline Ser & 7,5 & $-0,8$ & 32 \\
\hline Thr & 6,6 & $-0,7$ & 61 \\
\hline Trp & 5,2 & $-0,9$ & 170 \\
\hline Tyr & 5,4 & $-1,3$ & 136 \\
\hline Val & 5,6 & 4,2 & 84 \\
\hline \hline
\end{tabular}

\subsubsection{Erros de tradução e em função da posição da base}

Nucleotídeos são compostos por uma base nitrogenada, uma pentose e um fosfato. As bases nitrogenadas são classificadas em purinas e pirimidinas de acordo com sua estrutura (Lehninger et al., 2005). As purinas Adenina (A) e Guanina (G) tem um par de anéis fundidos, enquanto que as bases Citosina $(\mathrm{C})$, Timina $(\mathrm{T})$ e Uracila (U) contem um único anel (Lodish et al., 2007). Transições ocorrem quando uma purina é substituída por outra purina ou uma pirimidina por outra pirimidina. Por outro lado, transversões ocorrem quando uma purina é trocada por uma pirimidina ou vice-versa.

Dados experimentais mostram que erros no processo translacional ocorrem de maneira complexa (Parker, 1989), mas em geral, erros de tradução variam conforme a posição do nucleotídeo modificado dentro de um códon. Freeland e Hurst (Freeland e Hurst, 1998) sumarizaram esse conhecimento em quatro regras apresentadas a seguir:

- Erros de tradução da segunda base são menos frequentes que erros na tradução nas outras duas bases, ao passo que erros de tradução da primeira base são menos frequentes que da terceira base.

- A maioria dos erros de tradução da primeira e segunda base são transições.

- O viés no sentido das transições é bem pequeno nos erros de tradução da terceira base. 
Freeland e Hurst (Freeland e Hurst, 1998) propuseram a adição dessa informação à função de avaliação. Para este propósito, uma matriz de erros de tradução foi empregada, como mostrado na Tabela 2.2. O $M_{s}$ computado com essa informação do erro na tradução é chamado $M_{s t}$.

Tabela 2.2: Pesos usados no cálculo do $M_{s t}$. Os pesos representam a quantificação de erros na tradução usados para ponderar o erro como função da posição da base.

\begin{tabular}{c|c|c|c}
\hline Peso & Primeira base & Segunda base & Terceira base \\
\hline \hline Transições & 1 & 0,5 & 1 \\
Transversões & 0,5 & 0,1 & 1 \\
\hline \hline
\end{tabular}

O valor de $M_{s}(C)$ computado considerando os pesos da Tabela 2.2 é chamado de $M_{s t}(C)$ e é dado por:

$$
M_{s t}(C)=\frac{\sum_{i j} w(i, j)(X(i, C)-X(j, C))^{2}}{\sum_{i j} N(i, j, C)}
$$

sendo $w(i, j)$ o peso entre os aminoácidos codificados pelo $i$-ésimo e $j$-ésimo códons de um código $C$, cujos valores são dados pela Tabela 2.2 .

Outros autores já constataram que $M_{s t}$ é mais apropriado para avaliar os códigos, tanto na abordagem estatística quanto na abordagem por engenharia (Freeland e Hurst, 1998; Santos e Monteagudo, 2010). Nesta pesquisa, foram realizados experimentos com $M_{s}$, porém somente os resultados utilizando o $M_{s t}$ são apresentados. O valores de $M_{s t}$ para cada objetivo, ou propriedade é referido com a abreviatura da propriedade utilizada para o cálculo, assim $M_{s t}(P)$ é o valor de $M_{s t}$ para a polaridade; $M_{s t}(H)$, para a hidropatia e $M_{s t}(V M)$, para o volume molecular.

\subsubsection{Medidas para validação de códigos}

A fim de comparar o código genético padrão com os códigos gerados em simulação e avaliar os códigos hipotéticos gerados, utilizou-se a porcentagem de distância de minimização $(p d m)$, os valores de fitness dos indivíduos, a distância entre duas soluções, a dominância e o gráfico das soluções da fronteira de Pareto. Essas medidas são descritas a seguir.

- Porcentagem de distância de minimização $(p d m)$

Como descrito em (Di Giulio, 1989), o pdm é calculado da seguinte maneira:

$$
p d m_{i}=100 \frac{\left|\bar{f}_{i}-f_{i}\left(C_{\mathrm{c}}\right)\right|}{\left|\bar{f}_{i}-f_{i}(C)\right|}
$$

sendo que $\bar{f}_{i}$ é a avaliação média (fitness médio) do objetivo $i$ dos possíveis códigos genéticos gerados aleatoriamente, $f_{i}(C)$ é a avaliação do $i$-ésimo objetivo do código hiotético, ou seja, o código que está sendo avaliado, e $C_{\mathrm{C}}$ é o fitness do código genético 
padrão. Altos valores de $p d m$ indicam grande proximidade entre o fitness do melhor código gerado e o fitness do código padrão, comparado ao fitness médio de possíveis soluções geradas aleatoriamente (100 mil códigos aleatórios foram considerados). Desse modo, o pdm mostra o quão próximo o valor da avaliação do código padrão está do valor da avaliação da melhor solução encontrada.

- Valores de avaliação

O valor de avaliação ou fitness é o valor da função objetivo para um determinado código. Esse valor pode ser comparado com o valor da avaliação do código genético padrão.

- Distância entre códigos

A distância entre códigos foi calculada aqui como sendo a distância Euclidiana, entre os valores de avaliação de cada objetivo $\left(M_{s}\right)$ obtidos pelo código hipotético considerado e o código padrão.

\section{- Gráfico}

$\mathrm{Na}$ abordagem de Pareto são utilizados gráficos, sendo que cada eixo representa um objetivo e os códigos hipotéticos gerados podem ser representados através de pontos. Essa representação permite observar a proximidade visual entre os códigos gerados e o código genético padrão.

- Melhora

A Melhora é uma medida relacionada ao $p d m$, que fornece a porcentagem de melhora do melhor código obtido em relação ao código genético padrão em termos de valor de avaliação de um objetivo $i$ (Santos e Monteagudo, 2009).

$$
i m p_{i}=100 \frac{f_{i}\left(C_{\mathrm{c}}\right)-f_{i}(C)}{f_{i}\left(C_{\mathrm{C}}\right)}
$$

A Melhora decresce a medida que o $p d m$ cresce e provê uma medida de quanto o fitness do melhor indivíduo melhorou comparado ao código padrão. A melhora pode ser negativa, desde que os códigos hipotéticos gerados nem sempre possuem valores de avaliação melhores que o código padrão.

- Entropia

A entropia de um código genético é computada pela equação a seguir.

$$
S(C)=-\sum_{k} p(k, C) \log p(k, C)
$$

onde $p(k, C)$ é a frequência relativa (probabilidade estimada) do $k$-ésimo aminoácido no código genético $C$ (de Oliveira e Tinós, 2014a). Valores altos de entropia significam 
que a distribuição de códons associados com aminoácidos é mais uniforme. A situação oposta ocorre quando a entropia é baixa e poucos aminoácidos estão associados a grandes grupos de códons.

\subsection{Trabalhos relacionados}

Diversas abordagens têm sido propostas para estudar o código genético. Haig and Hurst em (Haig e Hurst, 1991) examinaram se o código genético padrão é ótimo ou encontrase próximo a um ótimo quando a minimização dos efeitos dos erros nas propriedades dos aminoácidos é considerada. Em outras palavras, verificou-se o quão conservada são as propriedades dos aminoácidos quando ocorrem erros de tradução, o quão robusto o código é perante esses erros. Neste caso, um código robusto é aquele com baixo valor de $M_{s}$ (ou $M_{s t}$ ). Para tanto, gerou-se 10 mil códigos aleatórios e verificou-se que apenas dois deles eram mais robustos que o código padrão quando a propriedade polaridade (Woese, 1965) era considerada.

Freeland and Hurst em 1998 refizeram a estatística gerada por Haig and Hurst desta vez empregando 1 milhão de códigos aleatórios. Os autores obtiveram 114 códigos melhores que o código padrão (0,0114\%), concluindo que o código padrão seria ainda mais robusto do que fora previsto anteriormente. Além disso, os autores introduziram vieses entre erros transversais e horizontais nas bases dos códons e dependentes da posição da base $\left(M_{s t}\right)$. Esses vieses foram incluídos através da adição de pesos diferentemente para cada base. A adição de pesos é detalhadamente descrita na seção 2.6.2. Por fim, os autores também realizaram a comparação estatística considerando os pesos e obtiveram apenas 1 código aleatório melhor que o código padrão (0,0001\%).

Outros autores também utilizaram e verificaram a relevância da polaridade de (Woese, $1965)$ como medida para cálculo da robustez do código, entre eles destacam-se os trabalhos de (Di Giulio, 1989; Szathmáry e Zintzaras, 1992). Contudo, a presença de uma determinada característica no código, podemos citar aqui a robustez, não significa necessariamente que essa característica tenha sido importante na evolução do código, mas pode ter surgido por acaso, ou por consequência da seleção de alguma outra característica (Judson e Haydon , 1999).

Em (Goldman, 1993), uma variante do algoritmo de Recozimento Simulado foi utilizado para otimizar um código aleatório. Esse algoritmo, possui um método diferente para aceitação das soluções que não são melhores. Goldman realizou dois tipos de simulação: a primeira delas utilizando a codificação restritiva e a segunda utilizando uma codificação intermediária. Nessa última, os 64 códons foram associados livremente aos 20 aminoácidos e 1 sinal de parada, porém levando em consideração que as quantidades de grupos de códons deveriam se manter as mesmas, por exemplo, deveriam haver 3 códons associados a sinais de paradas, 6 para leucinas, 1 para triptofano e assim por diante. Diferentemente da codificação restritiva, 
neste caso, os códons de dentro dos grupos podem variar.

Goldman, que também utilizou a robustez baseada na polaridade dos aminoácidos, concluiu que o algoritmo foi capaz de obter códigos hipotéticos robustos quando a polaridade é considerada. Os resultados obtidos mostram que o código padrão também não é o ótimo global e o autor afirma que é preciso pensar a respeito de se considerar a evolução do código padrão apenas usando como função de avaliação um mecanismo de minimização de erros.

Em (Judson e Haydon, 1999), Algoritmos Genéticos foram utilizados para realizar a minimização de várias propriedades físico-químicas dos aminoácidos. Além disso, os autores consideram propriedades estruturais do código na otimização, que são independentes das propriedades físico-químicas, por exemplo, a probabilidade de um códon ser mau lido durante a tradução ou de uma mutação pontual causar uma mudança não sinônima a uma proteína durante a replicação. Esse tipo de propriedade depende somente da estrutura do código analisado. Os resultados evidenciaram que o código padrão não é um ótimo global quando as propriedades físico-químicas foram consideradas e os autores questionam se o código estaria mesmo preso a um ótimo local.

Em (Monteagudo e Santos, 2007), Santos e Monteagudo empregaram um Algoritmo Genético com codificação restritiva, ou seja, os códons são mantidos em grupos da mesma forma que se encontram no código genético padrão e os aminoácidos são aleatoriamente associados a um grupo. Os autores utilizaram a medida de robustez $M_{s}$ para avaliar os códigos e concluíram que o código genético padrão não é um ótimo para a função de robustez utilizada. Além disso, utilizando-se o AG proposto, é relativamente fácil obter códigos hipotéticos melhores que o código genético padrão.

Resultados semelhantes foram obtidos por Santos e Monteagudo em trabalhos posteriores (Santos e Monteagudo, 2010), inclusive com a codificação não-restritiva (ver próximo capítulo). É importante salientar que, todos estes trabalhos, e outros similares, utilizam apenas um objetivo para comparar os diferentes códigos. Por exemplo, nos trabalhos que utilizaram AGs, apenas o $M_{s}$ (ou $M_{s t}$ ) para uma única propriedade dos aminoácidos foi utilizado como fitness, i.e., apenas um objetivo foi otimizado.

Já outros pesquisadores abordam o problema de uma maneira bastante diferente, utilizando conceitos da física elementar de partículas e tratando a evolução do código padrão como um problema de quebra de simetria (Hornos e Hornos, 1993; Maddox, 1994). 


\section{CAPÍTULO 3}

\section{Algoritmos Genéticos}

"Wisdom cannot be imparted. Wisdom that a wise man attempts to impart always sounds like foolishness to someone else ... Knowledge can be communicated, but not wisdom. One can find it, live it, do wonders through it, but one cannot communicate and teach it."

- Hermann Hesse

Na etapa do trabalho descrita nesta monografia, um algoritmo genético multiobjetivo foi desenvolvido na linguagem de programação $\mathrm{C}++$. Alguns conceitos importantes sobre algoritmos genéticos, sobre a codificação e os operadores utilizados nos AGs nas metodologias apresentadas neste trabalho e também sobre problemas multiobjetivo são apresentados nas seções seguintes.

\subsection{Algoritmos Genéticos}

Na década 1960, grupos de pesquisadores independentes começaram a utilizar sistemas evolutivos biológicos como inspiração para seus algoritmos adaptativos (Mitchell, 1996). Surgiram, nessa época, os principais algoritmos da computação evolutiva.

Os AGs, tais como são conhecidos hoje, foram introduzidos na década de 1960 por John Holland e popularizados por um de seus alunos, David Goldberg, na universidade de Michigan (Haupt e Haupt, 1998). Diferentemente das estratégias evolutivas e da programação 
evolutiva, que também se desenvolviam nessa época, o AG de Holland foi, desde o início, projetado com propósito mais geral e não para problemas específicos.

Com o passar do tempo e o desenvolvimento da computação evolutiva como um todo, as fronteiras entre AGs, estratégias evolutivas e programação evolutiva se tornaram mais tênues. Desse modo, autores tem usado o termo "Algoritmo Genético" para designar algoritmos bem diferentes do original criado por Holland (Mitchell, 1996).

\subsubsection{O Algoritmo Genético Padrão}

Otimização é o processo que consiste em tentar encontrar a melhor solução para determinado problema entre as várias soluções possíveis (Haupt e Haupt, 1998). Em problemas complexos de decisão, onde uma série de variáveis estão envolvidas, deve-se selecionar um objetivo capaz de quantificar a qualidade da decisão (Luenberger e Ye, 2008). O objetivo escolhido pode então ser maximizado ou minimizado de acordo com as características do problema, fornecendo uma boa combinação de variáveis, considerando as limitações do método utilizado.

As principais diferenças entre AGs e os métodos de otimização tradicionais são ressaltadas em (Goldberg, 1989) e sintetizadas a seguir:

- AGs utilizam uma população de soluções candidatas e não apenas com uma única solução em seu processo de busca. Essa propriedade reduz a probabilidade do algoritmo ficar preso em um ótimo local, principalmente no início do processo de otimização.

- AGs utilizam regras de transição probabilísticas e não determinísticas.

- AGs podem utilizar uma representação da solução candidata, não precisando trabalhar com a solução propriamente dita.

- AGs utilizam a informação fornecida diretamente pela função objetivo para guiar o processo de busca, ao invés de derivadas ou outro tipo de conhecimento.

Encontrar a melhor solução para um problema complexo em tempo factível nem sempre é uma tarefa possível. No AG padrão, algumas das possíveis soluções de um dado problema são representadas como um conjunto de indivíduos (ou cromossomos), a chamada população. Uma população está sujeita às leis de evolução, sendo que em cada geração, ou passo do algoritmo, operadores de seleção escolhem com maior probabilidade as soluções (indivíduos) mais aptas e operadores de transformação geram novos indivíduos a partir das soluções selecionadas.

A solução $\mathbf{x}_{i}$ representada pelo cromossomo $i=1, \ldots, N$, sendo $\mathrm{N}$ o número de indivíduos na população, é avaliada através de uma função de avaliação, ou fitness, $f\left(\mathbf{x}_{i}\right)$, que mede o nível de adequação do cromossomo.

A Figura 3.1 mostra o funcionamento básico do AG Padrão.

Alguns operadores de seleção comuns são: 


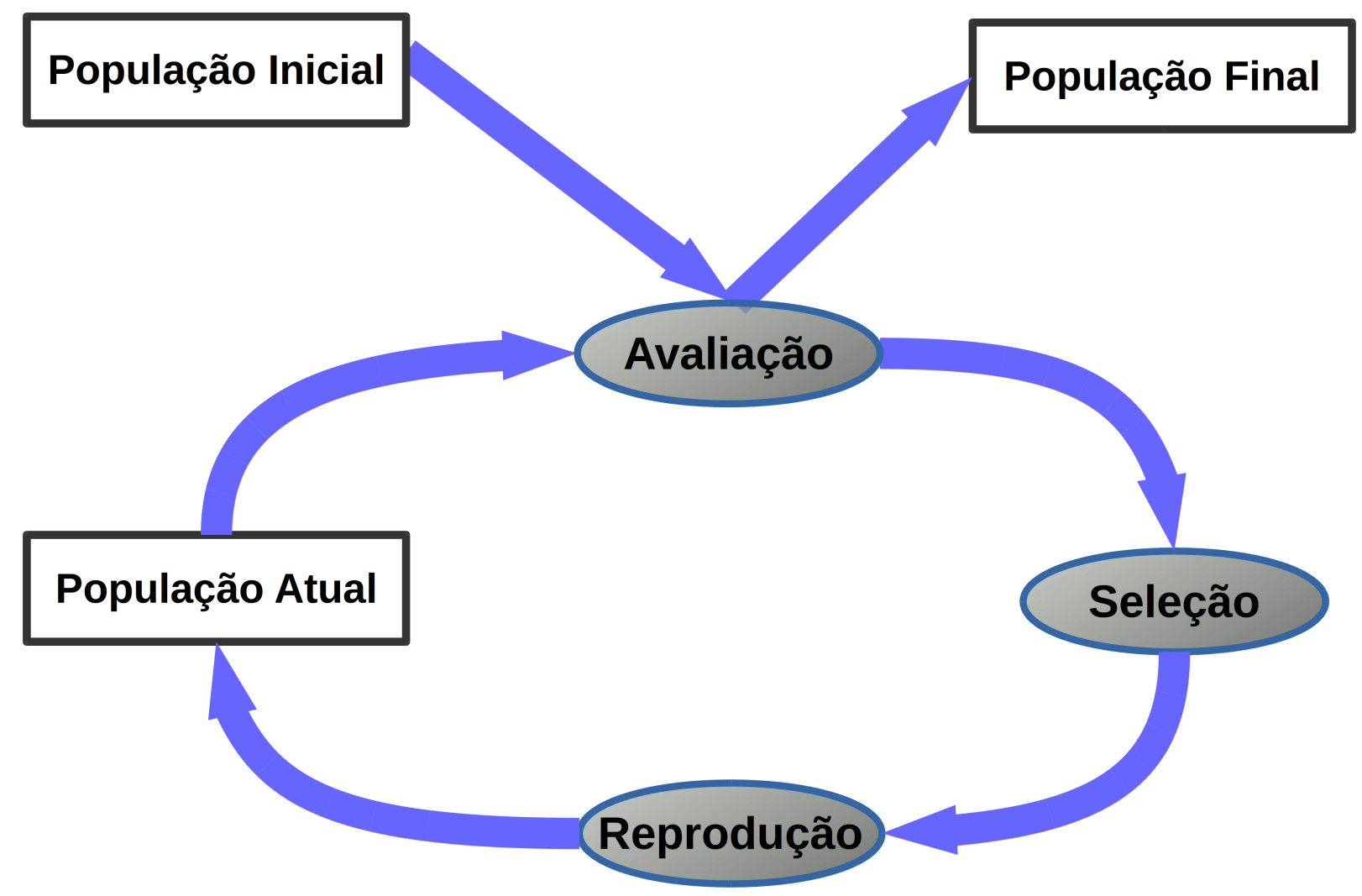

Figura 3.1: Funcionamento básico do $A G$.

- Roleta:

O método da roleta consiste em selecionar um indivíduo com uma probabilidade proporcional ao seu fitness relativo. Define-se fitness relativo como sendo a razão entre o fitness do $i$-ésimo indivíduo e a somatória dos fitness de toda a população em uma dada geração.

- Torneio:

Um conjunto de indivíduos é sorteado, sendo selecionado aquele indivíduo com melhor fitness dentro deste grupo para compor a próxima população. Este operador costuma ser empregado por proporcionar um controle da pressão seletiva, diferentemente do método anterior.

- Elitismo:

O Elitismo garante que o melhor indivíduo de uma dada geração seja automaticamente selecionado para a próxima geração.

Os principais operadores de transformação são:

- Crossover:

No crossover, dois indivíduos da população corrente escolhidos através de um critério de seleção têm alguns de seus genes permutados. O número de indivíduos escolhidos para o 
crossover em uma época é definido através de uma taxa $p_{c}$, chamada de taxa de crossover. A Figura 3.2 mostra o crossover de um ponto no caso binário.
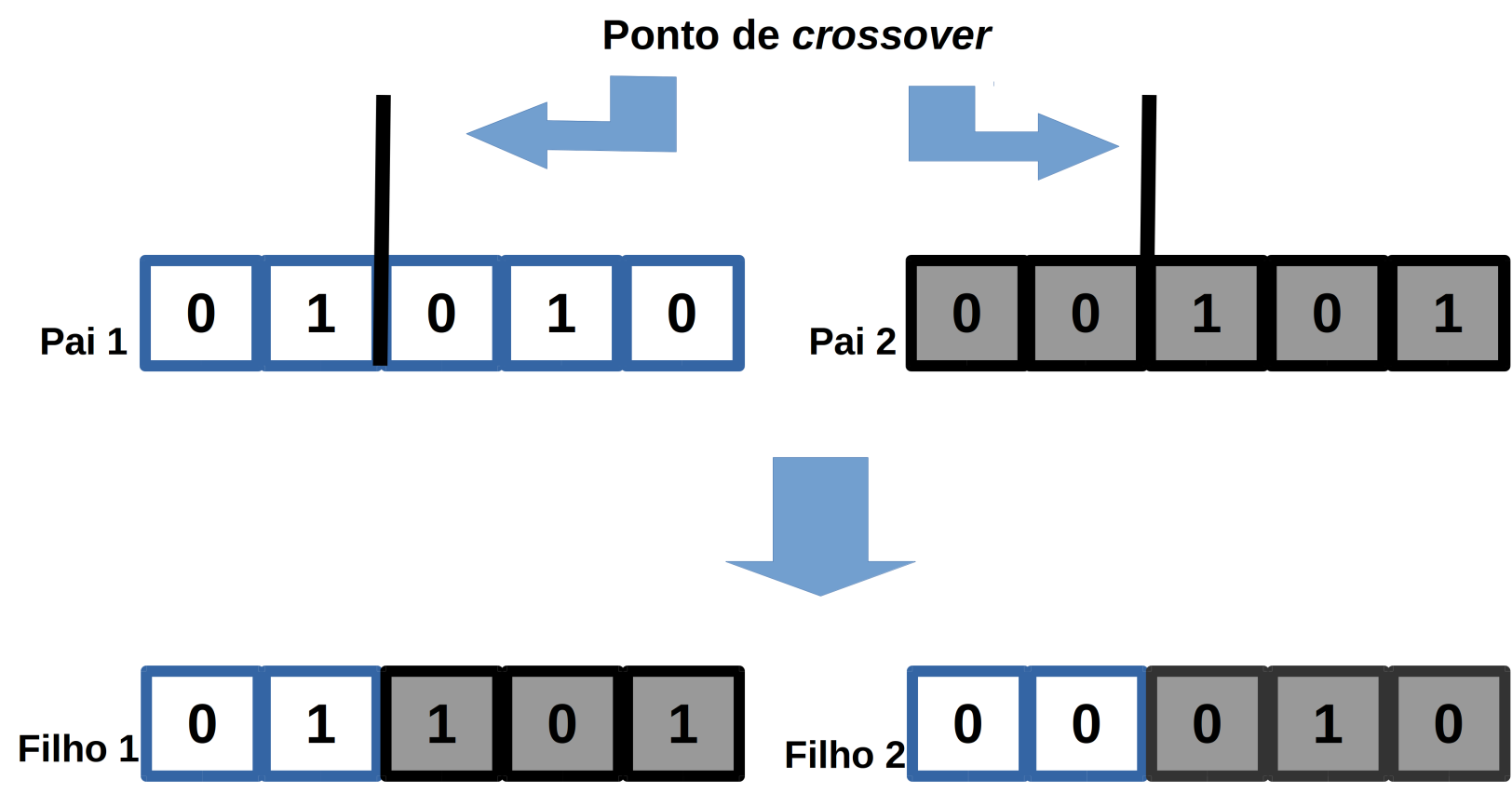

Figura 3.2: Funcionamento básico do crossover.

- Mutação:

Na mutação, indivíduos têm alguns de seus genes, escolhidos aleatoriamente, alterados através de uma regra pré-definida. Por exemplo, no caso binário, o valor do gene é invertido quando ele sofre mutação. O número de genes alterados por mutação é controlado por uma taxa $p_{m}$, chamada de taxa de mutação. A Figura 3.3 mostra o funcionamento básico da mutação.

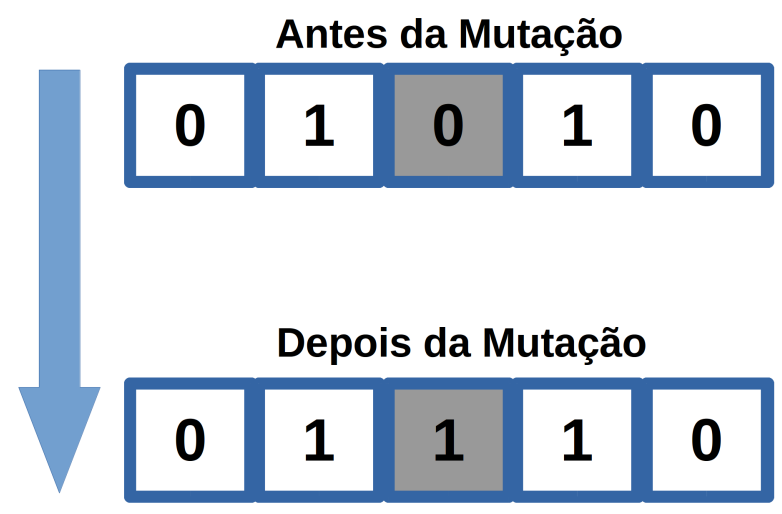

Figura 3.3: Funcionamento básico da mutação.

O pseudo-código do AG padrão pode ser visto no Algoritmo 3.1 


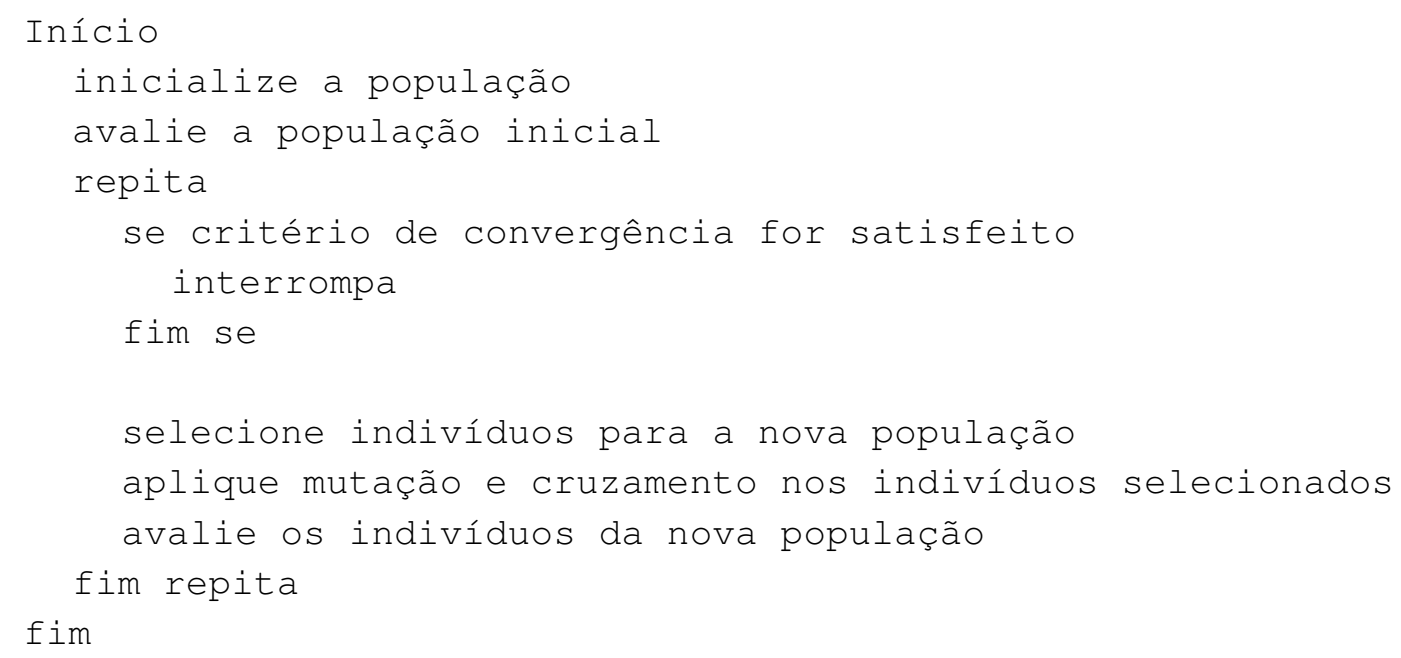

Algoritmo 3.1: Pseudo-código para AG Padrão

\subsubsection{Codificação, Operadores de Seleção e Reprodução Emprega- dos}

De acordo com (Santos e Monteagudo, 2010), existem duas codificações mais utilizadas no problema da adaptabilidade do código genético, uma não-restritiva e uma restritiva. Na codificação não-restritiva, cada indivíduo do AG codifica um código hipotético composto por 61 posições, cada uma relacionada com um dos 20 aminoácidos possíveis (os códons de parada são desconsiderados). Já na codificação restritiva, são empregadas informações da organização do código genético padrão e cada indivíduo é composto por 20 posições, que correspondem aos aminoácidos, associadas com grupos de códons, sendo que esses grupos são os mesmos do código genético padrão. Conforme observado em (Santos e Monteagudo , 2010), a codificação não-restritiva, quando utilizada com AGs monoobjetivo, causa o aumento da frequência de alguns aminoácidos. No entanto, a codificação restritiva utiliza informações do código padrão, enviesando portanto o processo de otimização. As figuras 3.4 e 3.5 mostram os dois tipos de codificação.

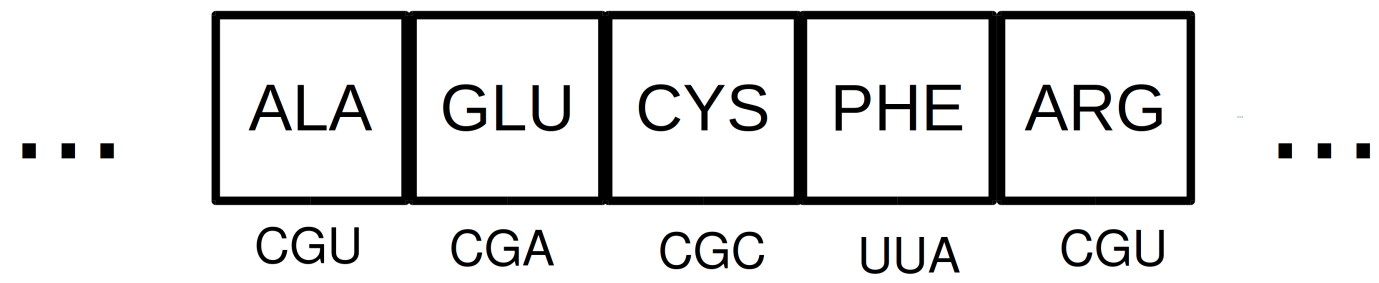

Figura 3.4: Fragmento de um indivíduo na codificação não restritiva. Cada posição corresponde a 1 dos 61 códons (exceto códons de parada) associada a um dos 20 possíveis aminoácidos. 


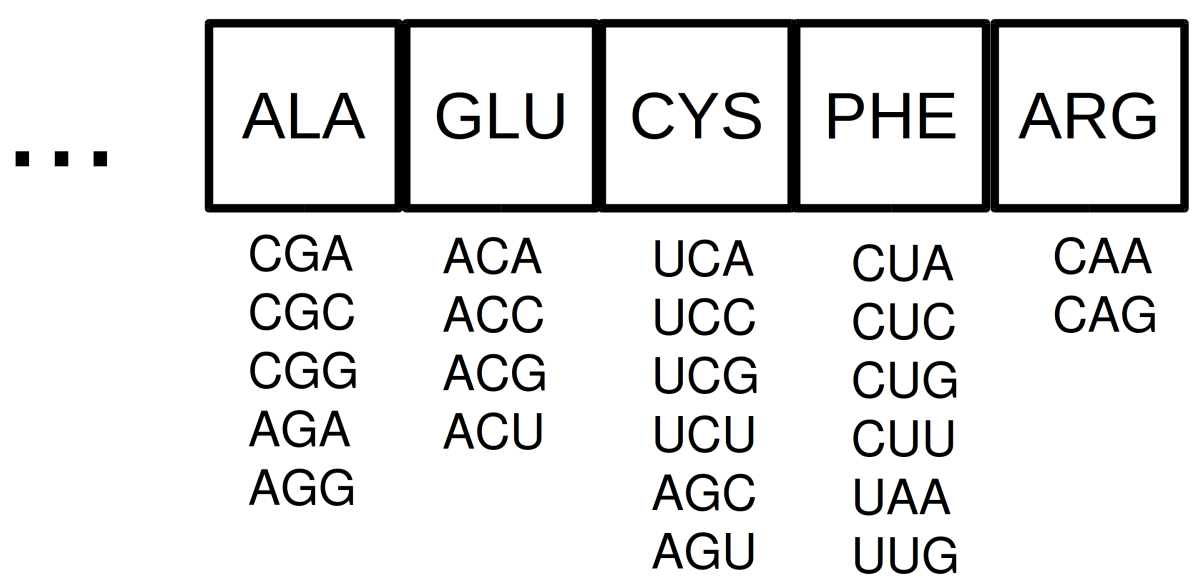

Figura 3.5: Codificação restritiva. Nesta codificação um indivíduo é composto por 20 posições referentes aos aminoácidos, sendo cada uma associada a um grupo de códons.

Nesta tese de doutorado, ambas as codificações foram investigadas. Entretanto, optou-se por mostrar no texto principal apenas os resultados dos experimentos com a abordagem não-restritiva. Como dito anteriormente, a abordagem não-restritiva é mais geral, não utilizado informações do código genético no processo de otimização realizado pelo AG. Resultados utilizando-se a abordagem restritiva para a o enfoque por Pareto são apresentados no Apêndice A. Estes resultados foram publicados no artigo (de Oliveira e Tinós, 2012). Já o Apêndice B mostra os resultados da abordagem multiobjetivo no qual o segundo objetivo empregado foi a entropia. Estes resultados foram publicados em (de Oliveira e Tinós, 2014a). A entropia foi utilizada em (de Oliveira e Tinós, 2014a) de modo a diminuir o problema da não-uniformidade dos códigos hipotéticos obtidos na abordagem monoobjetivo descrita em (Santos e Monteagudo, 2010). Como será visto posteriormente nesta tese, o problema da não-uniformidade dos códigos hipotéticos é resolvido pela abordagem multiobjetivo, não sendo necessário otimizar explicitamente a entropia.

Assim como em (Santos e Monteagudo, 2010), e de acordo com testes realizados na fase de seleção de parâmetros apenas a mutação foi empregada como operador de reprodução (um experimento utilizando o operador de crossover foi realizado, porém um teste não paramétrico de Wilcoxon não indicou diferença estatística quando o crossover é ou não usado). Nesse operador, uma posição do indivíduo é selecionada e o seu aminoácido é trocado por outro, aleatoriamente selecionado dentre os 20 possíveis. A posição e o novo aminoácido são aleatoriamente selecionados utilizando uma distribuição uniforme.

Os operadores utilizados foram: swap e mutação. No operador de swap duas posições do código hipotético são aleatoriamente selecionadas e têm o aminoácido associado trocado entre si (Santos e Monteagudo, 2010) (Figura 3.6). O swap é aplicado em cada indivíduo com probabilidade $p_{s}$ (taxa de swap). Já o operador de mutação tem probabilidade de $p_{m}$ de ser aplicado a um indivíduo. Nele, uma posição aleatória é selecionada e o aminoácido associado é trocado por um dos 20 aminoácidos possíveis. Neste caso, restrições do algoritmo impedem que algum aminoácido desapareça, ou seja, a frequência mínima de cada um dos 
20 aminoácidos deve ser pelo menos igual a 1 (Figura 3.7).

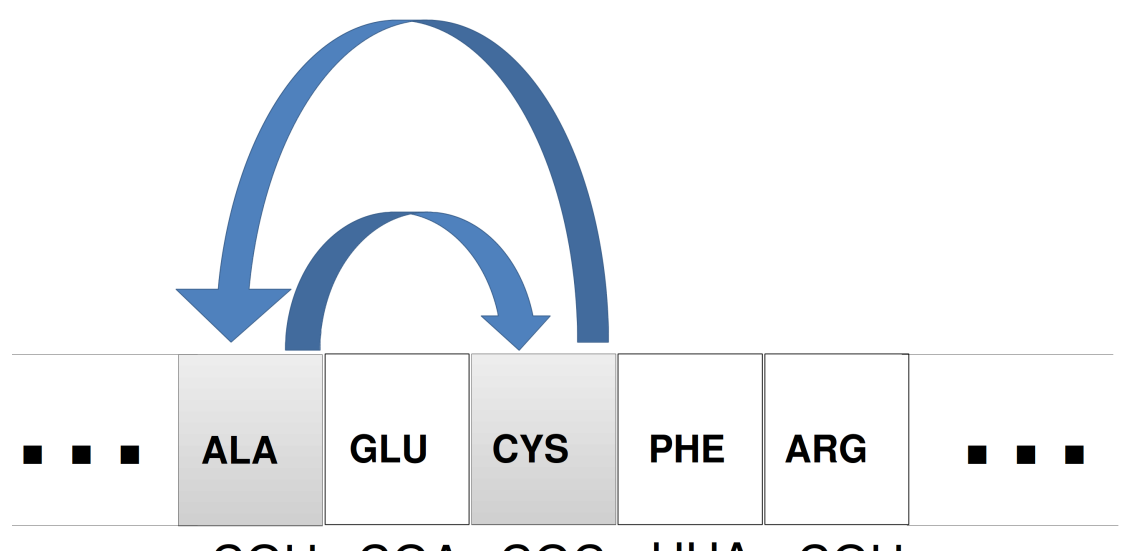

CGU CGA CGC UUA CGU

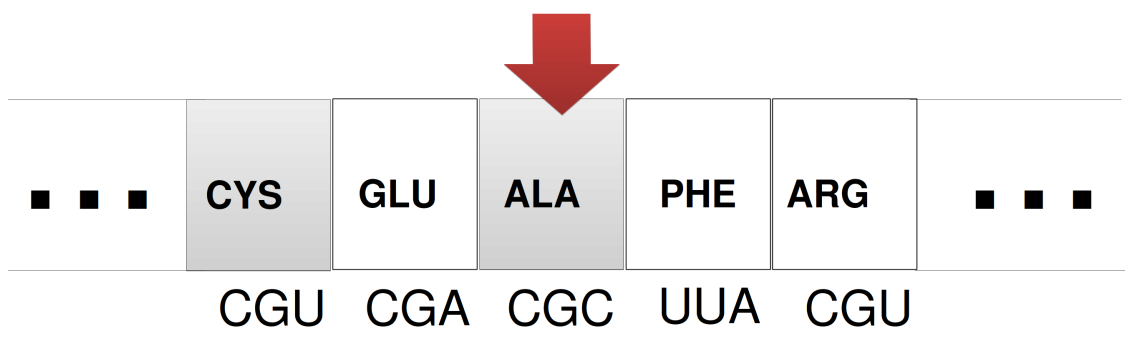

Figura 3.6: O operador de swap.

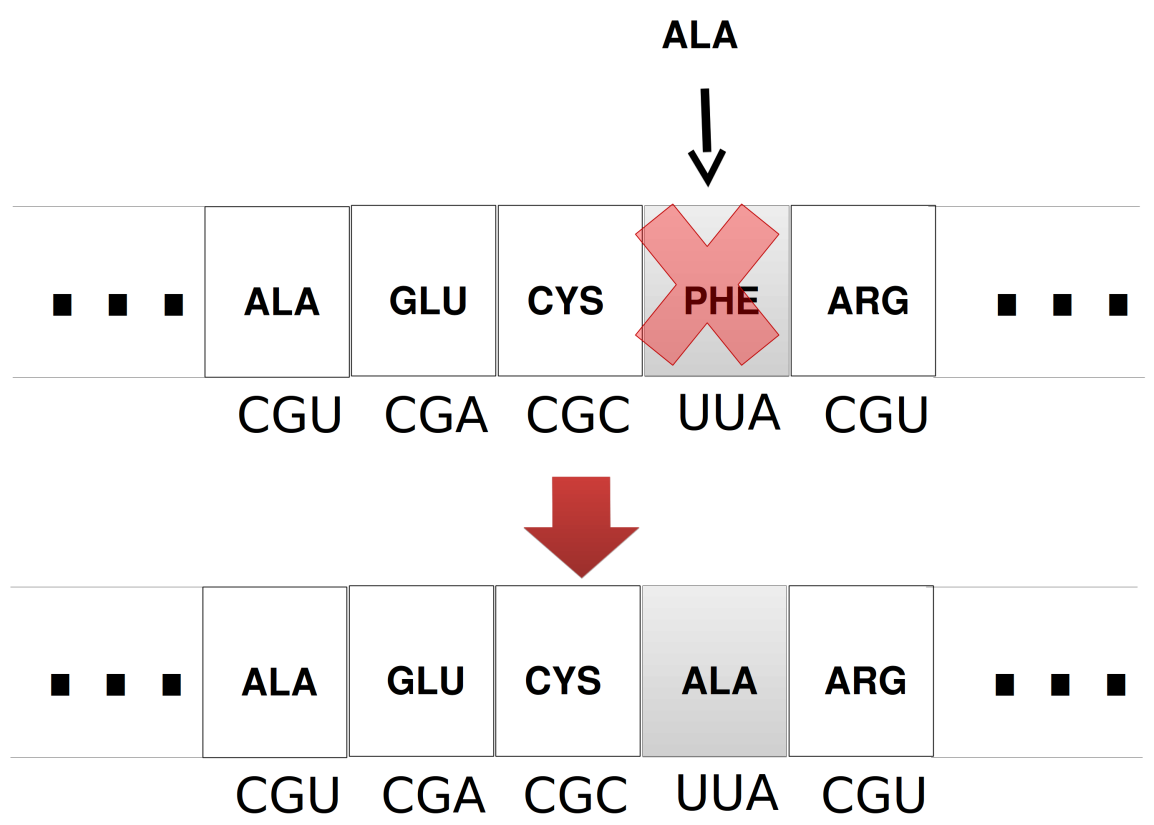

Figura 3.7: O operador de mutação.

O operador de seleção empregado foi o torneio. O torneio foi aplicado com uma taxa de 3\% (o melhor indivíduo de uma amostra aleatória de 3\% da população é selecionado). 
Além disso, o operador de elitismo também foi utilizado para preservar o melhor indivíduo encontrado nas gerações anteriores.

\subsubsection{Algoritmos Genéticos Multiobjetivo}

No mundo real, quando um processo de otimização é requerido, muitas vezes diversos critérios, ou objetivos têm que ser simultaneamente considerados. Na indústria por exemplo, durante a fabricação de um produto, é comum ter que minimizar o custo de produção ao mesmo tempo em que se maximize a qualidade. Esse mesmo tipo de otimização é necessária em diversas áreas do conhecimento como logística, transporte, telecomunicação e bioinformática (El-Ghazali, 2009).

Em problemas de otimização multiobjetivo (MOP-Multiobjective optimization problems), a presença de múltiplos objetivos faz com que ele, em geral, não possua apenas uma solução ótima, mas um conjunto delas. Isso ocorre porque as soluções podem possuir valores de objetivos diferentes melhores do que as outras. Por exemplo, uma dada solução $A$ tem o objetivo 1 melhor que o objetivo 1 de uma solução $B$, enquanto que o objetivo 2 da solução $B$ é melhor do que o da $A$. Sem nenhuma informação adicional não se pode afirmar qual das duas é melhor (Deb et al., 2002). Diz-se então que não existe relação de dominância entre as soluções. Por outro lado, se uma solução $A$ tem pelo menos um dos objetivos melhor avaliados que uma solução $B$, sendo que os outros objetivos não são pior avaliados, então diz-se que $A$ domina $B$. O conjunto de soluções não-dominadas de um problema é chamado de conjunto de Pareto.

A Figura 3.8 exemplifica este conceito. O ponto 1 possui um conforto alto e um custo alto se comparado, por exemplo, com o ponto 4, que possui um custo mais baixo e um conforto menor. Não é possível dizer qual dos dois é melhor, sem um conhecimento extra. Agora, se observarmos os pontos 3 e 4, que possuem o mesmo custo, porém diferentes valores de conforto, é possível dizer que 4 domina 3, dessa forma, a solução 3 não pertence à fronteira de Pareto. 


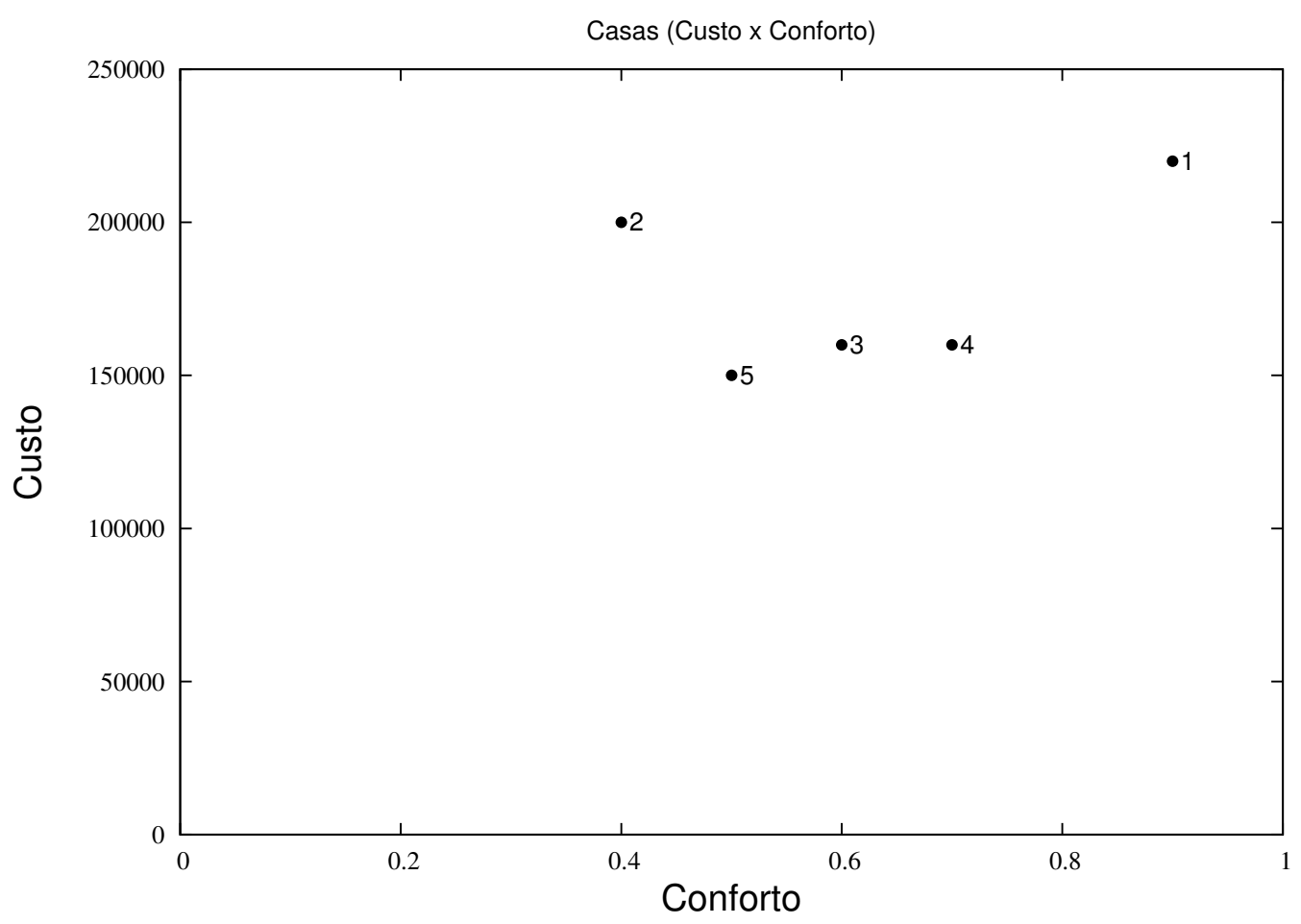

Figura 3.8: Exemplo de problema multiobjetivo.

Diversos algoritmos têm sido propostos para resolver problemas multiobjetivo (Konak et al. , 2006). Dentre eles, algoritmos evolutivos surgem como soluções naturais, uma vez que já trabalham com populações de soluções. Em (Coello, 1999), são listadas mais de 4000 referências utilizando computação evolutiva em problemas multiobjetivo. No entanto, outras técnicas, como aquelas baseadas em recozimento simulado (simulated anelling) (Suman e Kumar, 2005) e otimização por enxame de partículas (particle swarm optimization) (Parsopoulos e Vrahatis , 2002), também merecem destaque neste cenário. 


\section{CAPÍTULO 4}

\section{Abordagem Monoobjetivo}

'Gentlemen, what is easier than to make this egg stand on end which you said was impossible? It is the simplest thing in the world. Anybody could have done it after he had known how."

- Columbus

Os resultados aqui apresentados são de experimentos realizados utilizando-se a abordagem monoobjetivo descrita em (Santos e Monteagudo, 2010). Os AGs utilizados empregaram a mesma codificação (não-restritiva) e operadores de reprodução e seleção utilizados nas abordagens multiobjetivo apresentadas nos outros capítulos. O AG utilizado foi o padrão com uma população de 100 indivíduos e com os operadores de swap e mutação, conforme descritos na Seção 3.1.2. As simulações foram feitas considerando 30 sementes aleatórias. Cada individuo é avaliado usando a função do erro médio $\left(M_{s t}\right)^{1}$, considerando a polaridade dos aminoácidos.

A fim de ajustar os parâmetros do experimento, três taxas de Swap (50\%, 70\% e 90\%) e duas taxas de mutação (1\% e 5\%) foram empregadas. A Tabela 4.1 apresenta os valores da robustez obtidos considerando a polaridade dos aminoácidos. A primeira coluna representa o valor das taxas de swap e mutação.

De acordo com a Tabela 4.1 os valores mais baixos de avaliação foram obtidos para taxa de mutação de $1 \%$. O teste estatístico de Wilcoxon signed-rank foi aplicado para comparar

\footnotetext{
${ }^{1} \mathrm{~A}$ função do erro médio $M_{s t}$ é minimizada, enquanto que a robustez é indiretamente maximizada.
} 
Tabela 4.1: Média, desvio padrão e minimo dos valores de avaliação ( $M_{\text {st }}$ considerando a polaridade dos aminoácidos) calculados para o melhor código obtido pelo AG monoobjetivo na ultima geração (para 30 sementes aleatórias).

\begin{tabular}{lll}
\hline \hline swap/mutação & média \pm desvio & mínimo \\
\hline \hline $50 \% / 1 \%$ & $1,16 \pm 0,14$ & 0,92 \\
\hline $70 \% / 1 \%$ & $1,21 \pm 0,14$ & 0,98 \\
\hline $90 \% / 1 \%$ & $1,24 \pm 0,15$ & 1,05 \\
\hline $50 \% / 5 \%$ & $1,56 \pm 0,24$ & 1,10 \\
\hline $70 \% / 5 \%$ & $1,51 \pm 0,17$ & 1,09 \\
\hline $90 \% / 5 \%$ & $1,61 \pm 0,24$ & 1,20 \\
\hline \hline
\end{tabular}

Tabela 4.2: P-valores obtidos usando o teste Wilcoxon signed-rank para comparação entre as taxas de swap e mutação. Os valores de robustez utilizados no cálculo foram obtidos para o melhores códigos hipotéticos retornados pelo AG monoobjetivo.

\begin{tabular}{lllllll}
\hline \hline swap /mutação & $50 \% 1 \%$ & $70 \% 1 \%$ & $90 \% 1 \%$ & $50 \% 5 \%$ & $70 \% 5 \%$ & $90 \% 5 \%$ \\
\hline \hline $50 \% 1 \%$ & & 0,0961 & 0,02479 & $1,061 \mathrm{e}-05$ & & \\
\hline $70 \% 1 \%$ & 0,0961 & & 0,3085 & & $7,911 \mathrm{e}-05$ & \\
\hline $90 \% 1 \%$ & 0,02479 & 0,3085 & & & & $2,367 \mathrm{e}-05$ \\
\hline $50 \% 5 \%$ & $1,061 \mathrm{e}-05$ & & & & 0,8553 & 0,03842 \\
\hline $70 \% 5 \%$ & & $7,911 \mathrm{e}-05$ & & 0,8553 & & 0,04049 \\
\hline $90 \% 5 \%$ & & & $2,367 \mathrm{e}-05$ & 0,03842 & 0,04049 & \\
\hline \hline
\end{tabular}

os resultados para as diferentes taxas de swap e mutação. Os p-valores obtidos podem ser observados na Tabela 4.2 .

De acordo com a Tabela 4.2, há diferença estatística entre as simulações com a mesma taxa de swap e diferentes taxas de mutação (1\% e 5\%), considerando um intervalo de confiança de 5\%. Comparando os resultados para diferentes taxas de swap, porém com mutação de 1\%, não foi verificada diferença estatística entre as simulações. A Tabela 4.1 mostrou que o experimento com taxa de swap de $50 \%$ e com taxa de mutação de $1 \%$ foi a de menor valor de fitness. Dessa forma, nas simulações seguintes optou-se por utilizar esses valores de parâmetros neste e nos demais capítulos desta tese.

A Tabela 4.3 apresenta os valores de avaliação, pdm (para a polaridade ${ }^{2}$ ), melhora, número de coincidências com o CGP e entropia calculados para os melhores códigos obtidos pelo AG monoobjetivo, utilizando os valores de $M_{s t}$ que foram calculados empregando a propriedade polaridade dos aminoácidos. Os melhores valores de $p d m$ são os mais altos, próximos a 100\%, enquanto que os melhores valores de melhora são os próximos a zero.

Os resultados apresentados na Tabela 4.3 são próximos àqueles reportados na literatura. Santos e Monteagudo obtiveram um valor máximo de $p d m$ de $85 \%$ e uma melhora de $63 \%$ (Santos e Monteagudo, 2010) (valores obtidos para a polaridade), ou seja, valores próximos aos obtidos aqui. Além disso, observa-se que os valores de avaliação obtidos pelo AG mo-

\footnotetext{
${ }^{2}$ Os valores de $p d m$ e melhora foram calculados apenas para a polaridade por permitir a comparação com os valores reportados na literatura.
} 
Tabela 4.3: Média, desvio padrão e melhores valores dos valores de avaliação, pdm (considerando a polaridade), melhora, número de coincidências e entropia calculados para os melhores códigos obtidos pelo AG monoobjetivo na última geração (para 30 sementes aleatórias). $M_{s t}(P)$ é o valor do erro para a polaridade, as demais medidas são indicadas como (H) para hidropatia e (VM) para o volume.

\begin{tabular}{lll}
\hline \hline & média \pm desvio & melhor \\
\hline \hline$M_{s t}(\mathrm{P})$ & $1,16 \pm 0,14$ & 0,92 \\
\hline$M_{s t}(\mathrm{H})$ & $5,35 \pm 1,14$ & 3,92 \\
\hline$M_{s t}(\mathrm{VM})$ & $1331,63 \pm 257,99$ & 989,50 \\
\hline$p d m$ & $86,75 \pm 1.10 \%$ & $89,75 \%$ \\
\hline melhora & $55,94 \pm 5,23 \%$ & $41,08 \%$ \\
\hline coincidências & $4,97(8,14 \%) \pm 3,93$ & $15(24,59 \%)$ \\
\hline entropia & $1,74 \pm 0,12$ & 1,92 \\
\hline \hline
\end{tabular}

noobjetivo são bem menores que os valores de avaliação do código genético padrão que são respectivamente: 2,$63 ; 4,60$ e 1766,77 para polaridade, hidropatia e volume molecular. Isso sugere que o CGP não é o ótimo global na otimização da função de avaliação com um único objetivo baseado em robustez para a polaridade. O AG facilmente obtém códigos superiores ao padrão pelo menos em termos de valor de avaliação.

A Figura 4.1 mostra o histograma com a frequência de códons associados a cada a cada aminoácido. O histograma é relacionado com a entropia dos códigos. Quanto mais uniforme o histograma, maior é a entropia. O código apresentado é o com maior $p d m$, ou seja aquele com valor de avaliação mais próximo do código padrão. Nos experimentos, obteve-se a entropia de 1,81 para o código genético de melhor $p d m$, enquanto que a entropia do código padrão é de 2,87 .

De acordo com a Figura 4.1 as frequências do código hipotético obtido pelo AG monoobjetivo divergem das frequências encontradas no código padrão. No entanto, esse código hipotético é o código com valor de avaliação mais próximo do código padrão, ou seja, com o maior $p d m$. Desse modo, nota-se que não há uma correspondência direta entre obter um valor satisfatório de avaliação (considera-se aqui como sendo satisfatório um valor próximo ao valor de avaliação do código padrão) e a estrutura do código.

Também, pode-se observar que o código hipotético possui poucos códons associados com muitos aminoácidos e muitos códons associados com poucos aminoácidos, sendo que o aminoácido com maior número de códons associados possui 18 códons; no código padrão o número máximo de códons por aminoácido é 6 . Essa diferença se deve ao fato de que a codificação restritiva não limita o número de códons associados a um aminoácido, desse modo, esse número varia livremente. Intuitivamente, considerando quais são os aminoácidos mais importantes na minimização da Eq. do $M$ st, conclui-se que serão aqueles com menores distâncias médias para todos os demais (ou seja, os aminoácidos com valores de polaridade intermediária), por essa razão, o algoritmo monoobjetivo (que minimiza o Mst considerando a polaridado dos aminoácidos) associa um número maior de códons aos aminoácidos com 


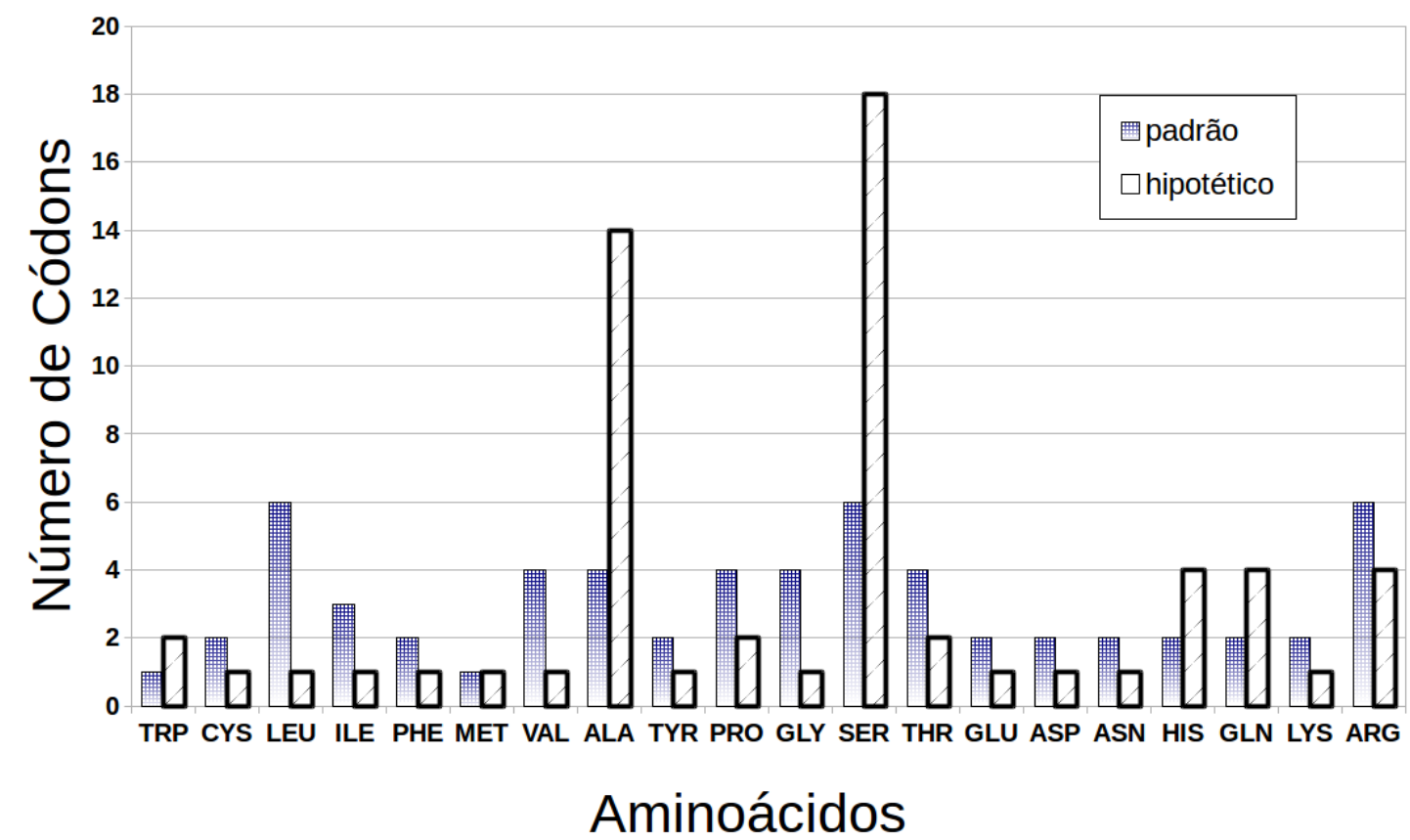

Figura 4.1: Frequência de códons associados a cada aminoácido para o código hipotético de maior pdm e para o código padrão.

Tabela 4.4: Polaridade dos aminoácidos.

\begin{tabular}{c|c|c|c|c|c|c|c|c|c|c}
\hline \hline Aminoácido & Cys & Leu & Ile & Phe & Trp & Met & Tyr & Val & Pro & Thr \\
\hline Polaridade & 4,8 & 4,9 & 4,9 & 5 & 5,2 & 5,3 & 5,4 & 5,6 & 6,6 & 6,6 \\
Distância Média & 12,86 & 12,35 & 12,35 & 11,85 & 10,93 & 10,49 & 10,08 & 9,31 & 6,67 & 6,67 \\
\hline Aminoácido & Ala & Ser & Gly & His & Gln & Arg & Asn & Lys & Glu & Asp \\
\hline Polaridade & 7 & 7,5 & 7,9 & 8,4 & 8,6 & 9,1 & 10 & 10,1 & 12,5 & 13 \\
Distância Média & 6,17 & 6,00 & 6,23 & 6,96 & 7,39 & 8,82 & 12,65 & 13,18 & 31,80 & 37,13 \\
\hline \hline
\end{tabular}

valores de polaridade intermediárias.

A Tabela 4.4 mostra as distâncias médias de cada aminoácido para todos os demais. Os aminoácidos Alanina e Serina, por exemplo, possuem valores intermediários de polaridade (em torno de 7), o que os confere menor distância média. Ainda de acordo com a Figura 4.1, observa-se que são justamente esses dois aminoácidos os com maior frequência de códons associados.

A Tabela 4.5 mostra o código hipotético com maior $p d m$ e também aquele com melhor valor de avaliação, juntamente com o código genético padrão, Observa-se um pequeno número de correspondências. 
Tabela 4.5: Código genético padrão e melhores códigos hipotéticos obtidos pelo AG Monoobjetivo (os códigos de parada foram omitidos).

\begin{tabular}{|c|c|c|c|}
\hline codon & CGP & Menor Avaliação $M s t$ & Melhor $p d m$ \\
\hline$\overline{\text { UUU }}$ & $\bar{F}$ & $\overline{\mathrm{V}}$ & $\bar{T}$ \\
\hline UUC & $\mathrm{F}$ & $\mathrm{V}$ & $\mathrm{P}$ \\
\hline UUA & $\mathrm{L}$ & $\mathrm{V}$ & $\mathrm{T}$ \\
\hline UUG & $\mathrm{L}$ & $\mathrm{V}$ & $\mathrm{P}$ \\
\hline $\mathrm{UCU}$ & $\mathrm{S}$ & $\mathrm{A}$ & $\mathrm{R}$ \\
\hline UCC & $\mathrm{S}$ & $\mathrm{P}$ & $\mathrm{R}$ \\
\hline UCA & $\mathrm{S}$ & $\mathrm{T}$ & $\mathrm{R}$ \\
\hline UCG & $\mathrm{S}$ & $\mathrm{T}$ & $\mathrm{R}$ \\
\hline UAU & $\mathrm{Y}$ & $\mathrm{D}$ & $\mathrm{S}$ \\
\hline UAC & $\mathrm{Y}$ & $\mathrm{E}$ & G \\
\hline UGU & $\mathrm{C}$ & $\mathrm{Q}$ & $\mathrm{A}$ \\
\hline UGC & $\bar{C}$ & Q & $\mathrm{S}$ \\
\hline UGG & $\mathrm{W}$ & $\mathrm{H}$ & A \\
\hline CUU & $\mathrm{L}$ & $\mathrm{V}$ & $\mathrm{A}$ \\
\hline CUC & $\mathrm{L}$ & $\mathrm{V}$ & A \\
\hline CUA & $\mathrm{L}$ & $\mathrm{V}$ & A \\
\hline CUG & $\mathrm{L}$ & $\mathrm{V}$ & $\mathrm{A}$ \\
\hline $\mathrm{CCU}$ & $\mathrm{P}$ & $\mathrm{T}$ & $\mathrm{N}$ \\
\hline $\mathrm{CCC}$ & $\mathrm{P}$ & $\mathrm{T}$ & $\mathrm{E}$ \\
\hline $\mathrm{CCA}$ & $\mathbf{P}$ & $\mathbf{P}$ & $\mathrm{K}$ \\
\hline $\mathrm{CCG}$ & $\mathbf{P}$ & $\mathbf{P}$ & $\mathrm{D}$ \\
\hline $\mathrm{CAU}$ & $\mathrm{H}$ & $\mathrm{K}$ & $\mathrm{S}$ \\
\hline CAC & $\mathrm{H}$ & $\mathrm{N}$ & $\mathrm{S}$ \\
\hline CAA & $\mathrm{Q}$ & $\mathrm{R}$ & $\mathrm{S}$ \\
\hline CAG & $\mathrm{Q}$ & $\mathrm{R}$ & $\mathrm{S}$ \\
\hline CGU & $\mathrm{R}$ & $\mathrm{H}$ & A \\
\hline $\mathrm{CGC}$ & $\mathrm{R}$ & $\mathrm{H}$ & A \\
\hline CGA & $\mathrm{R}$ & $\mathrm{H}$ & $\mathrm{A}$ \\
\hline CGG & $\mathrm{R}$ & $\mathrm{H}$ & $\mathrm{A}$ \\
\hline AUU & I & $\mathrm{Y}$ & $\mathrm{L}$ \\
\hline AUC & I & $\mathrm{M}$ & $\mathrm{W}$ \\
\hline AUA & I & $\mathrm{V}$ & $\mathrm{C}$ \\
\hline AUG & $\mathrm{M}$ & $\overline{\mathrm{W}}$ & I \\
\hline $\mathrm{ACU}$ & $\mathbf{T}$ & $\mathbf{T}$ & $\mathrm{H}$ \\
\hline $\mathrm{ACC}$ & $\mathrm{T}$ & $\mathrm{P}$ & $\mathrm{Q}$ \\
\hline ACA & $T$ & $T$ & $\mathrm{H}$ \\
\hline ACG & $\mathrm{T}$ & $\mathrm{P}$ & $\mathrm{Q}$ \\
\hline AAU & $\mathrm{N}$ & $\mathrm{R}$ & $\mathrm{S}$ \\
\hline AAC & $\mathrm{N}$ & $\mathrm{R}$ & $\mathrm{S}$ \\
\hline AAA & $\mathrm{K}$ & $\mathrm{Q}$ & $\mathrm{S}$ \\
\hline AAG & $\mathrm{K}$ & $\mathrm{Q}$ & $\mathrm{S}$ \\
\hline $\mathrm{AGU}$ & $\mathrm{S}$ & G & A \\
\hline AGC & $\mathrm{S}$ & G & A \\
\hline AGA & $\mathrm{R}$ & G & A \\
\hline AGG & $\mathrm{R}$ & G & $\mathrm{A}$ \\
\hline GUU & $\mathrm{V}$ & $\mathrm{L}$ & $\mathrm{M}$ \\
\hline GUC & $\mathrm{V}$ & I & $\mathrm{Y}$ \\
\hline GUA & $\mathrm{V}$ & $\mathrm{F}$ & $\mathrm{F}$ \\
\hline GUG & $\mathrm{V}$ & $\mathrm{C}$ & $\mathrm{V}$ \\
\hline GCU & A & $\mathrm{T}$ & $\mathrm{H}$ \\
\hline $\mathrm{GCC}$ & A & $\mathrm{P}$ & Q \\
\hline GCA & A & $\mathrm{P}$ & $\mathrm{H}$ \\
\hline GCG & $\mathrm{A}$ & $\mathrm{T}$ & $\mathrm{Q}$ \\
\hline GAU & $\mathrm{D}$ & $\mathrm{R}$ & $\mathrm{S}$ \\
\hline GAC & $\mathrm{D}$ & $\mathrm{R}$ & $\mathrm{S}$ \\
\hline GAA & $\mathrm{E}$ & $\mathrm{Q}$ & $\mathrm{S}$ \\
\hline GAG & $\mathrm{E}$ & $\mathrm{Q}$ & $\mathrm{S}$ \\
\hline GGU & G & G & $\mathrm{S}$ \\
\hline GGC & G & G & $\mathrm{S}$ \\
\hline GGA & G & $\mathrm{S}$ & $\mathrm{S}$ \\
\hline GGG & G & $\mathbf{G}$ & $\mathrm{S}$ \\
\hline
\end{tabular}




\section{CAPÍTULO 5}

\section{Abordagem Ponderada}

"You want weapons? We're in a library! Books! The best weapons in the world!."

- The Doctor, Season 2, Episode 2

A abordagem ponderada transforma um problema multiobjetivo em um monoobjetivo, atribuindo um peso para cada objetivo. Assim, se tivermos $n$ objetivos a fórmula ponderada para o valor de aptidão do indivíduo tem a forma:

$$
F=w_{1} \times o b j_{1}+w_{2} \times o b j_{2}+\ldots+w_{n} \times o b j_{n}
$$

na qual $w_{i}$ é o $i$-ésimo peso e $o b j_{i}$ é a avaliação do $i$-ésimo objetivo. O principal problema com esta abordagem é determinar os valores de $w_{i}$, que são geralmente valores ad-hoc. Aqui, três objetivos são empregados: $M_{s t}$ para polaridade, hidropatia e volume molecular, representados respectivamente por $M_{s t}(\mathrm{P}), M_{s t}(\mathrm{H})$ e $M_{s t}(\mathrm{VM})$.

A fim de limitar o número de combinações de pesos possíveis, assumiu-se, aqui, a ordem de prioridade dos objetivos: polaridade, hidropatia e volume molecular ${ }^{1}$. Dessa forma, optouse por combinações de pesos que levassem em conta essa prioridade. A Tabela 5.1 mostra os resultados de avaliação (neste caso, o valor da avaliação é dado como a soma ponderada dos valores normalizados de $M_{s t}$ calculado para as três propriedades).

\footnotetext{
${ }^{1}$ As mesmas prioridades também foram empregadas na abordagem lexicográfica que será discutida no próximo capítulo.
} 
Tabela 5.1: Resultados de avaliação, $M_{s t}, p d m$, melhora, número de coindiciências e entropia para os melhores códigos obtidos pelo AG ponderado.

\begin{tabular}{llllll}
\hline \hline$w_{1}$ & $w_{2}$ & $w_{3}$ & avaliação & média \pm std & melhor \\
\hline \hline 0,4 & 0,35 & 0,25 & avaliação $(\mathrm{F})$ & $0,17 \pm 0,02$ & 0,13 \\
0,6 & 0,3 & 0,1 & avaliação $(\mathrm{F})$ & $0,14 \pm 0,01$ & 0,12 \\
0,8 & 0,15 & 0,05 & avaliação $(\mathrm{F})$ & $0,13 \pm 0,02$ & 0,10 \\
\hline 0,4 & 0,35 & 0,25 & $M_{s t}(\mathrm{P})$ & $1,80 \pm 0,30$ & 1,17 \\
0,6 & 0,3 & 0,1 & $M_{s t}(\mathrm{P})$ & $1,49 \pm 0,20$ & 1,14 \\
0,8 & 0,15 & 0,05 & $M_{s t}(\mathrm{P})$ & $1,40 \pm 0,25$ & 1,05 \\
\hline 0,4 & 0,35 & 0,25 & $M_{s t}(\mathrm{H})$ & $2,75 \pm 0,44$ & 1,86 \\
0,6 & 0,3 & 0,1 & $M_{s t}(\mathrm{H})$ & $2,20 \pm 0,39$ & 1,57 \\
0,8 & 0,15 & 0,05 & $M_{s t}(\mathrm{H})$ & $2,38 \pm 0,34$ & 1,79 \\
\hline 0,4 & 0,35 & 0,25 & $M_{s t}(\mathrm{MV})$ & $760,10 \pm 111,14$ & 527,67 \\
0,6 & 0,3 & 0,1 & $M_{s t}(\mathrm{MV})$ & $972,09 \pm 163,03$ & 743,17 \\
0,8 & 0,15 & 0,05 & $M_{s t}(\mathrm{MV})$ & $969,97 \pm 168,21$ & 691,97 \\
\hline 0,4 & 0,35 & 0,25 & $p d m$ & $92,03 \pm 2,70 \%$ & $96,45 \%$ \\
0,6 & 0,3 & 0,1 & pdm & $89,33 \pm 1,67 \%$ & $93,50 \%$ \\
0,8 & 0,15 & 0,05 & $p d m$ & $88,54 \pm 2,11 \%$ & $93,09 \%$ \\
\hline 0,4 & 0,35 & 0,25 & melhora & $31,49 \pm 11,58 \%$ & $13,22 \%$ \\
0,6 & 0,3 & 0,1 & melhora & $43,11 \pm 7,44 \%$ & $25,00 \%$ \\
0,8 & 0,15 & 0,05 & melhora & $46,81 \pm 9,55 \%$ & $26,72 \%$ \\
\hline 0,4 & 0,35 & 0,25 & coincidências & $3,57(5,85 \%) \pm 2,76$ & $9(14,75 \%)$ \\
0,6 & 0,3 & 0,1 & coincidências & $3,33(5,46 \%) \pm 3,92$ & $15(24,59 \%)$ \\
0,8 & 0,15 & 0,05 & coincidências & $3,47(5,68 \%) \pm 3,45$ & $13(21,31 \%)$ \\
\hline 0,4 & 0,35 & 0,25 & entropia & $2,42 \pm 0,09$ & 2,63 \\
\hline 0,6 & 0,3 & 0,1 & entropia & $2,40 \pm 0,12$ & 2,62 \\
\hline 0,8 & 0,15 & 0,05 & entropia & $2,41 \pm 0,10$ & 2,56 \\
\hline \hline
\end{tabular}


De acordo com a Tabela 5.1, o melhor valor de avaliação para a polaridade, ou fitness foi obtido para os pesos: $w_{1}=0,8, w_{2}=0,15$ e $w_{3}=0,05$. Os melhores valores médios de $M_{s t}$ para a polaridade também foram obtidos para essa combinação de pesos. Para o $M_{s t}$ da hidropatia, o menor valor médio foi obtido no experimento com pesos $w_{1}=0,6, w_{2}=0,3$ e $w_{3}=0,1$. Já quando o volume foi considerado, o melhor valor foi obtido para $w_{1}=0,4$, $w_{2}=0,35$ e $w_{3}=0,25$.

Ainda sobre a Tabela 5.1, os melhores valores de $p d m$ foram obtidos para a combinação de pesos: $w_{1}=0,4, w_{2}=0,35$ e $w_{3}=0,25$. O melhor $p d m$ para a polaridade foi de $96,45 \%$.

Quanto a análise de códigos, observa-se que o maior número de coincidências $(24,59 \%)$ foi obtido para os pesos $w_{1}=0,6, w_{2}=0,3$ e $w_{3}=0,1$. O maior valor de entropia obtido foi 1,14 para os pesos $w_{1}=0,4, w_{2}=0,35, w_{3}=0,25$ e $w_{1}=0,6, w_{2}=0,3, w_{3}=0,1$. A entropia dos códigos obtidos pela abordagem ponderada foi relativamente baixa em comparação a entropia do CGP (2,87). As figuras 5.1, 5.2 e 5.3 apresentam os histogramas associados com as frequências dos aminoácidos. É possível observar que alguns aminoácidos possuem grande número de códons associados.

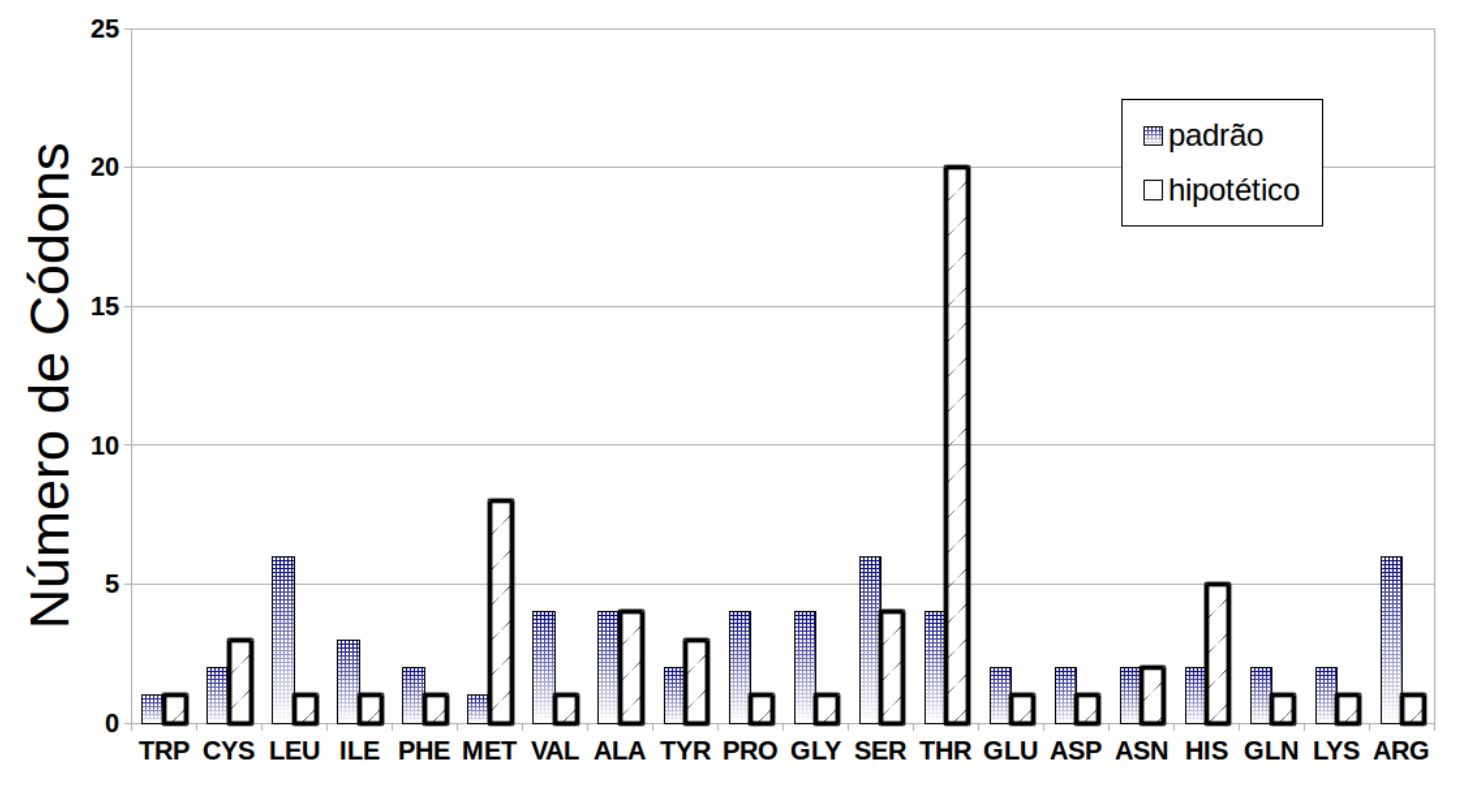

\section{Aminoácidos}

Figura 5.1: Frequência de códons associados a cada aminoácido para o código hipotético de maior pdm e para o código padrão para a combinação de pesos $w_{1}=0,4, w_{2}=0,35, w_{3}=0,25$.

A Tabela 5.2 mostra os dois melhores códigos obtidos pela abordagem ponderada, sendo um de melhor $M_{s t}$ e o outro de melhor $p d m$. 
Tabela 5.2: Código genético padrão e melhores códigos hipotéticos obtidos pelo AG Ponderado (os códigos de parada foram omitidos).

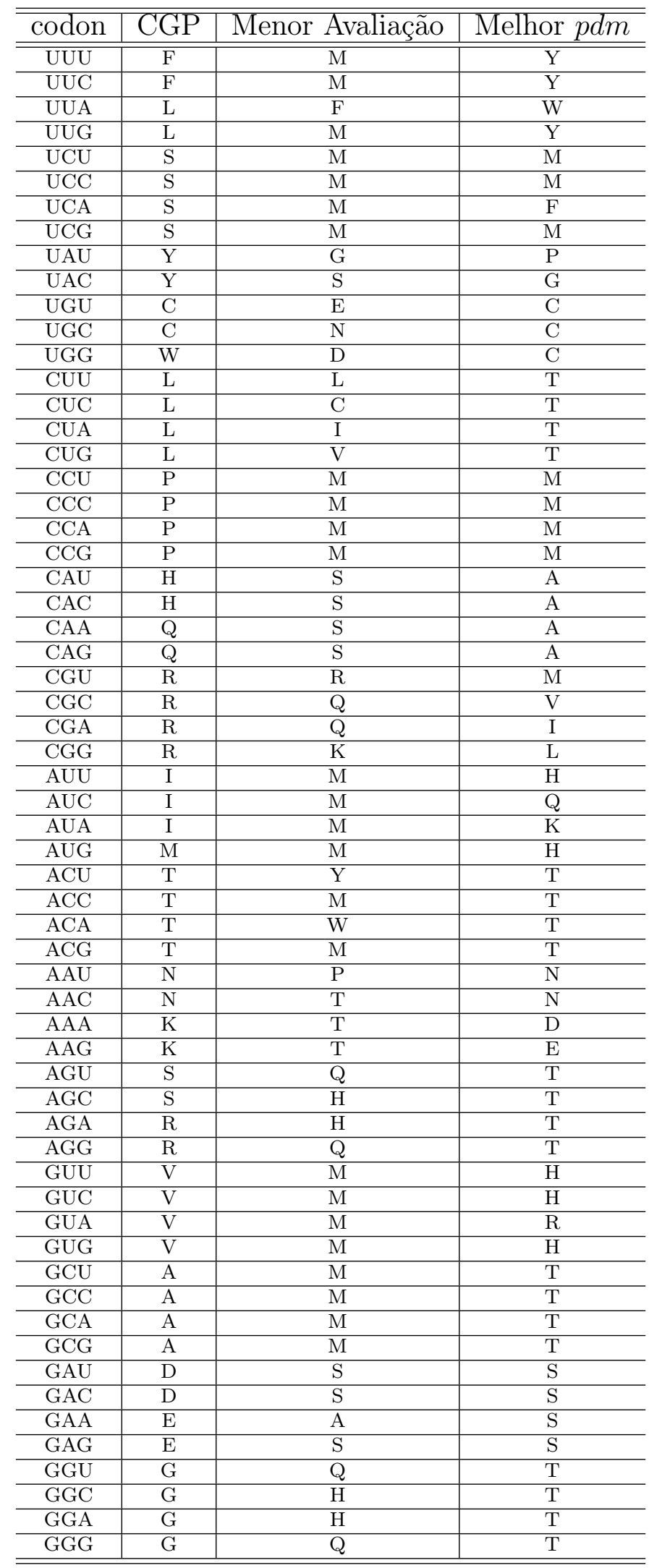




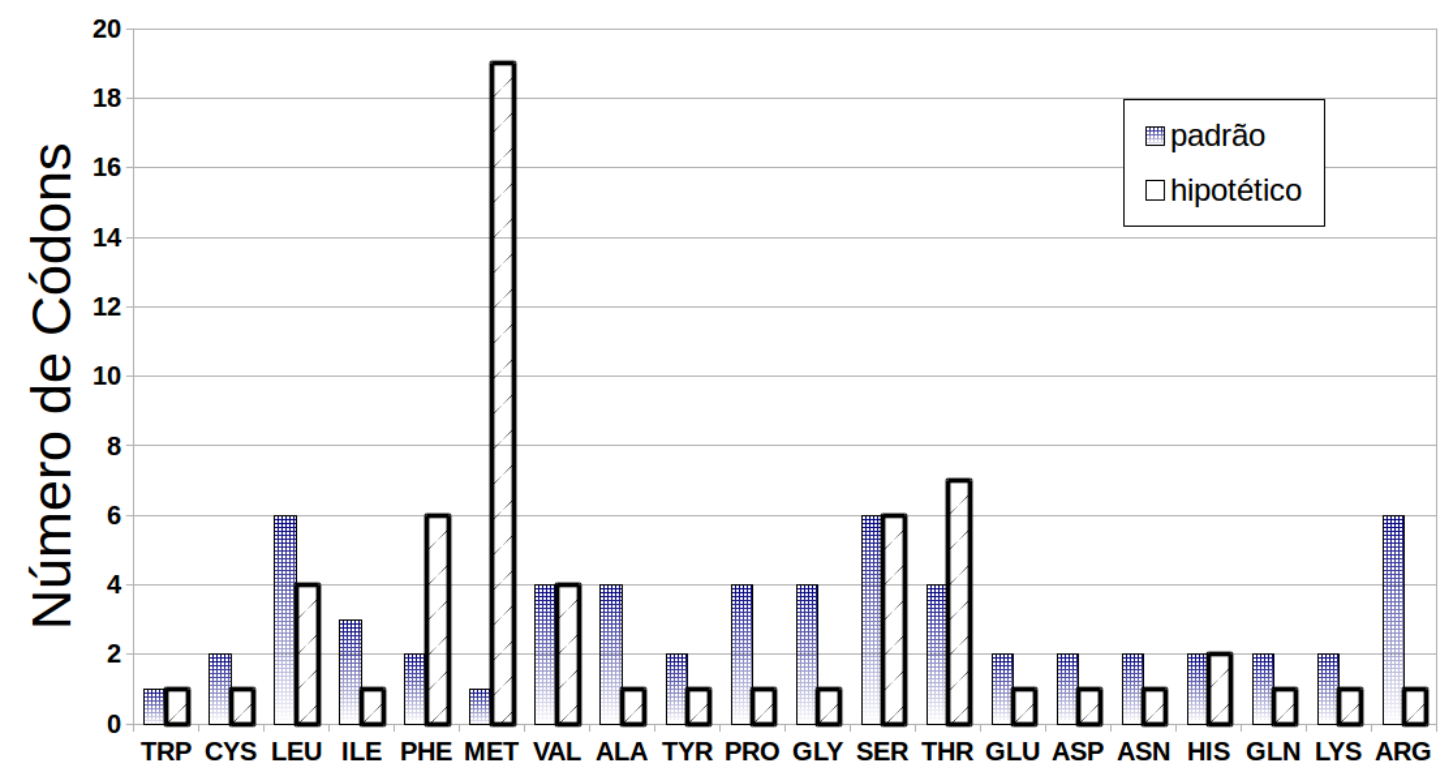

Aminoácidos

Figura 5.2: Frequência de códons associados a cada aminoácido para o código hipotético de maior pdm e para o código padrão para a combinação de pesos $w_{1}=0,6, w_{2}=0,3, w_{3}=0,1$.

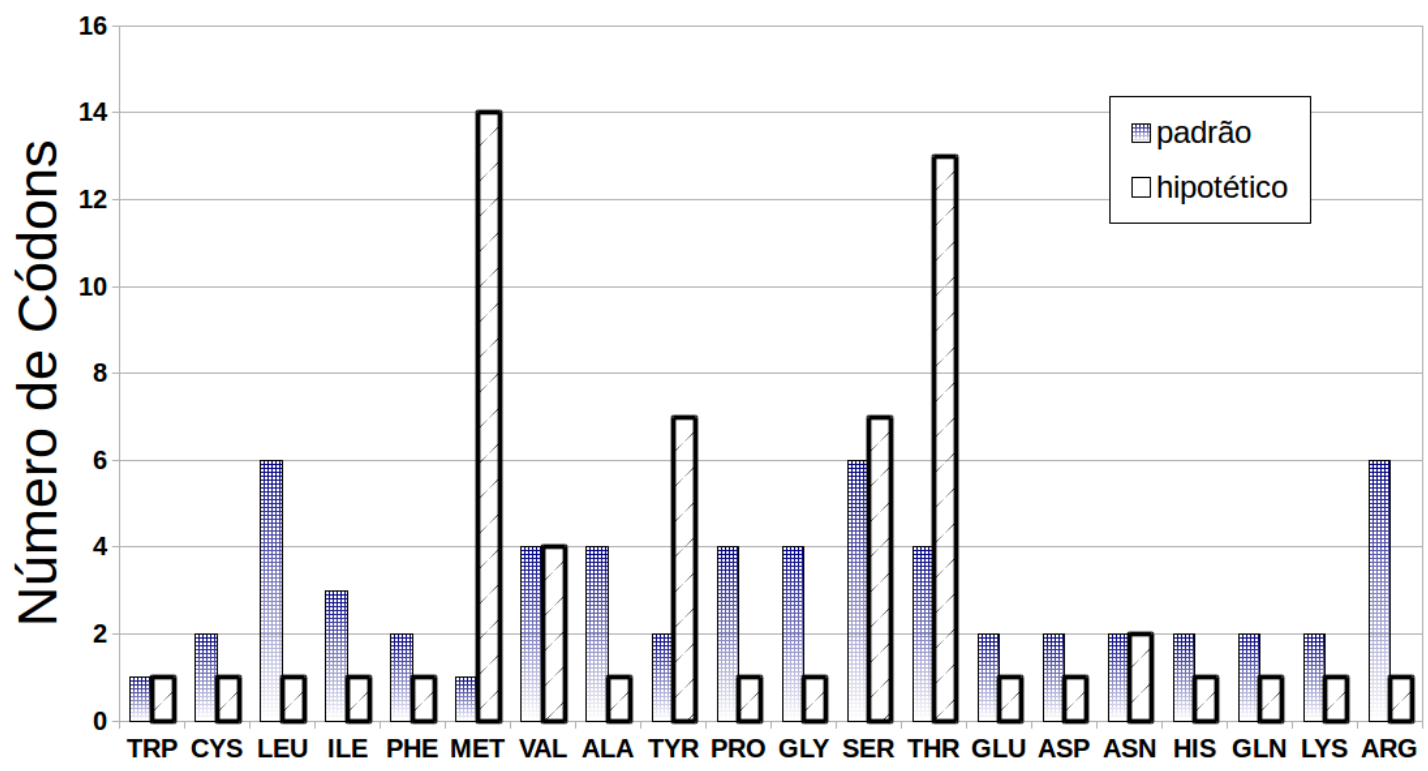

Aminoácidos

Figura 5.3: Frequência de códons associados a cada aminoácido para o código hipotético de maior pdm e para o código padrão para a combinação de pesos $w_{1}=0,8, w_{2}=0,15$ e $w_{3}=0,05$. 


\section{CAPÍTULO 6}

\section{Abordagem Lexicográfica}

'The fact that we live at the bottom of a deep gravity well, on the surface of a gas covered planet going around a nuclear fireball 90 million miles away and think this to be normal is obviously some indication of how skewed our perspective tends to be."

- Douglas Adams, The Salmon of Doubt: Hitchhiking the Galaxy One Last Time

A abordagem lexicográfica atribui diferentes prioridades aos objetivos de acordo com sua importância. Aqui, as prioridades foram definidas como sendo: polaridade, hidropatia e por último volume molecular. Essa ordem foi definida com base no quão robusto o código padrão é quando essas propriedades são utilizadas no cálculo do $M_{s t}$.

Na literatura, a polaridade (Woese, 1965) tem sido frequentemente utilizada para explicar a estrutura do código padrão (Di Giulio, 1989; Haig e Hurst, 1991; Santos e Monteagudo , 2010), devido ao fato de que o código é consideravelmente mais robusto quando essa propriedade é analisada, ou seja, quando um códon é mutado, na maioria das vezes o novo código irá codificar o mesmo aminoácido ou um com polaridade similar. Essa robustez ocorre para as demais propriedades também, mas é mais evidente para a polaridade, em segundo lugar para a hidropatia e por fim para o volume.

Na abordagem lexicográfica, a fim de escolher a melhor solução entre duas soluções $(A$ e $B$ ), observa-se inicialmente o objetivo de mais alta prioridade. Desse modo, compara-se o valor da avaliação ou fitness $f_{1}$ para cada solução, que nada mais é que o valor do $M_{s t}$ 
Tabela 6.1: Resultados de avaliação para os três objetivos, pdm, melhora (para a polaridade) and número de coincidências para os melhores códigos obtidos pelo AG lexicográfico.

\begin{tabular}{lll}
\hline \hline & média \pm desvio & melhor \\
\hline \hline$M_{s t}(\mathrm{P})$ & $1.86 \pm 0.25$ & 1.40 \\
\hline$M_{s t}(\mathrm{H})$ & $3.71 \pm 0.72$ & 2.56 \\
\hline$M_{s t}(\mathrm{VM})$ & $1590.46 \pm 339.79$ & 996.13 \\
\hline$p d m$ & $92.59 \pm 2.29 \%$ & $98.04 \%$ \\
\hline melhora & $19.04 \pm 9.44 \%$ & $7.19 \%$ \\
\hline coincidências & $3,10(5,08 \%) \pm 2,51$ & $9(14,75 \%)$ \\
\hline entropia & $1,70 \pm 0,11$ & 2,90 \\
\hline \hline
\end{tabular}

calculado para a polaridade. Se o valor absoluto da diferença entre os valores das avaliações das duas soluções é significativo, ou seja, é maior que um desvio padrão, então a solução com menor valor de avaliação é escolhida como sendo a melhor solução, não sendo necessário analisar os demais objetivos. O desvio padrão é calculado em cada geração, utilizando o valor de avaliação de toda a população para o determinado objetivo. Dessa forma, o desvio será mais alto no início da experimento e, em geral, tende a decrescer ao longo do tempo.

Contudo, se a diferença não for significativa, ou seja, for menor que um desvio padrão, analisa-se o próximo objetivo ( $f_{2}$, ou seja, $M_{s t}$ para a hidropatia) e assim sucessivamente. A desvantagem da abordagem lexicográfica é que é necessário ter algum conhecimento a priori sobre a prioridades dos objetivos (Freitas, 2004). Os operadores de swap e mutação foram empregados, da mesma forma como descritos na abordagem monoobjetivo. Contudo os operadores de elitismo e torneio empregam a técnica lexicográfica para determinar se um indivíduo é melhor que o outro, conforme acima descrito.

A Tabela 6.1 mostra os resultados da avaliação, $p d m$, melhora, entropia e número de coincidências. O melhor valor $p d m$ obtido foi $98,04 \%$ (máximo) e a melhor melhora foi de $7,19 \%$. Os valores de $p d m$ e melhora são superiores que os obtidos pelo AG monoobjetivo e de que aqueles reportados na literatura (Santos e Monteagudo, 2010).

A Figura 6.1 apresenta o histograma com a frequência de códons associados a cada aminoácido. O código apresentado é o com maior $p d m$. Observa-se que as frequências dos códons associados com aminoácidos é mais uniforme, mais similar ao código padrão. Isso ocorre, pois na abordagem lexicográfica mais de um objetivo é considerado.

A Tabela 6.2 mostra o código hipotético com maior $p d m$ e também aquele com menor valor de avaliação, juntamente com o código genético padrão. 
Tabela 6.2: Código genético padrão e melhores códigos hipotéticos obtidos pelo AG Lexicografico (os códigos de parada foram omitidos).

\begin{tabular}{|c|c|c|c|}
\hline codon & CGP & Menor Avaliação & Melhor $p d m$ \\
\hline$\overline{\mathrm{UUU}}$ & $\overline{\bar{F}}$ & $\overline{\mathrm{T}}$ & $\overline{\mathrm{C}}$ \\
\hline UUC & $\mathrm{F}$ & $\bar{T}$ & I \\
\hline$\overline{\text { UUA }}$ & $\mathrm{L}$ & $\mathrm{T}$ & $\mathrm{C}$ \\
\hline UUG & $\mathrm{L}$ & $\mathrm{T}$ & $\mathrm{M}$ \\
\hline $\mathrm{UCU}$ & $\mathrm{S}$ & $\mathrm{M}$ & $\mathrm{N}$ \\
\hline $\mathrm{UCC}$ & $\mathrm{S}$ & $\mathrm{F}$ & $\mathrm{N}$ \\
\hline$\overline{\text { UCA }}$ & $\mathrm{S}$ & $\bar{M}$ & $\bar{D}$ \\
\hline $\mathrm{UCG}$ & $\mathrm{S}$ & $\mathrm{L}$ & $\mathrm{E}$ \\
\hline UAU & $\mathrm{Y}$ & $\mathrm{T}$ & $\mathrm{Y}$ \\
\hline UAC & $\bar{Y}$ & $\bar{G}$ & $\bar{T}$ \\
\hline$\overline{\mathrm{UGU}}$ & $\mathrm{C}$ & $\overline{\mathrm{K}}$ & $\mathrm{P}$ \\
\hline UGC & $\mathrm{C}$ & $\mathrm{D}$ & G \\
\hline UGG & $\mathrm{W}$ & $\mathrm{E}$ & G \\
\hline CUU & $\mathrm{L}$ & $\mathrm{S}$ & $\overline{\mathrm{M}}$ \\
\hline$\overline{\text { CUC }}$ & $\overline{\mathrm{L}}$ & $\overline{\mathrm{T}}$ & $\overline{\mathrm{V}}$ \\
\hline CUA & $\mathrm{L}$ & $\mathrm{S}$ & $\mathrm{F}$ \\
\hline CUG & $\mathrm{L}$ & $\mathrm{P}$ & $\mathrm{L}$ \\
\hline $\mathrm{CCU}$ & $\mathrm{P}$ & $\mathrm{V}$ & $\mathrm{Q}$ \\
\hline $\mathrm{CCC}$ & $\mathrm{P}$ & $\mathrm{C}$ & $\mathrm{Q}$ \\
\hline CCA & $\mathrm{P}$ & I & $\mathrm{N}$ \\
\hline CCG & $\mathrm{P}$ & I & K \\
\hline CAU & $\overline{\mathrm{H}}$ & $\bar{T}$ & $\mathrm{~T}$ \\
\hline CAC & $\mathrm{H}$ & $\mathrm{P}$ & $\mathrm{T}$ \\
\hline CAA & $\mathrm{Q}$ & $\mathrm{S}$ & $\mathrm{P}$ \\
\hline CAG & $\mathrm{Q}$ & $\mathrm{G}$ & $\mathrm{P}$ \\
\hline CGU & $\overline{\mathrm{R}}$ & $\overline{\mathrm{R}}$ & $\bar{T}$ \\
\hline CGC & $\bar{R}$ & $\mathrm{~N}$ & $\mathrm{P}$ \\
\hline CGA & $\mathrm{R}$ & $\mathrm{H}$ & $\mathrm{S}$ \\
\hline CGG & $\mathrm{R}$ & $\mathrm{Q}$ & G \\
\hline$\overline{\mathrm{AUU}}$ & I & $\bar{S}$ & $\overline{\mathrm{L}}$ \\
\hline AUC & I & $\overline{\mathrm{T}}$ & I \\
\hline AUA & I & $\mathrm{P}$ & I \\
\hline AUG & $\mathrm{M}$ & $\mathrm{P}$ & $\mathrm{F}$ \\
\hline $\mathrm{ACU}$ & $\mathrm{T}$ & $\mathrm{M}$ & $\mathrm{P}$ \\
\hline$\overline{\mathrm{ACC}}$ & $\bar{T}$ & $\overline{\mathrm{Y}}$ & $\bar{Q}$ \\
\hline ACA & $\mathrm{T}$ & $\mathrm{F}$ & $\mathrm{S}$ \\
\hline $\mathrm{ACG}$ & $\mathrm{T}$ & $\mathrm{M}$ & $\mathrm{H}$ \\
\hline $\mathrm{AAU}$ & $\mathrm{N}$ & $\mathrm{T}$ & $\mathrm{Y}$ \\
\hline AAC & $\mathrm{N}$ & $\mathrm{S}$ & $\mathrm{T}$ \\
\hline AAA & $\mathrm{K}$ & $\mathrm{S}$ & $\mathrm{T}$ \\
\hline AAG & $\bar{K}$ & $\mathrm{G}$ & $\mathrm{T}$ \\
\hline AGU & $\mathrm{S}$ & $\mathrm{R}$ & G \\
\hline AGC & $\mathrm{S}$ & $\overline{\mathrm{H}}$ & $\mathrm{T}$ \\
\hline AGA & $\mathrm{R}$ & $\mathrm{R}$ & $\mathrm{A}$ \\
\hline AGG & $\mathrm{R}$ & $\overline{\mathrm{H}}$ & $\mathrm{A}$ \\
\hline GUU & $\mathrm{V}$ & $\mathrm{S}$ & $\mathrm{Y}$ \\
\hline GUC & $\mathrm{V}$ & $\mathrm{P}$ & $\bar{F}$ \\
\hline GUA & $\mathrm{V}$ & $\mathrm{T}$ & $\mathrm{F}$ \\
\hline GUG & $\mathrm{V}$ & $\mathrm{A}$ & W \\
\hline GCU & $\mathrm{A}$ & $\mathrm{M}$ & K \\
\hline GCC & $\mathrm{A}$ & $\mathrm{W}$ & $\mathrm{N}$ \\
\hline GCA & $\mathrm{A}$ & $\mathrm{M}$ & $\mathrm{N}$ \\
\hline GCG & $\mathrm{A}$ & $\mathrm{M}$ & $\mathrm{R}$ \\
\hline GAU & $\mathrm{D}$ & $\mathrm{S}$ & $\mathrm{P}$ \\
\hline GAC & $\overline{\mathrm{D}}$ & $\bar{S}$ & G \\
\hline GAA & $\mathrm{E}$ & $\mathrm{G}$ & $\mathrm{T}$ \\
\hline GAG & $\mathrm{E}$ & $\mathrm{G}$ & $\mathrm{T}$ \\
\hline GGU & $\mathrm{G}$ & Q & A \\
\hline GGC & $\bar{G}$ & $\overline{\mathrm{H}}$ & $\mathrm{S}$ \\
\hline GGA & G & $\mathrm{R}$ & $\mathrm{A}$ \\
\hline GGG & $\mathrm{G}$ & $\mathrm{Q}$ & $\mathrm{A}$ \\
\hline
\end{tabular}




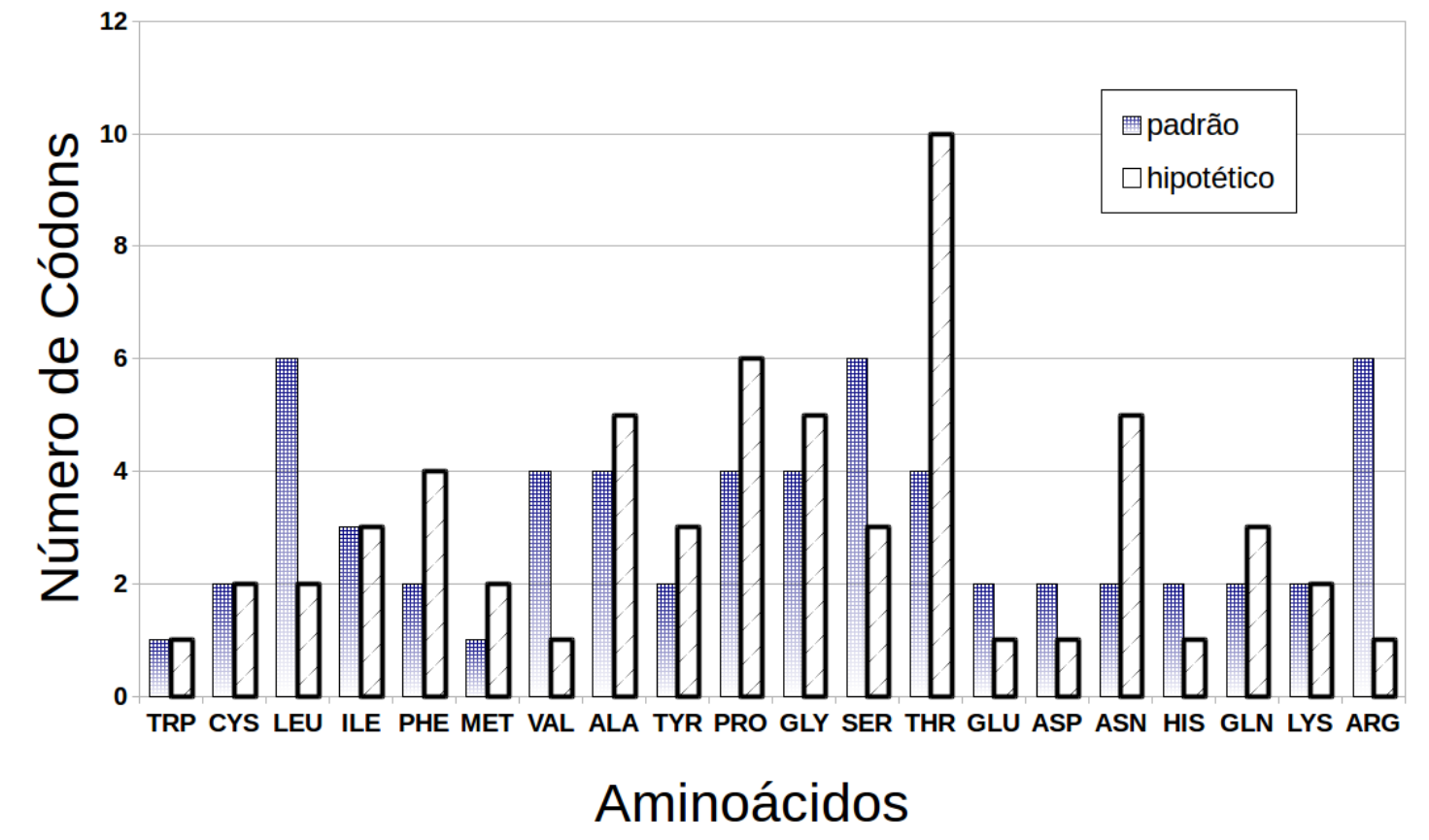

Figura 6.1: Frequência de códons associados a cada aminoácido para o código hipotético de maior pdm e para o código padrão. 


\section{CAPÍTULO 7}

\section{Abordagem de Pareto}

"Do. Or do not. There is no try."

- Yoda, Star Wars: The Empire Strikes Back

A abordagem de Pareto, diferentemente das abordagens previamente apresentadas, lida com os problemas multiobjetivo sem converte-los em monoobjetivo.

Aqui, o algoritmo empregado na otimização multiobjetivo que é frequentemente empregado na literatura foi o NSGA-II Deb et al. (2002). O NSGA-II (Nondominated Sorting Genetic Algorithm II) é frequentemente empregado quando o número de objetivos não é muito alto. Além disso, o algoritmo apresenta um bom desempenho e sua complexidade é no máximo $O\left(M N^{2}\right)$, sendo $M$ o tamanho da população e $N$ o número de objetivos. $\mathrm{O}$ algoritmo também possui um mecanismo de manutenção da diversidade das soluções Deb et al. (2002).

Os detalhes da abordagem são apresentados a seguir.

\subsection{NSGA-II}

O NSGA-II emprega um método de ordenação elitista por não dominância. Dessa forma, o NSGA-II separa a população em camadas por ordem de dominância. Esse processo é realizado por meio de um algoritmo rápido de ordenação por dominância (Fast Nondominated Sorting Approach), apresentado no Algoritmo 7.1. 


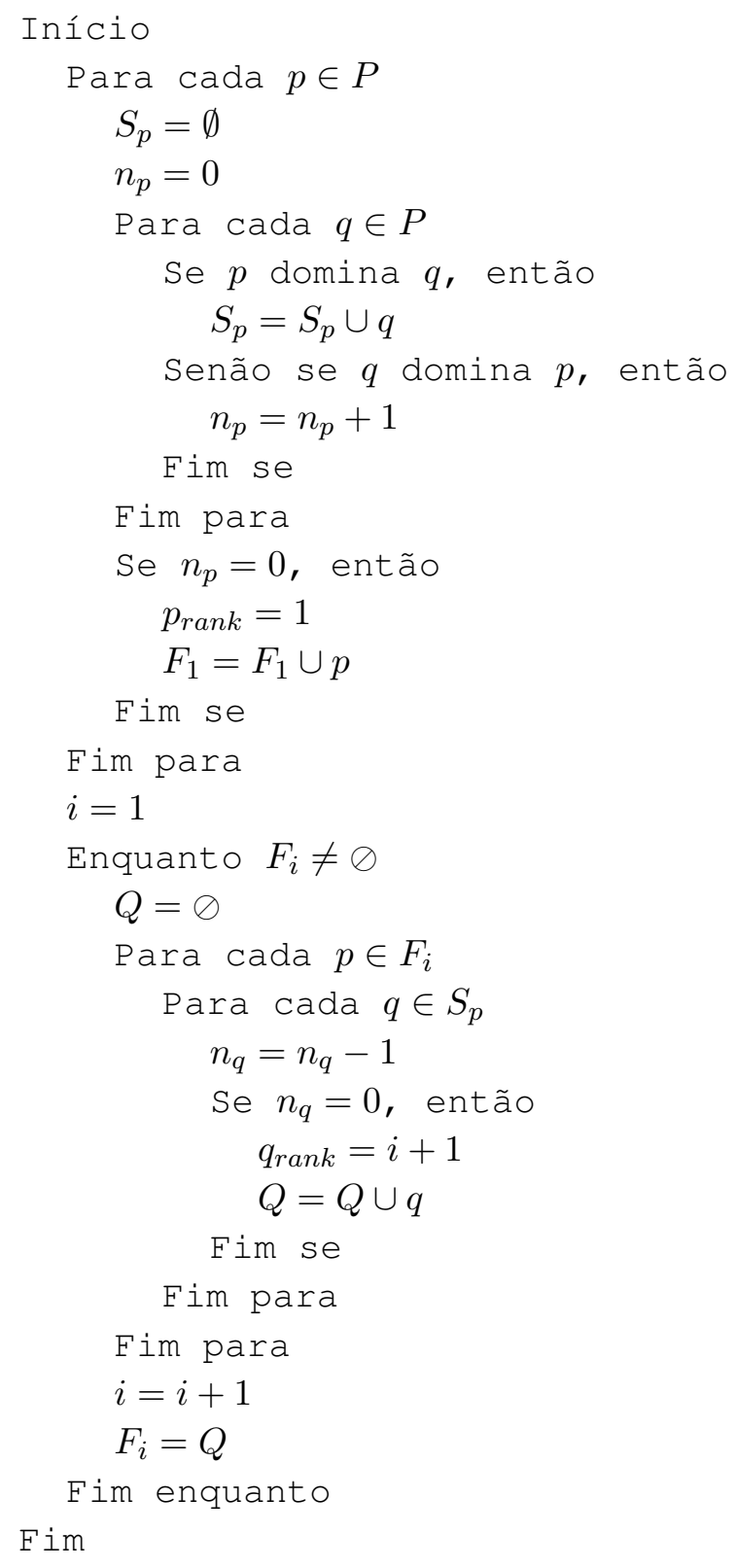

Algoritmo 7.1: Pseudo-código para o algoritmo rápido de ordenação por dominância no algoritmo $N S G A-I I$

O algoritmo de ordenação por dominância (Algoritmo 7.1) calcula para cada solução: um contador de dominância $n_{p}$, que é o número de soluções que dominam a solução em questão, e $S_{p}$, conjunto de soluções que a solução domina. No início, localiza-se as soluções da primeira fronteira, as quais terão $n_{p}=0$, ou seja, são as soluções não dominadas por nenhuma outra. Em seguida, para cada solução $p$ com $n_{p}=0$, visita-se as soluções $q$ do seu conjunto $S_{p}$ e essas soluções tem seu contador de dominância $n_{p}$ decrementado de 1 . Quando o contador de dominância de uma solução $q$ se torna zero ela é adicionada a uma lista $Q$. Essas soluções pertencem à segunda fronteira de dominância. O procedimento continua até que todas as fronteiras de dominância sejam identificadas. 
No NSGA-II, inicialmente uma população $P_{0}$ de tamanho $N$ é criada e ordenada por dominância. Cada indivíduo é associado a um valor de fitness que, nesse caso, refere-se a fronteira a qual pertence. Assim, os indivíduos da primeira fronteira são melhores que os da segunda e assim sucessivamente. Os operadores de reprodução e seleção são aplicados gerando uma população $Q_{t}$, também de tamanho $N$. As populações $P_{t}$ e $Q_{t}$ são unidas e o procedimento de ordenação por dominância é aplicado novamente. A partir dessa população de tamanho $2 N$, a população $P_{t+1}$ (de tamanho $N$ ) é montada, adicionando as fronteiras iniciais. Contudo, nem sempre será possível que o número de fronteiras adicionadas some o valor exato $N$. Muitas vezes a última camada a ser adicionada irá exceder esse número. Neste caso, o NSGA-II utiliza um método chamado de distância de multidão para escolher os indivíduos mais diversos dentro de uma fronteira. $\mathrm{O}$ algoritmo que calcula a distância de multidão é mostrado no Algoritmo 7.2.

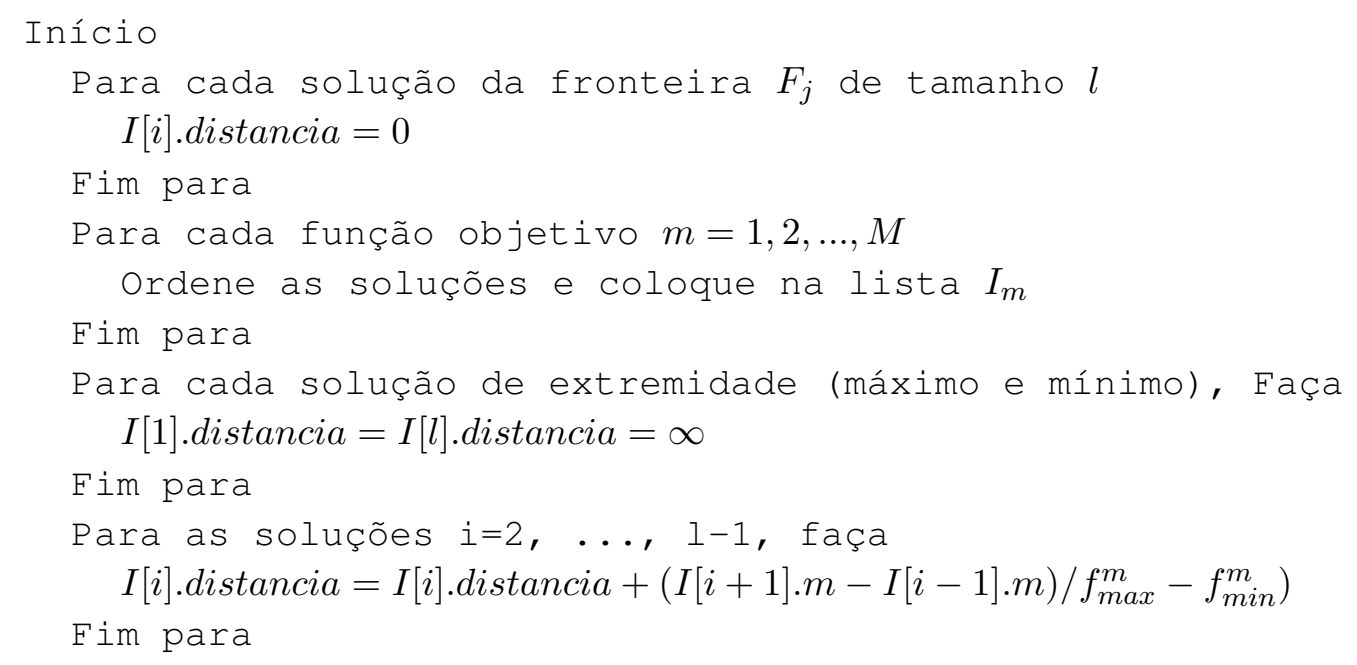

Algoritmo 7.2: Pseudo-código para o algoritmo que calcula a distância de multidão no NSGA-II.

A distância de multidão ordena a população de acordo com cada um dos seus objetivos. Em seguida, para cada objetivo, as soluções de borda (maiores e menores) são associadas a uma distância infinita. Todos os valores intermediários são associados a um valor de distância que é igual a diferença absoluta normalizada dos valores da função das duas soluções vizinhas. $I[i] . m$ refere-se ao $m$-ésimo objetivo do $i$-ésimo indivíduo e $f_{\max }^{m}$ e $f_{\min }^{m}$ são os valores de máximo e mínimo do $m$-ésimo objetivo. Depois de associar cada solução a um valor de distância, torna-se possível comparar duas soluções de acordo com sua proximidade com as demais.

Quando a última fronteira é ordenada, segundo o valor da distância de multidão, os indivíduos com maior distância, ou seja, os mais diversos, são adicionados em $P_{t+1}$ até completar o tamanho $N$ da população.

A seguir os resultados com a abordagem multiobjetivo são apresentados. Inicialmente os objetivos foram combinados dois a dois, utilizando sempre a polaridade e outro medida 
Tabela 7.1: Resultados de avaliação para os objetivos ( $M_{s t}$ considerando polaridade e hidropatia), pdm e melhora para as soluções não dominadas obtidas pelo NSGA-II.

\begin{tabular}{c|c|c|c}
\hline \hline & objetivo 1 & objetivo 2 & \\
\hline solução & $M_{s t}$ polaridade & $M_{s t}$ hidropatia & dominância \\
\hline \hline 1 & 3,78 & 2,29 & Não \\
\hline 2 & 2,44 & 2,59 & Sim \\
\hline 3 & 2,53 & 2,44 & Sim \\
\hline 4 & 1,73 & 3,43 & Sim \\
\hline 5 & 1,64 & 4,23 & Sim \\
\hline 6 & 1,64 & 4,19 & Sim \\
\hline 7 & 1,74 & 3,57 & Sim \\
\hline 8 & 1,59 & 4,62 & Não \\
\hline 9 & 1,65 & 4,18 & Sim \\
\hline 10 & 1,57 & 4,68 & Não \\
\hline 11 & 1,65 & 4,07 & Sim \\
\hline 12 & 1,56 & 4,72 & Não \\
\hline 13 & 1,75 & 3,27 & Sim \\
\hline 14 & 2,14 & 2,73 & Sim \\
\hline \hline
\end{tabular}

(hidropatia ou volume molecular). Em seguida, combinou-se os três objetivos.

\subsubsection{Abordagem de Pareto utilizando dois objetivos: Polaridade e Hidropatia}

A Tabela 7.1 mostra os valores de avaliação para os códigos não dominados considerando a polaridade e hidropatia. Os códigos não dominados são obtidos a partir das populações finais das 30 execuções do AG.

De acordo com a Tabela 7.1 podemos observar que quatro soluções são dominadas pelo código padrão. Nesse caso, essas soluções possuem um dos objetivos pior avaliado do que o obtido para o CGP. A Figura 7.1 ajuda a ilustrar isso. Se traçarmos uma linha perpendicular ao eixo $x$ e passando pelo CGP, podemos observar que os valores à direita da linha serão os códigos com $M_{s t}$ para a polaridade mais alto do que o CGP; pode-se observar um código nessas condições. Da mesma forma, traçando uma linha pelo ponto CGP perpendicular ao eixo $y$, observa-se que acima da linha encontram-se 3 pontos (códigos); são aqueles cujo segundo objetivo ( $M_{s t}$ para a hidropatia) é mais alto do que para o CGP. 
Tabela 7.2: Resultados de avaliação para os dois objetivos considerados, pdm, melhora (para a polaridade), número de coincidências e entropia para os melhores códigos obtidos pelo AG com Pareto para Polaridade e Hidropatia (para 30 sementes aleatórias).

\begin{tabular}{c|c|c}
\hline \hline & média \pm desvio & melhor \\
\hline \hline$M_{s t}(\mathrm{P})$ & $1,96 \pm 0,61$ & 1,57 \\
\hline$M_{s t}(\mathrm{H})$ & $3,65 \pm 0,86$ & 2,29 \\
\hline$M_{s t}(\mathrm{VM})$ & $2755,20 \pm 704,21$ & 2008,49 \\
\hline$p d m$ & $91,92 \pm 3,22 \%$ & $98,98 \%$ \\
\hline melhora & $25,32 \pm 23,35 \%$ & $3,70 \%$ \\
\hline coincidências & $3,86 \pm 2,07(\%)$ & $9(\%)$ \\
\hline entropia & $2,64 \pm 0,03$ & 2,71 \\
\hline \hline
\end{tabular}

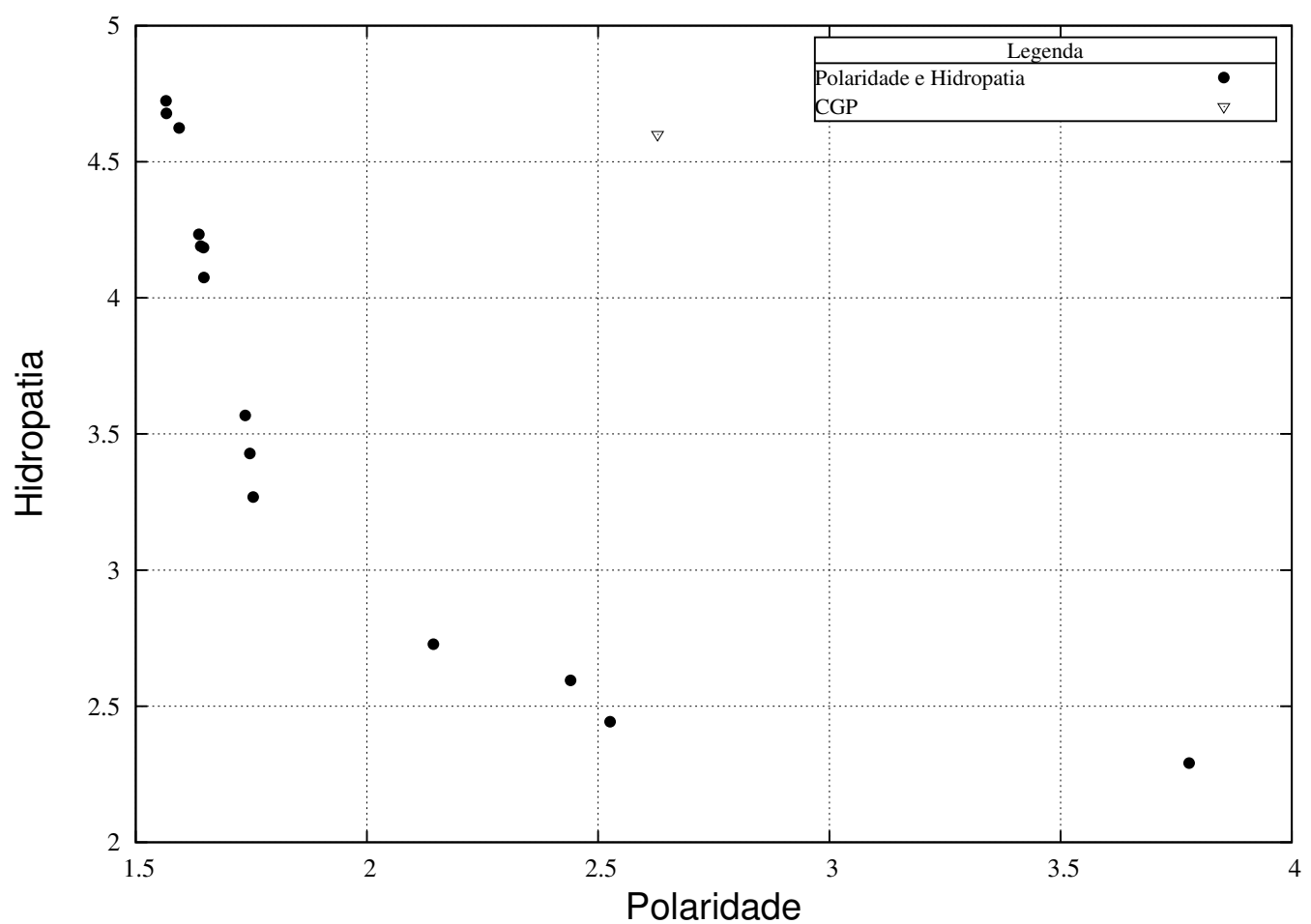

Figura 7.1: Fronteira de Pareto para o experimento utilizando polaridade e hidropatia.

A Tabela 7.1 mostra os valores de avaliação, $p d m$, melhora, número de coincidências e entropia para os códigos não dominados. Os valores de $p d m$ e melhora obtidos superam os reportados na literatura para as abordagens monoobjetivo Santos e Monteagudo (2010). Observa-se também o valor do volume molecular, que não foi otimizado e portanto é alto quando comparado ao CGP. Os valores de entropia estão próximos ao obtido para o CGP $(1,22)$. O histograma de frequências da Figura 7.2 evidencia esse resultado; observa-se que as frequências de códons associadas a aminoácidos são mais uniformes, como ocorre no CGP.

A Tabela 7.3 apresenta os melhores códigos obtidos nos experimentos com a abordagem de Pareto considerando polaridade e hidropatia. 
Tabela 7.3: Código genético padrão e melhores códigos hipotéticos obtidos pelo AG multiobjetivo com dois objetivos: polaridade e hidropatia.

\begin{tabular}{|c|c|c|c|}
\hline codon & CGP & Menor Avaliação & Melhor $p d m$ \\
\hline$\overline{\text { UUU }}$ & $\bar{F}$ & $\overline{\mathrm{M}}$ & $\overline{\mathrm{T}}$ \\
\hline UUC & $\mathrm{F}$ & $\mathrm{Y}$ & $\mathrm{G}$ \\
\hline UUA & $\mathrm{L}$ & I & G \\
\hline$\overline{\text { UUG }}$ & $\mathrm{L}$ & $\overline{\mathrm{W}}$ & $\mathrm{T}$ \\
\hline $\mathrm{UCU}$ & $\mathrm{S}$ & $\mathrm{Y}$ & $\mathrm{F}$ \\
\hline UCC & $\mathrm{S}$ & $\mathrm{W}$ & $\mathrm{L}$ \\
\hline UCA & $\mathrm{S}$ & $\mathrm{M}$ & $\mathrm{F}$ \\
\hline UCG & $\mathrm{S}$ & $Y$ & $\mathrm{C}$ \\
\hline UAU & $\mathrm{Y}$ & $\mathrm{S}$ & $\mathrm{Q}$ \\
\hline UAC & $\mathrm{Y}$ & A & $\mathrm{N}$ \\
\hline UGU & $\mathrm{C}$ & $\mathrm{E}$ & W \\
\hline UGC & $\mathrm{C}$ & $\mathrm{K}$ & $\mathrm{W}$ \\
\hline UGG & $\overline{\mathrm{W}}$ & $\mathrm{D}$ & $\mathrm{W}$ \\
\hline CUU & $\mathrm{L}$ & I & G \\
\hline CUC & $\mathrm{L}$ & $\mathrm{M}$ & $\mathrm{S}$ \\
\hline CUA & $\mathrm{L}$ & $\mathrm{I}$ & G \\
\hline CUG & $\mathrm{L}$ & $\mathrm{V}$ & $\mathrm{S}$ \\
\hline $\mathrm{CCU}$ & $\mathrm{P}$ & $\mathrm{M}$ & M \\
\hline $\mathrm{CCC}$ & $\mathrm{P}$ & $\mathrm{M}$ & $\mathrm{L}$ \\
\hline $\mathrm{CCA}$ & $\mathrm{P}$ & $\mathrm{M}$ & $\mathrm{F}$ \\
\hline CCG & $\mathrm{P}$ & $\mathrm{P}$ & $\bar{M}$ \\
\hline CAU & $\mathrm{H}$ & G & $\mathrm{E}$ \\
\hline CAC & $\mathrm{H}$ & $\mathrm{A}$ & $\mathrm{E}$ \\
\hline CAA & $\mathrm{Q}$ & $\mathrm{Y}$ & $\mathrm{D}$ \\
\hline CAG & $\mathrm{Q}$ & $\mathrm{S}$ & $\mathrm{K}$ \\
\hline CGU & $\mathrm{R}$ & $\mathrm{H}$ & $\mathrm{S}$ \\
\hline CGC & $\mathrm{R}$ & $\mathrm{R}$ & $\mathrm{P}$ \\
\hline CGA & $\mathrm{R}$ & $\mathrm{N}$ & $\mathrm{H}$ \\
\hline CGG & $\mathrm{R}$ & $\mathrm{K}$ & $\mathrm{H}$ \\
\hline AUU & I & I & A \\
\hline AUC & I & $\mathrm{F}$ & A \\
\hline AUA & I & $\mathrm{L}$ & $\mathrm{A}$ \\
\hline AUG & $\bar{M}$ & $\mathrm{~F}$ & $\mathrm{G}$ \\
\hline $\mathrm{ACU}$ & $\mathrm{T}$ & $\mathrm{M}$ & $\mathrm{L}$ \\
\hline $\mathrm{ACC}$ & $\mathrm{T}$ & $\mathrm{F}$ & $\mathrm{C}$ \\
\hline $\mathrm{ACA}$ & $\mathrm{T}$ & $\mathrm{C}$ & $\mathrm{L}$ \\
\hline $\mathrm{ACG}$ & $\mathrm{T}$ & $\mathrm{M}$ & $\mathrm{C}$ \\
\hline AAU & $\mathrm{N}$ & $\mathrm{T}$ & $\mathrm{N}$ \\
\hline AAC & $\mathrm{N}$ & A & $\mathrm{H}$ \\
\hline AAA & $\mathrm{K}$ & $\mathrm{W}$ & $\mathrm{Q}$ \\
\hline AAG & $\bar{K}$ & $\mathrm{~T}$ & $\mathrm{Q}$ \\
\hline AGU & $\mathrm{S}$ & $\mathrm{R}$ & $\mathrm{Y}$ \\
\hline AGC & $\mathrm{S}$ & $\mathrm{Q}$ & $\mathrm{P}$ \\
\hline AGA & $\mathrm{R}$ & $\mathrm{Q}$ & $\mathrm{T}$ \\
\hline AGG & $\mathrm{R}$ & $\mathrm{R}$ & $\mathrm{P}$ \\
\hline GUU & $\mathrm{V}$ & $\mathrm{L}$ & $\mathrm{W}$ \\
\hline GUC & $\mathrm{V}$ & I & $\mathrm{M}$ \\
\hline GUA & $\mathrm{V}$ & $\mathrm{C}$ & A \\
\hline GUG & $\mathrm{V}$ & $\mathrm{V}$ & $\overline{\mathrm{W}}$ \\
\hline GCU & $\mathrm{A}$ & $\mathrm{C}$ & $\mathrm{V}$ \\
\hline GCC & A & $\mathrm{C}$ & I \\
\hline GCA & $\mathrm{A}$ & $\mathrm{C}$ & $\mathrm{V}$ \\
\hline GCG & $\mathrm{A}$ & $\mathrm{I}$ & $\mathrm{L}$ \\
\hline GAU & $\mathrm{D}$ & $\mathrm{S}$ & $\mathrm{K}$ \\
\hline GAC & $\mathrm{D}$ & $\mathrm{P}$ & $\mathrm{R}$ \\
\hline GAA & $\mathrm{E}$ & $\mathrm{P}$ & $\mathrm{K}$ \\
\hline GAG & $\mathrm{E}$ & $\mathrm{S}$ & $\mathrm{R}$ \\
\hline GGU & G & $\mathrm{Q}$ & $\mathrm{Y}$ \\
\hline GGC & G & $\mathrm{H}$ & $\mathrm{T}$ \\
\hline GGA & G & $\mathrm{H}$ & $\mathrm{S}$ \\
\hline GGG & G & $\mathrm{H}$ & $\mathrm{S}$ \\
\hline
\end{tabular}




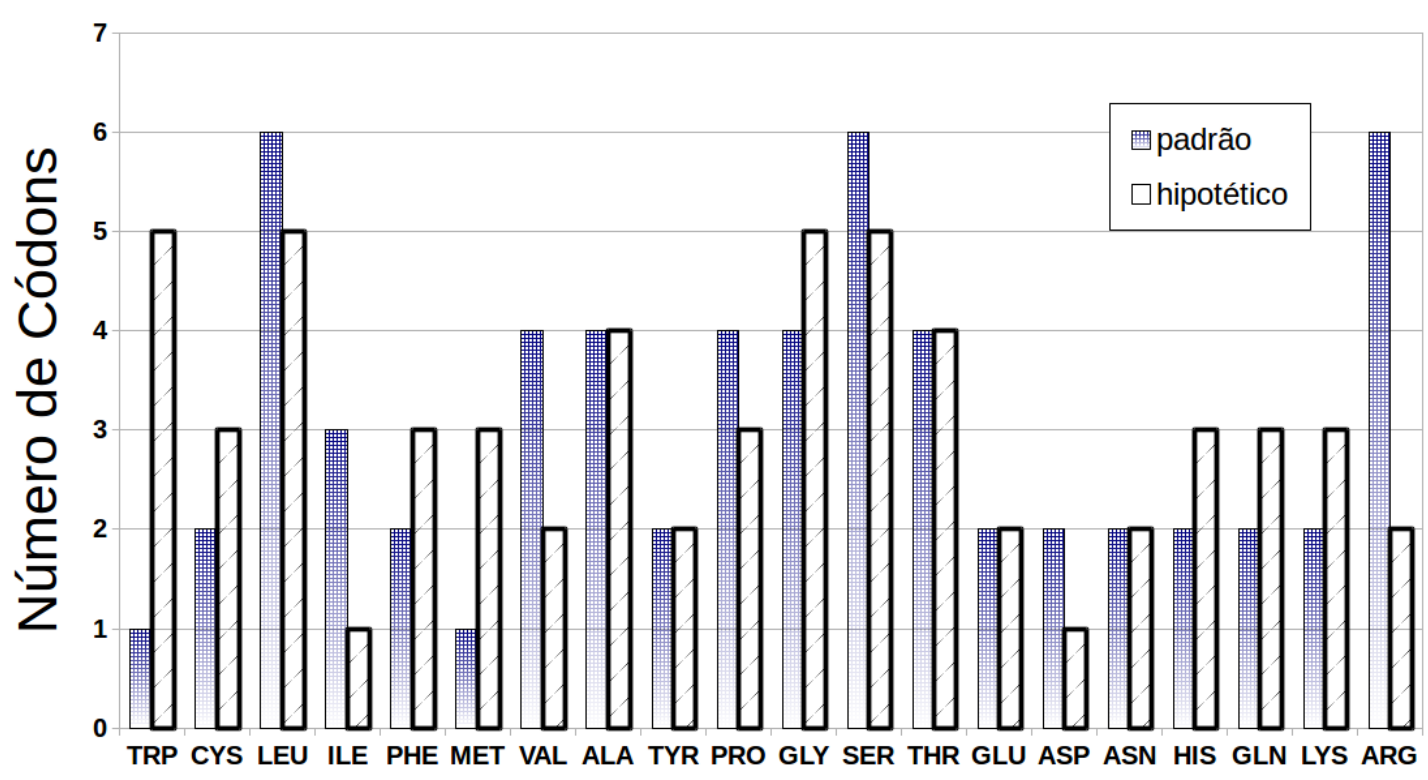

Aminoácidos

Figura 7.2: Frequência de códons associados a cada aminoácido para o código hipotético de maior pdm e para o código genético padrão,utilizando a abordagem de Pareto com dois objetivos: polaridade e hidropatia.

Tabela 7.4: Resultados de avaliação para os objetivos ( $M_{\text {st }}$ considerando polaridade e hidropatia), pdm e melhora para as soluções não dominadas obtidas pelo NSGA-II (em 30 execuções do AG).

\begin{tabular}{c|c|c|c|}
\hline solução & $\begin{array}{c}\text { objetivo 1 } \\
M_{s t} \text { polaridade }\end{array}$ & $\begin{array}{c}\text { objetivo 2 } \\
M_{s t} \text { volume molecular }\end{array}$ & dominância \\
\hline \hline 1 & 6,3824 & 1123,55 & Não \\
\hline 2 & 6,51695 & 1103,1 & Não \\
\hline 3 & 7,61847 & 1027,73 & Não \\
\hline \hline
\end{tabular}

\subsubsection{Abordagem de Pareto utilizando dois objetivos: Polaridade e Volume Molecular}

A seguir, os resultados apresentados são do experimento com abordagem de Pareto, considerando dois objetivos: $M_{s t}$ para a polaridade e $M_{s t}$ para o volume molecular.

A Tabela 7.4 mostra os valores de avaliação para as solução de Pareto. Observa-se que todas são dominadas pelo CGP. A Figura 7.5 evidencia esse resultado; as soluções hipotéticas obtidas encontram-se à direita do CGP. 
Tabela 7.5: Resultados de avaliação para os dois objetivos considerados, pdm, melhora (para a polaridade) and número de coincidências para os melhores códigos obtidos pela abordagem de Pareto com dois objetivos: Polaridade e o Volume Molecular.

\begin{tabular}{lll}
\hline \hline & média \pm desvio & melhor \\
\hline \hline$M_{s t}(\mathrm{P})$ & $6,84 \pm 0,68$ & 6,38 \\
\hline$M_{s t}(\mathrm{H})$ & $14,73 \pm 1,67$ & 13,69 \\
\hline$M_{s t}(\mathrm{VM})$ & $1084,79 \pm 50,47$ & 1027,73 \\
\hline$p d m$ & $55,32 \pm 7,19 \%$ & $60,16 \%$ \\
\hline melhora & $-160,76 \pm 25,85 \%$ & $-143,34 \%$ \\
\hline coincidências & $3,33 \pm 0,58(\%)$ & $4(\%)$ \\
\hline entropia & $2,89 \pm 0,03$ & 2,91 \\
\hline \hline
\end{tabular}

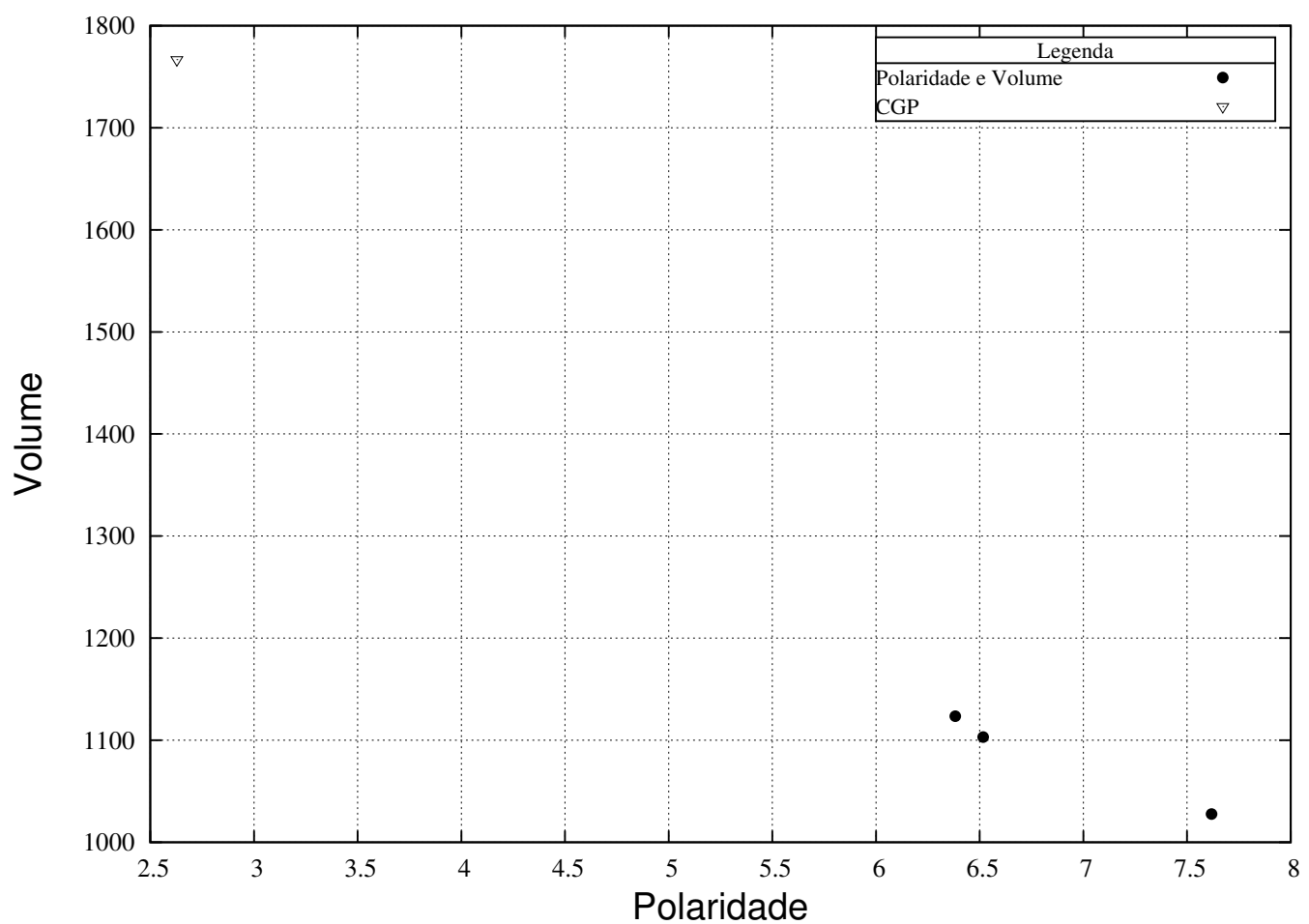

Figura 7.3: Fronteira de pareto para o experimento utilizando polaridade e volume.

A Tabela 7.5 mostra os valores de avaliação, $p d m$, melhora, número de coincidências e entropia. Neste caso, os valores de $M_{s t}$ para a polaridade foram altos, quando comparados ao CGP $(2,63)$. Os valores médios de $M_{s t}$ para o volume foi mais baixos que no CGP. A entropia das soluções foi alta e mais próxima do CGP à Figura 7.4 evidencia a uniformidade da solução de maior $p d m$.

A Tabela 7.6 apresenta o código de maior $p d m$ que coincidentemente também é o de menor valor de avaliação. 
Tabela 7.6: Código genético padrão e melhores códigos hipotéticos obtidos pelo AG multiobjetivo na abordagem de Pareto com dois objetivos: polaridade e volume molecular.

\begin{tabular}{|c|c|c|}
\hline codon & CGP & Menor Avaliação e Melhor $p d m$ \\
\hline$\overline{\mathrm{UUU}}$ & $\overline{\mathrm{F}}$ & $\overline{\mathrm{F}}$ \\
\hline$\overline{\text { UUC }}$ & $\mathrm{F}$ & $\mathrm{L}$ \\
\hline UUA & $\overline{\mathrm{L}}$ & $\overline{\mathrm{W}}$ \\
\hline UUG & $\mathrm{L}$ & $\mathrm{M}$ \\
\hline $\mathrm{UCU}$ & $\mathrm{S}$ & V \\
\hline$\overline{\mathrm{UCC}}$ & $\bar{S}$ & $\overline{\mathrm{H}}$ \\
\hline UCA & $\mathrm{S}$ & $\mathrm{V}$ \\
\hline UCG & $\mathrm{S}$ & $\mathrm{V}$ \\
\hline UAU & $\mathrm{Y}$ & $\mathrm{K}$ \\
\hline UAC & $\bar{Y}$ & $\mathrm{~S}$ \\
\hline$\overline{\mathrm{UGU}}$ & $\bar{C}$ & $\bar{S}$ \\
\hline UGC & C & $\mathrm{E}$ \\
\hline UGG & $\mathrm{W}$ & $\mathrm{N}$ \\
\hline CUU & $\mathrm{L}$ & $\mathrm{Y}$ \\
\hline$\overline{\text { CUC }}$ & $\overline{\mathrm{L}}$ & $\overline{\mathrm{L}}$ \\
\hline CUA & $\mathrm{L}$ & W \\
\hline CUG & $\mathrm{L}$ & $\mathrm{R}$ \\
\hline$\overline{\mathrm{CCU}}$ & $\overline{\mathrm{P}}$ & $\overline{\mathrm{F}}$ \\
\hline $\mathrm{CCC}$ & $\mathrm{P}$ & $\mathrm{Q}$ \\
\hline CCA & $\mathrm{P}$ & $\mathrm{Q}$ \\
\hline CCG & $\mathrm{P}$ & $\mathrm{Q}$ \\
\hline CAU & $\mathrm{H}$ & $\mathrm{A}$ \\
\hline CAC & $\overline{\mathrm{H}}$ & $\mathrm{A}$ \\
\hline CAA & $\mathrm{Q}$ & $\mathrm{P}$ \\
\hline CAG & $\mathrm{Q}$ & $\mathrm{S}$ \\
\hline CGU & $\bar{R}$ & $\mathrm{~A}$ \\
\hline CGC & $\mathrm{R}$ & $\mathrm{P}$ \\
\hline CGA & $\mathrm{R}$ & $\mathrm{E}$ \\
\hline CGG & $\mathrm{R}$ & $\mathrm{P}$ \\
\hline$\overline{\mathrm{AUU}}$ & $\mathrm{I}$ & $\mathrm{I}$ \\
\hline AUC & I & I \\
\hline AUA & I & $\mathrm{F}$ \\
\hline AUG & $\mathrm{M}$ & I \\
\hline$\overline{\mathrm{ACU}}$ & $\mathrm{T}$ & $\mathrm{C}$ \\
\hline$\overline{\mathrm{ACC}}$ & $\bar{T}$ & $\bar{V}$ \\
\hline ACA & $\mathrm{T}$ & $\mathrm{M}$ \\
\hline $\mathrm{ACG}$ & $\mathrm{T}$ & V \\
\hline$\overline{\mathrm{AAU}}$ & $\mathrm{N}$ & $\bar{D}$ \\
\hline AAC & $\mathrm{N}$ & $\mathrm{D}$ \\
\hline AAA & K & $\mathrm{T}$ \\
\hline AAG & $\mathrm{K}$ & $\mathrm{S}$ \\
\hline AGU & $\mathrm{S}$ & $\mathrm{A}$ \\
\hline AGC & $\bar{S}$ & $\mathrm{C}$ \\
\hline AGA & $\mathrm{R}$ & G \\
\hline AGG & $\mathrm{R}$ & G \\
\hline GUU & V & $\mathrm{L}$ \\
\hline GUC & $\mathrm{V}$ & $\mathrm{L}$ \\
\hline GUA & $\mathrm{V}$ & $\mathrm{W}$ \\
\hline GUG & V & $\mathrm{Y}$ \\
\hline GCU & $\mathrm{A}$ & $\mathrm{T}$ \\
\hline GCC & $\mathrm{A}$ & $\mathrm{Q}$ \\
\hline GCA & A & $\mathrm{V}$ \\
\hline GCG & A & $\mathrm{V}$ \\
\hline GAU & $\mathrm{D}$ & A \\
\hline GAC & $\bar{D}$ & $\mathrm{~N}$ \\
\hline GAA & $\mathrm{E}$ & $\mathrm{C}$ \\
\hline GAG & $\mathrm{E}$ & $\mathrm{S}$ \\
\hline GGU & G & A \\
\hline GGC & $\mathrm{G}$ & $\bar{T}$ \\
\hline GGA & G & $\mathrm{V}$ \\
\hline GGG & G & $\mathrm{P}$ \\
\hline
\end{tabular}




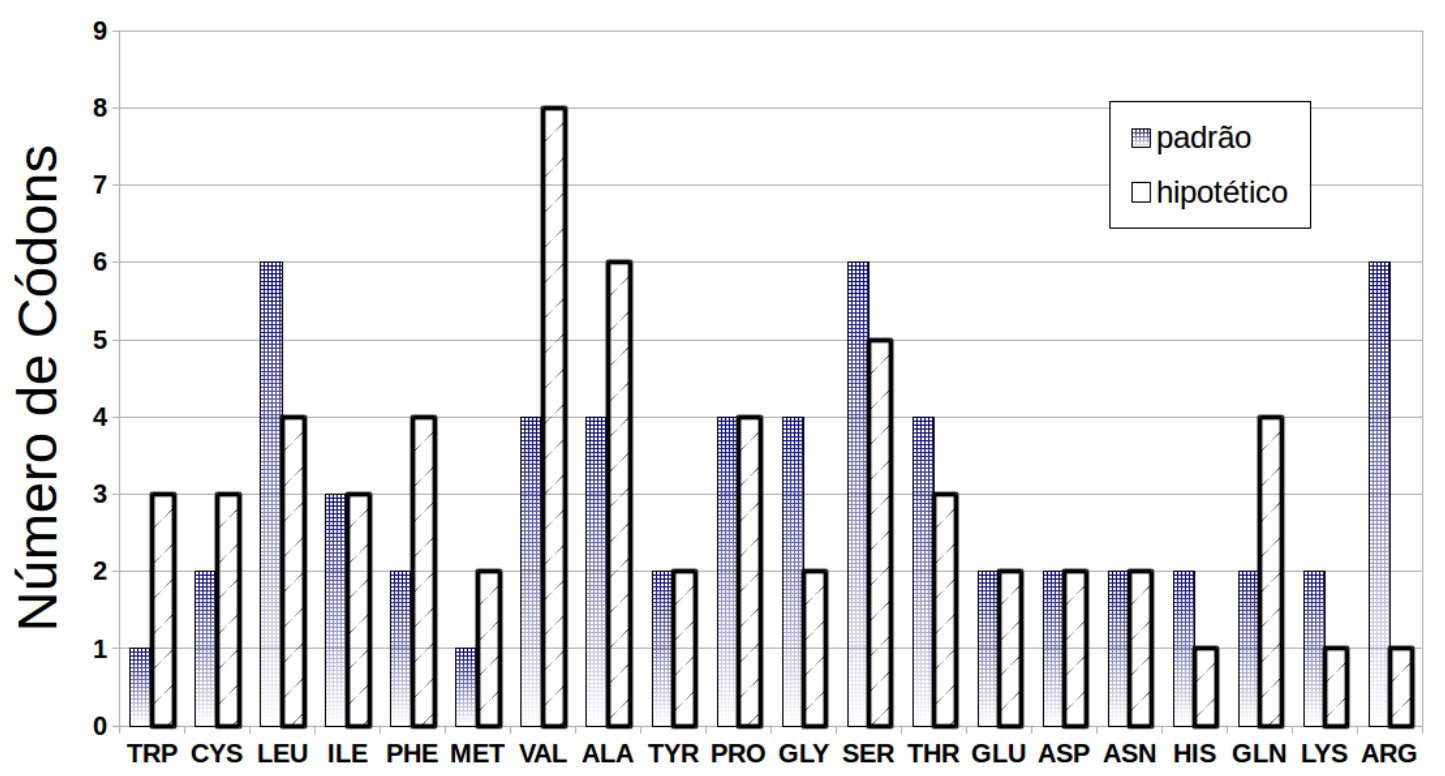

Aminoácidos

Figura 7.4: Frequência de códons associados a cada aminoácido para o código hipotético de maior pdm e para o código genético padrão para a abordagem de Pareto com dois objetivos: polaridade e volume molecular.

\subsubsection{Abordagem de Pareto utilizando três objetivos: Polaridade, Hidropatia e Volume Molecular}

Nesta seção, é empregado o algoritmo NSGA-II com as três propriedades. O problema do crescimento do número de propriedades é o aumento da complexidade do algoritmo e da dificuldade de avaliação da fronteira de Pareto, que agora possui 3 dimensões. A Tabela 7.7 mostra os valores dos três objetivos que agora foram otimizados simultaneamente. Observa-se que nenhum deles domina o código genético padrão, cujos valores de $M_{s t}$ para a polaridade, hidropatia e volume molecular são, respectivamente: 2,63; 4,6; 1766,78. Dessa forma, em todas as soluções obtidas, ao menos um objetivo é pior que o CGP. A Figura 7.3 mostra a localização espacial dos códigos da fronteira de Pareto e neste caso, no espaço tridimensional torna-se mais difícil de verificar a proximidade com o CGP. 
Tabela 7.7: Resultados de avaliação para os objetivos ( $M_{\text {st }}$ considerando polaridade, hidropatia e volume molecular), pdm e melhora para as soluções não dominadas obtidas pelo NSGA-II (em 30 execuções do $A G)$.

\begin{tabular}{c|c|c|c|c}
\hline \hline solução & $\begin{array}{c}\text { objetivo 1 } \\
M_{s t} \text { polaridade }\end{array}$ & $\begin{array}{c}\text { objetivo 2 } \\
M_{s t} \text { hidropatia }\end{array}$ & $\begin{array}{c}\text { objetivo 3 } \\
\text { volume }\end{array}$ & dominância \\
\hline \hline 1 & 4,02 & 7,03 & 1495,98 & Não \\
\hline 2 & 6,59 & 7,26 & 1342,22 & Não \\
\hline 3 & 7,71 & 11,07 & 1097,21 & Não \\
\hline 4 & 7,68 & 11,27 & 1149,68 & Não \\
\hline 5 & 6,21 & 6,98 & 1352,49 & Não \\
\hline 6 & 3,37 & 5,80 & 1906,11 & Não \\
\hline 7 & 3,20 & 5,80 & 1932,55 & Não \\
\hline 8 & 3,44 & 5,72 & 1922,42 & Não \\
\hline 9 & 3,21 & 6,20 & 1923,99 & Não \\
\hline \hline
\end{tabular}

\begin{tabular}{|lc|}
\hline \multicolumn{2}{|c|}{ Legenda } \\
\hline Polaridade, Hidropatia Volume & $\bullet$ \\
CGP & $\nabla$ \\
\hline
\end{tabular}

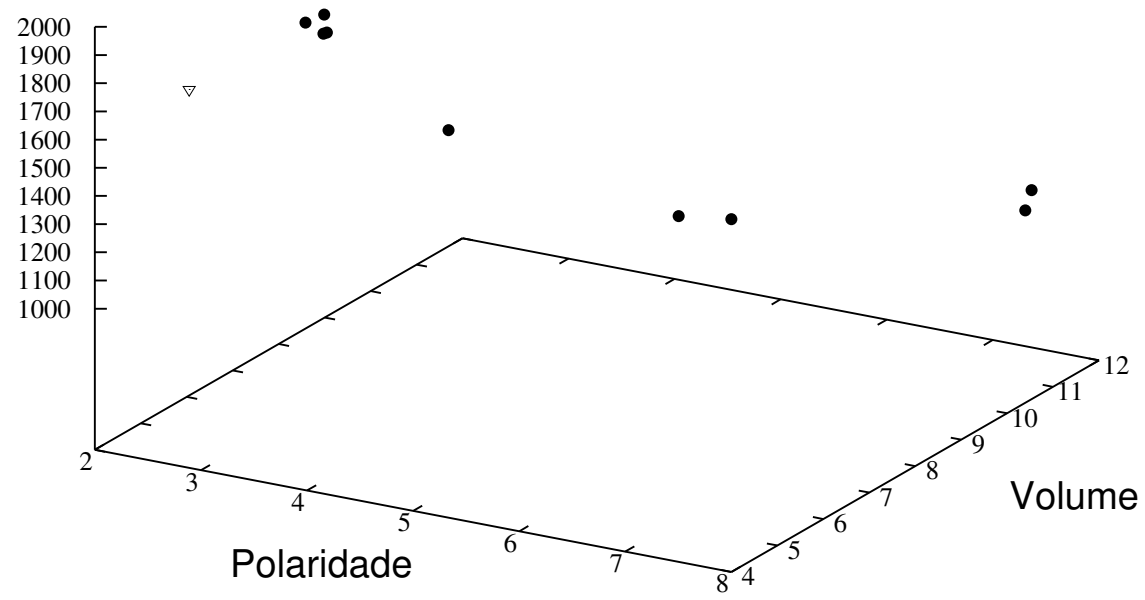

Figura 7.5: Fronteira de Pareto para o experimento utilizando polaridade e volume.

A Tabela 7.8 mostra os resultados médios obtidos para o experimento. No caso do $M_{s t}$ para a experimento com três objetivos, os valores são altos se comparados ao código padrão, apenas o $M_{s t}$ volume molecular médio é mais baixo que o $M_{s t}$ do código padrão. Por essa razão a melhora média é negativa, indicando que a maioria dos códigos não possui avaliação melhor que a do CGP. A entropia dos códigos é alta e em termos de uniformidade os códigos hipotéticos se aproximam do CGP e a Figura 7.6 evidencia essa similaridade de frequências.

O código de melhor $p d m$ que também é o código de menor $M_{s t}$ é apresentado na Tabela 7.9 . 
Tabela 7.8: Resultados de avaliação para os três objetivos considerados, pdm, melhora (para a polaridade), número de coincidências e entropia para os melhores códigos obtidos pelo AG com Pareto considerando polaridade, hidropatia e volume molecular.

\begin{tabular}{lll}
\hline \hline & média \pm desvio & melhor \\
\hline \hline$M_{s t}(\mathrm{P})$ & $5,05 \pm 1,97$ & 3,20 \\
\hline$M_{s t}(\mathrm{H})$ & $7,46 \pm 2,18$ & 5,72 \\
\hline$M_{s t}(\mathrm{VM})$ & $1569,18 \pm 353,34$ & 1097,21 \\
\hline$p d m$ & $74,29 \pm 20,84 \%$ & $93,85 \%$ \\
\hline melhora & $-92,49 \pm 74,98 \%$ & $-22,14 \%$ \\
\hline coincidências & $3,71 \pm 2,36(\%)$ & $6(\%)$ \\
\hline entropia & $2,89 \pm 0,01$ & 2,92 \\
\hline \hline
\end{tabular}

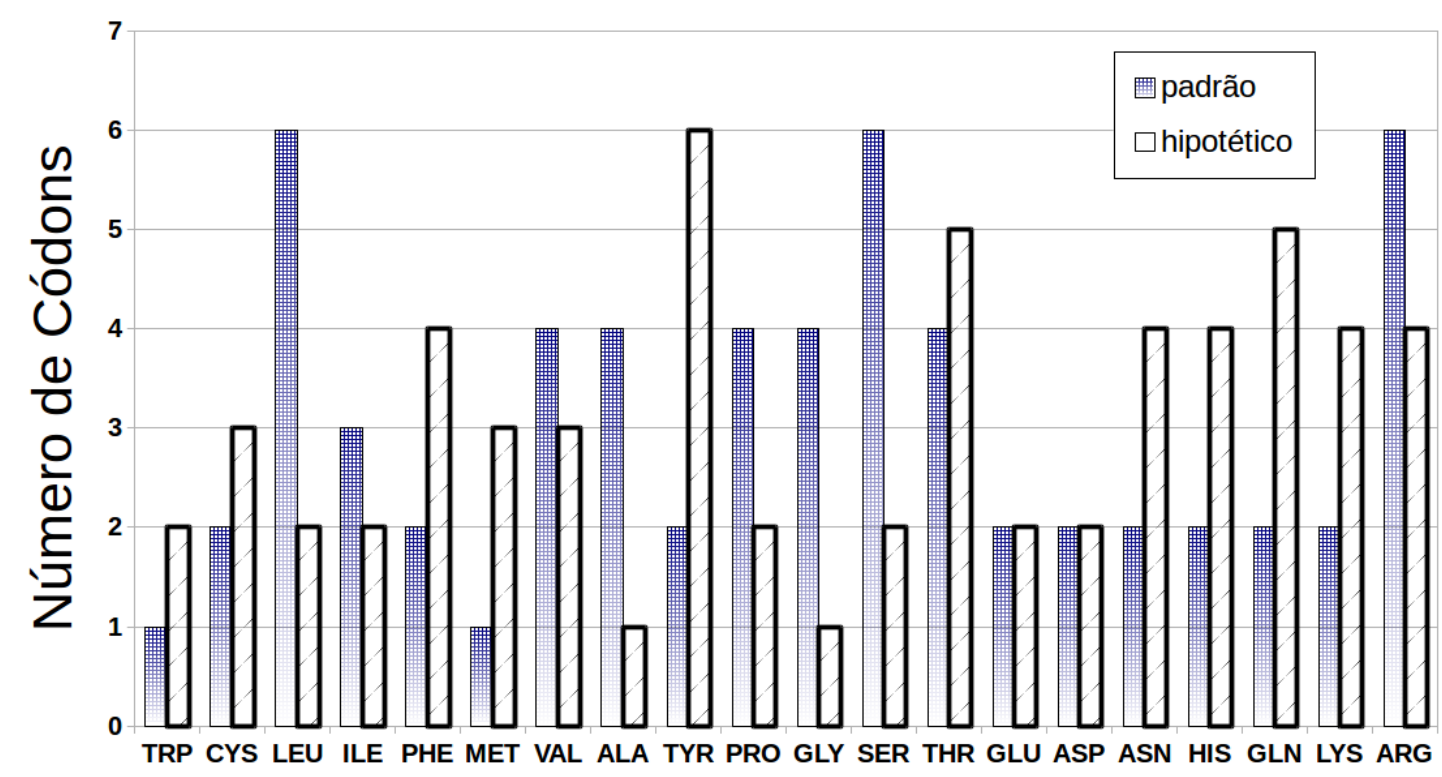

Aminoácidos

Figura 7.6: Frequência de códons associados a cada aminoácido para o código hipotético de maior pdm e para o código genético padrão, considerando a abordagem de Pareto com 3 objetivos (polaridade, hidropatia e volume molecular). 
Tabela 7.9: Código genético padrão e melhores códigos hipotéticos obtidos pelo AG multiobjetivo na abordagem de Pareto com três objetivos: polaridade, hidropatia e volume molecular.

\begin{tabular}{|c|c|c|}
\hline codon & CGP & Menor Avaliação e Melhor $p d m$ \\
\hline$\overline{\overline{\text { UUU }}}$ & $\overline{\bar{F}}$ & 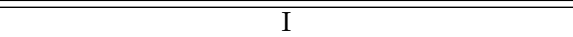 \\
\hline UUC & $\mathrm{F}$ & $\mathrm{F}$ \\
\hline UUA & $\mathrm{L}$ & I \\
\hline$\overline{\text { UUG }}$ & $\bar{L}$ & $\mathrm{~L}$ \\
\hline$\overline{\mathrm{UCU}}$ & $\mathrm{S}$ & $\mathrm{V}$ \\
\hline UCC & $\mathrm{S}$ & Y \\
\hline $\mathrm{UCA}$ & $\mathrm{S}$ & $\mathrm{L}$ \\
\hline UCG & $\mathrm{S}$ & $\mathrm{V}$ \\
\hline UAU & $\bar{Y}$ & $\mathrm{Q}$ \\
\hline UAC & $\mathrm{Y}$ & $\mathrm{H}$ \\
\hline UGU & $\mathrm{C}$ & $\mathrm{H}$ \\
\hline UGC & $\mathrm{C}$ & $\mathrm{D}$ \\
\hline UGG & $\mathrm{W}$ & $\mathrm{K}$ \\
\hline CUU & $\mathrm{L}$ & $\mathrm{W}$ \\
\hline CUC & $\mathrm{L}$ & $\mathrm{F}$ \\
\hline CUA & $\mathrm{L}$ & $\mathrm{F}$ \\
\hline CUG & $\bar{L}$ & $\mathrm{M}$ \\
\hline $\mathrm{CCU}$ & $\mathrm{P}$ & $\mathrm{S}$ \\
\hline $\mathrm{CCC}$ & $\mathrm{P}$ & $\mathrm{T}$ \\
\hline $\mathrm{CCA}$ & $\mathrm{P}$ & $\mathrm{S}$ \\
\hline $\mathrm{CCG}$ & $\mathrm{P}$ & $\mathrm{T}$ \\
\hline CAU & $\mathrm{H}$ & $\mathrm{Q}$ \\
\hline CAC & $\mathrm{H}$ & $\mathrm{N}$ \\
\hline CAA & $\bar{Q}$ & G \\
\hline CAG & $\mathrm{Q}$ & $\mathrm{N}$ \\
\hline CGU & $\mathrm{R}$ & $\mathrm{Q}$ \\
\hline $\mathrm{CGC}$ & $\mathrm{R}$ & $\mathrm{D}$ \\
\hline CGA & $\mathrm{R}$ & $\mathrm{T}$ \\
\hline CGG & $\mathrm{R}$ & $\mathrm{N}$ \\
\hline AUU & I & $\mathrm{F}$ \\
\hline AUC & I & C \\
\hline AUA & I & $\mathrm{Y}$ \\
\hline AUG & $\bar{M}$ & $\mathrm{C}$ \\
\hline $\mathrm{ACU}$ & $\mathrm{T}$ & A \\
\hline $\mathrm{ACC}$ & $\mathrm{T}$ & $\mathrm{T}$ \\
\hline ACA & $\mathrm{T}$ & $\mathrm{P}$ \\
\hline$\overline{\mathrm{ACG}}$ & $\bar{T}$ & $\mathrm{~T}$ \\
\hline AAU & $\mathrm{N}$ & $\mathrm{R}$ \\
\hline AAC & $\mathrm{N}$ & $\mathrm{N}$ \\
\hline AAA & $\mathrm{K}$ & $\mathrm{K}$ \\
\hline AAG & $\bar{K}$ & $\mathrm{H}$ \\
\hline AGU & $\mathrm{S}$ & $\mathrm{Q}$ \\
\hline AGC & $\mathrm{S}$ & $\mathrm{E}$ \\
\hline AGA & $\mathrm{R}$ & $\mathrm{K}$ \\
\hline AGG & $\mathrm{R}$ & $\mathrm{E}$ \\
\hline GUU & $\mathrm{V}$ & $\mathrm{Y}$ \\
\hline GUC & $\mathrm{V}$ & $\mathrm{M}$ \\
\hline GUA & $\mathrm{V}$ & W \\
\hline GUG & $\mathrm{V}$ & $\mathrm{Y}$ \\
\hline GCU & A & $\mathrm{M}$ \\
\hline GCC & $\mathrm{A}$ & $\mathrm{Y}$ \\
\hline GCA & A & $\mathrm{C}$ \\
\hline GCG & $\mathrm{A}$ & $\mathrm{V}$ \\
\hline GAU & $\mathrm{D}$ & $\mathrm{R}$ \\
\hline GAC & $\mathrm{D}$ & $\mathrm{R}$ \\
\hline GAA & $\mathrm{E}$ & $\mathrm{P}$ \\
\hline GAG & $\mathrm{E}$ & $\mathrm{Y}$ \\
\hline GGU & $\mathrm{G}$ & $\mathrm{R}$ \\
\hline GGC & $\mathrm{G}$ & $\mathrm{H}$ \\
\hline GGA & $\mathrm{G}$ & $\mathrm{Q}$ \\
\hline GGG & $\mathrm{G}$ & $\mathrm{K}$ \\
\hline
\end{tabular}




\section{CAPÍTULO 8}

\section{Discussão e Conclusões}

"First there is a mountain, then there is no mountain, then there is"

- Donavan

\subsection{Comparação das abordagens}

Os três tipos de abordagens multiobjetivo testados nesta pesquisa (lexicográfica, ponderada e Pareto) mostraram-se promissoras e superiores à abordagem monoobjetivo comumente empregada na literatura. Ressalta-se que, de acordo com o conhecimento da autora, esta é a primeira vez que a abordagem multiobjetivo é empregada para o estudo do código genético.

A Tabela 8.1 apresenta uma comparação entre o valores de avaliação de todas as abordagens $\left(M_{s t}\right)$, comparando-as com o valor de avaliação do código genético padrão.

De acordo com a Tabela 8.1, podemos observar que o menor valor de $M_{s t}$ para a polaridade foi obtido pela abordagem monoobjetivo, uma vez que nesse experimento somente essa propriedade foi considerada. Quando o AG monoobjetivo é empregado os valores dos dois outros objetivos (hidropatia e volume molecular) não são otimizados. Porém, em algumas situações as simulações multiobjetivo, possuem valores mais altos para os objetivos que consideram hidropatia e volume; isso ocorre, principalmente devido a influência da otimização da polaridade. Além disso, também é possível observar que mesmo não sendo otimizado 
Tabela 8.1: Comparação dos resultados de avaliação $\left(M_{s t}\right)$ para os três objetivos do CGC e de todas as abordagens testadas. O melhor valor de cada objetivo também é apresentado. Neste caso, ele não corresponde necessariamente a mesma solução.

\begin{tabular}{llll}
\hline \hline & & média \pm desvio & melhor \\
\hline \hline monoobjetivo & $M_{s t}(\mathrm{P})$ & $1,16 \pm 0,14$ & 0,92 \\
\hline monoobjetivo & $M_{s t}(\mathrm{H})$ & $5,35 \pm 1,14$ & 3,92 \\
\hline monoobjetivo & $M_{s t}(\mathrm{VM})$ & $1331,63 \pm 257,99$ & 989,50 \\
\hline \hline lexicográfico & $M_{s t}(\mathrm{P})$ & $1,86 \pm 0,25$ & 1,40 \\
\hline lexicográfico & $M_{s t}(\mathrm{H})$ & $3,71 \pm 0,72$ & 2,56 \\
\hline lexicográfico & $M_{s t}(\mathrm{VM})$ & $1590,46 \pm 339,79$ & 996,13 \\
\hline \hline ponderado(0,4/0,35/0,25) & $M_{s t}(\mathrm{P})$ & $1,80 \pm 0,30$ & 1,17 \\
\hline ponderado(0,4/0,35/0,25) & $M_{s t}(\mathrm{H})$ & $2,75 \pm 0,44$ & 1,86 \\
\hline ponderado(0,4/0,35/0,25) & $M_{s t}(\mathrm{MV})$ & $760,10 \pm 111,14$ & 527,67 \\
\hline \hline ponderado(0,6/0,3/0,1) & $M_{s t}(\mathrm{P})$ & $1,49 \pm 0,20$ & 1,14 \\
\hline ponderado(0,6/0,3/0,1) & $M_{s t}(\mathrm{H})$ & $2,20 \pm 0,39$ & 1,57 \\
\hline ponderado(0,6/0,3/0,1) & $M_{s t}(\mathrm{MV})$ & $972,09 \pm 163,03$ & 743,17 \\
\hline \hline ponderado(0,8/0,15/0,05) & $M_{s t}(\mathrm{P})$ & $1,40 \pm 0,25$ & 1,05 \\
\hline ponderado(0,8/0,15/0,05) & $M_{s t}(\mathrm{H})$ & $2,38 \pm 0,34$ & 1,79 \\
\hline ponderado(0,8/0,15/0,05) & $M_{s t}(\mathrm{MV})$ & $969,97 \pm 168,21$ & 691,97 \\
\hline \hline Pareto(P e H) & $M_{s t}(\mathrm{P})$ & $1,96 \pm 0,61$ & 1,57 \\
\hline Pareto(P e H) & $M_{s t}(\mathrm{H})$ & $3,65 \pm 0,86$ & 2,29 \\
\hline Pareto(P e H) & $M_{s t}(\mathrm{VM})$ & $2755,20 \pm 704,21$ & 2008,49 \\
\hline \hline Pareto(P e MV) & $M_{s t}(\mathrm{P})$ & $6,84 \pm 0,68$ & 6,38 \\
\hline Pareto(P e MV) & $M_{s t}(\mathrm{H})$ & $14,73 \pm 1,67$ & 13,69 \\
\hline Pareto(P e MV) & $M_{s t}(\mathrm{VM})$ & $1084,79 \pm 50,47$ & 1027,73 \\
\hline \hline Pareto(P, H e MV) & $M_{s t}(\mathrm{P})$ & $5,05 \pm 1,97$ & 3,20 \\
\hline Pareto(P, H e MV) & $M_{s t}(\mathrm{H})$ & $7,46 \pm 2,18$ & 5,72 \\
\hline Pareto(P, H e MV & $M_{s t}(\mathrm{VM})$ & $1569,18 \pm 353,34$ & 1027,73 \\
\hline \hline CGP & $M_{s t}(\mathrm{P})$ & & 2,63 \\
\hline CGP & $M_{s t}(\mathrm{H})$ & & 4,61 \\
\hline CGP & $M_{s t}(\mathrm{VM})$ & & 1766,77 \\
\hline \hline
\end{tabular}


o volume molecular médio das melhores soluções obtidas pelo AG monoobjetivo possuem valores mais robustos do que para CGP.

Considerando as abordagens multiobjetivo, observa-se que o menor valor médio de $M_{s t}$ para a polaridade foi obtido para a abordagem ponderada com pesos $w_{1}=0,8, w_{2}=0,15 \mathrm{e}$ $w_{3}=0,05$, que é a que concede maior peso para a polaridade. O problema dessa abordagem é que a escolha dos pesos é arbitrária.

Já com relação a abordagem de Pareto, nas três simulações consideradas, a que empregou apenas a polaridade e a hidropatia obteve valores melhores de $M_{s t}$ para a polaridade. No entanto, quando o volume foi considerado, a polaridade, em geral, se manteve alta. O melhor valor para o $M_{s t}$ considerando a hidropatia foi obtido no experimento com as três propriedades, enquanto que o melhor valor de $M_{s t}$ para o volume foi obtido no experimento que considerou a polaridade e o volume.

Comparando as abordagens com os valores do CGP, observa-se que com exceção do AG com abordagem de Pareto para a polaridade e hidropatia as duas demais abordagens (Pareto (P e MV) e Pareto (P, H e MV) ) obtiveram valores de $M_{s t}$ piores que o CGP.

A Tabela 8.2 mostra os valores de avaliação do código padrão e dos melhores códigos obtidos. No caso das abordagens monoobjetivo, lexicográfico e ponderado, apenas uma solução com menor valor de avaliação é retornada (para cada execução), mas no caso da abordagem por Pareto todos os indivíduos não dominados da fronteira são considerados. Observando os valores de cada objetivo, é possível verificar que as melhores soluções obtidas pelas abordagens Moonobjetivo, lexicográfico e ponderado dominam o código genético padrão e também dominam as soluções obtidas pela abordagem de Pareto. Já as soluções geradas pela abordagem de Pareto, não dominam o CGP, quando consideramos o volume molecular. No Capítulo 7, as soluções obtidas pela abordagem de Pareto com polaridade e hidropatia dominam o CGP quando o volume (o qual não é otimizado nesse experimento) não é levado em consideração, porém se adicionarmos o volume na comparação com o CGP, as soluções passam a não mais dominar o CGP, ou seja, o CGP faz parte da fronteira de Pareto.

A Figura 8.1 mostra todas as soluções obtidas pelas abordagens de Pareto, juntamente com o CGP. As soluções dominadas pelo CGP, que são as 4 últimas soluções obtidas pela combinação das 3 propriedades, foram removidas. É possível observar que as soluções dos experimentos de Pareto que utilizaram polaridade e hidropatia parecem mais próximas do CGP, enquanto que as que empregaram as 3 propriedades são as mais distantes. 
Tabela 8.2: Comparação dos resultados de avaliação $\left(M_{s t}\right)$ para os três objetivos do CGC e dos melhores indivíduos de todas as abordagens testadas.

\begin{tabular}{|c|c|c|c|c|}
\hline Abordagem & Polaridade & Hidropatia & Volume molecular & Domina \\
\hline monoobjetivo & 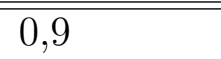 & 44,1 & 1684,7 & sim \\
\hline lexicográfico & 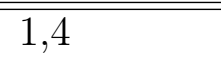 & 2,9 & 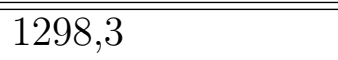 & sim \\
\hline ponderado $(0,4 / 0,35 / 0,25)$ & 1,3 & 2,0 & $\overline{7711,0}$ & sim \\
\hline ponderado $(0,6 / 0,3 / 0,1)$ & 1,4 & 1,7 & 743,2 & $\operatorname{sim}$ \\
\hline ponderado $(0,8 / 0,15 / 0,05)$ & 1,1 & 2,1 & 692,0 & $\operatorname{sim}$ \\
\hline$\overline{P a r e t o(P ~ e ~ H)}$ & 3,8 & 2,3 & 4209,7 & não \\
\hline $\operatorname{Pareto}(\mathrm{P}$ e $\mathrm{H})$ & 2,4 & 2,6 & 3230,5 & não \\
\hline $\operatorname{Pareto}(\mathrm{P}$ e $\mathrm{H})$ & 2,5 & 2,4 & 3849,2 & não \\
\hline $\operatorname{Pareto}(\mathrm{P}$ e $\mathrm{H})$ & 1,7 & 3,4 & 2649,0 & não \\
\hline $\operatorname{Pareto}(\mathrm{P}$ e $\mathrm{H})$ & 1,6 & 4,2 & 2320,6 & não \\
\hline $\operatorname{Pareto}(\mathrm{P}$ e $\mathrm{H})$ & 1,6 & 4,2 & 2375,5 & não \\
\hline $\operatorname{Pareto}(\mathrm{P}$ e $\mathrm{H})$ & 1,7 & 3,6 & 2519,3 & não \\
\hline $\operatorname{Pareto}(\mathrm{P}$ e $\mathrm{H})$ & 1,6 & 4,6 & 2298,4 & não \\
\hline $\operatorname{Pareto}(\mathrm{P}$ e $\mathrm{H})$ & 1,6 & 4,2 & 2333,6 & não \\
\hline Pareto(P e H) & 1,6 & 4,7 & 2008,5 & não \\
\hline $\operatorname{Pareto}(\mathrm{P}$ e $\mathrm{H})$ & 1,6 & 4,1 & 2294,9 & não \\
\hline $\operatorname{Pareto}(\mathrm{P}$ e $\mathrm{H})$ & 1,6 & 4,7 & 2188,7 & não \\
\hline $\operatorname{Pareto}(\mathrm{P}$ e $\mathrm{H})$ & 1,8 & 3,3 & 2545,8 & não \\
\hline $\operatorname{Pareto}(\mathrm{P}$ e $\mathrm{H})$ & 2,1 & 2,7 & 3749,1 & não \\
\hline Pareto(P e MV) & 6,4 & 13,7 & 1123,6 & não \\
\hline Pareto(P e MV) & 6,5 & 13,8 & 1103,1 & não \\
\hline Pareto(P e MV) & 7,6 & 16,7 & 1027,7 & não \\
\hline Pareto(P, H e MV) & 4,0 & 7,0 & 1496,0 & não \\
\hline Pareto(P, H e MV) & 6,6 & 7,3 & 1342,2 & não \\
\hline Pareto(P, H e MV) & 7,7 & 11,1 & 1097,2 & não \\
\hline Pareto(P, H e MV) & 7,7 & 11,3 & 1149,7 & não \\
\hline Pareto(P, H e MV) & 6,2 & 7,0 & 1352,5 & não \\
\hline Pareto(P, H e MV) & 3,4 & 5,8 & 1906,1 & não \\
\hline Pareto(P, H e MV) & 3,2 & 5,8 & 1932,6 & não \\
\hline Pareto(P, H e MV) & 3,4 & 5,7 & 1922,4 & não \\
\hline Pareto(P, H e MV) & 3,2 & 6,2 & 1924,0 & não \\
\hline CGP & 2,6 & 4,6 & 1766,8 & \\
\hline
\end{tabular}


Tabela 8.3: Comparação dos valores de pdm de todas as abordagens testadas.

\begin{tabular}{llll}
\hline \hline & & média \pm desvio & melhor \\
\hline Mono & $p d m$ & $86,75 \pm 1,10 \%$ & $89,75 \%$ \\
\hline Lexico & $p d m$ & $92,59 \pm 2,29 \%$ & $98,04 \%$ \\
\hline Ponder$(0,4 / 0,35 / 0,25)$ & $p d m$ & $92,03 \pm 2,70 \%$ & $96,45 \%$ \\
\hline Ponder(0,6/0,3/0,1) & $p d m$ & $89,33 \pm 1,67 \%$ & $93,50 \%$ \\
\hline Ponder(0,8/0,15/0,05) & $p d m$ & $88,54 \pm 2,11 \%$ & $93,09 \%$ \\
\hline Pareto(P e H) & $p d m$ & $91,92 \pm 3,22 \%$ & $98,98 \%$ \\
\hline \hline Pareto(P e MV) & $p d m$ & $55,32 \pm 7,19 \%$ & $60,16 \%$ \\
\hline \hline Pareto(P, H e MV) & $p d m$ & $74,29 \pm 20,84 \%$ & $93,85 \%$ \\
\hline \hline
\end{tabular}

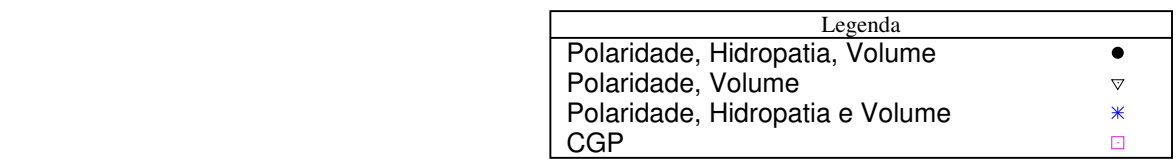

Volume

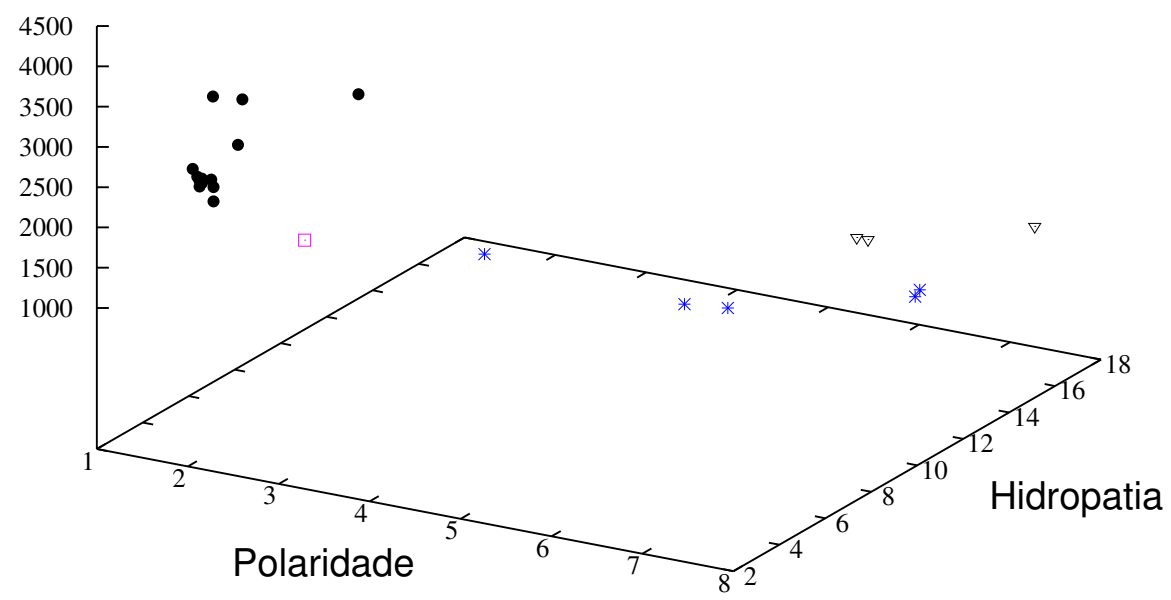

Figura 8.1: Fronteira considerando todas as soluções obtidas pelas abordagens de Pareto .

A Tabela 8.3 mostra os valores de $p d m$ (para a polaridade) obtidos para todas as abordagens. O pdm indica que os valores de fitness ou avaliação estão próximos ao valor de avaliação do CGP, não sendo necessariamente melhores. Os melhores resultados de $p d m$ foram obtidos pelas abordagens lexicográfica, ponderada e Pareto; as três obtiveram valores de $p d m$ médio acima de $90 \%$.

Já a Tabela 8.4 apresenta os valores de melhora de todas as abordagens. A melhora indica quanto o código hipotético "melhorou"o fitness em relação ao CGP. No caso, se o valor de avaliação do código hipotético é pior que o do CGP a melhora é negativa, ou seja, neste caso, indica quanto que o código hipotético "piorou". A melhora e o pdm são medidas complementares, assim por exemplo, observando o AG monoobjetivo percebe-se que ele obteve o menor $p d m$ e a maior melhora, ou seja, seu valor de avaliação está mais distante do 
Tabela 8.4: Comparação dos valores de melhora para a polaridade de todas as abordagens testadas.

\begin{tabular}{lll}
\hline \hline & média \pm desvio & melhor \\
\hline \hline Mono & $55,94 \pm 5,23 \%$ & $41,08 \%$ \\
\hline Lexico & $19.04 \pm 9.44 \%$ & $7.19 \%$ \\
\hline Ponder $(0,4 / 0,35 / 0,25)$ & $31,49 \pm 11,58 \%$ & $13,22 \%$ \\
\hline Ponder(0,6/0,3/0,1) & $43,11 \pm 7,44 \%$ & $25,00 \%$ \\
\hline Ponder(0,8/0,15/0,05) & $46,81 \pm 9,55 \%$ & $26,72 \%$ \\
\hline Pareto(P e H) & $25,32 \pm 3,79 \%$ & $23,35 \%$ \\
\hline Pareto(P e MV) & $-136,23 \pm 61,27$ & $-69,76 \%$ \\
\hline Pareto(P, H, MV) & $-92,49 \pm 74,98 \%$ & $-22,14 \%$ \\
\hline \hline
\end{tabular}

Tabela 8.5: Comparação dos valores de coincidências para a polaridade de todas as abordagens testadas.

\begin{tabular}{lll}
\hline \hline & média \pm desvio & melhor \\
\hline \hline Mono & $4,97(8,14 \%) \pm 3,93$ & $15(24,59 \%)$ \\
\hline Lexico & $3,10 \pm 2,51$ & 9 \\
\hline Ponder $(0,4 / 0,35 / 0,25)$ & $3,57(5,85 \%) \pm 2,76$ & $9(14,75 \%)$ \\
\hline Ponder $(0,6 / 0,3 / 0,1)$ & $3,33(5,46 \%) \pm 3,92$ & $15(24,59 \%)$ \\
\hline Ponder $(0,8 / 0,15 / 0,05)$ & $3,57(5,68 \%) \pm 2,76$ & $13(21,31 \%)$ \\
\hline Pareto(P e H) & $3,86 \pm 2,07$ & 9 \\
\hline Pareto(P e MV) & $3,33 \pm 0,58$ & 4 \\
\hline Pareto(P, H, MV) & $3,71 \pm 2,36$ & 6 \\
\hline \hline
\end{tabular}

CGP. Valores de melhora baixos correspondem a valores mais baixos de $p d m$. Neste caso, o AG lexicográfico foi o experimento com menor valor de melhora.

A Tabela 8.5 mostra o número de coincidências entre os melhores códigos hipotéticos de cada abordagem e o CGP. É importante observar que os valores são baixos. Uma das explicações é que a codificação utilizada não relaciona códons a seus respectivos aminoácidos, ou seja, desde que a função de robustez seja minimizada, o aminoácido que se liga a determinado códon não é levado em consideração. Nota-se que as associações códon-aminoácido que emergem das soluções obtidas são diferentes das associações presentes no CGP. Uma explicação plausível é a de que, obviamente, durante a evolução do CGP, diversos outros fatores levaram ao surgimento dessas associações, fatores estes que não estão sendo considerados pela função de robustez utilizada neste trabalho.

A Tabela 8.6 apresenta os valores de entropia obtidos. Valores de entropia altos significam uma distribuição mais uniforme das frequências de códons associados aos aminoácidos. Neste caso, as soluções mais entrópicas se aproximam mais do CGP. A entropia do CGP é 2,87. As abordagens com soluções mais entrópicas foram as de Pareto e a lexicográfica. Nota-se que a abordagem monoobjetivo apresenta o menor valor de entropia, o que é esperado, já que conforme previamente discutido, a combinação codificação não-restritiva e abordagem monoobjetivo ocasiona um aumento desenfreado da frequência de códons associados a alguns aminoácidos, aqueles com menores distâncias para os demais. Dessa forma, 
Tabela 8.6: Comparação dos valores de entropia para a polaridade de todas as abordagens testadas.

\begin{tabular}{llll}
\hline \hline & & média \pm desvio & melhor \\
\hline \hline Mono & $0,75 \pm 0,05$ & 0,84 & \\
\hline Lexico & $2,70 \pm 0,11$ & 2,90 & \\
\hline Ponder $(0,4 / 0,35 / 0,25)$ & $2,42 \pm 0,09$ & 2,63 & \\
\hline Ponder$(0,6 / 0,3 / 0,1)$ & $2,40 \pm 0,12$ & 2,62 & \\
\hline Ponder$(0,8 / 0,15 / 0,05)$ & $2,41 \pm 0,10$ & 2,56 & \\
\hline Pareto(P e H) & $2,64 \pm 0,03$ & 2,71 & \\
\hline Pareto(P e MV) & $2,89 \pm 0,03$ & 2,91 & \\
\hline Pareto(P, H, MV) & $2,89 \pm 0,01$ & 2,92 & \\
\hline Codigo genético padrão & 2,87 & & \\
\hline \hline
\end{tabular}

Tabela 8.7: Tabela Resumo: indica qual abordagem obteve o melhor valor médio da medida indicada.

\begin{tabular}{ll}
\hline \hline medida & algoritmo \\
\hline \hline$M_{s t}(\mathrm{P})$ & Mono \\
\hline$M_{s t}(\mathrm{H})$ & Ponder $(0,6 / 0,3 / 0,1)$ \\
\hline$M_{s t}(\mathrm{VM})$ & Ponder $(0,4 / 0,35 / 0,25)$ \\
\hline$p d m$ & Lexico \\
\hline melhora & Pareto $(\mathrm{P}$ e $\mathrm{H})$ \\
\hline coincidências & Mono \\
\hline entropia & Pareto $(\mathrm{P}, \mathrm{H}, \mathrm{MV})$ \\
\hline \hline
\end{tabular}

apesar da entropia não ser diretamente utilizada na função de avaliação, a utilização de mais de um objetivo soluciona o problema de frequências e nota-se isso em todas as abordagens utilizadas em maior ou menor proporção.

A Tabela 8.7 apresenta um resumo dos resultados obtidos, evidenciando o bom desempenho das abordagens multiobjetivo aqui empregadas.

\subsection{Conclusões}

Na pesquisa apresentada nesta tese de doutorado, Algoritmos Genéticos foram empregados no estudo da adaptabilidade do código genético. Funções de avaliação baseadas na robustez do código para diferentes propriedades foram empregadas para avaliar os códigos. $\mathrm{Na}$ literatura, tanto na abordagem estatística quanto na abordagem por engenharia (i.e., empregando um algoritmo de otimização para achar os melhores códigos hipotéticos) apenas um objetivo foi empregado na geração de códigos ótimos. Neste trabalho, pela primeira vez que se tem conhecimento, abordagens multiobjetivo foram empregadas no estudo desse problema.

No trabalho aqui apresentado, um algoritmo genético foi implementado considerando 4 abordagens: monoobjetivo, seguindo o que já existe na literatura; ponderada; lexicográfica e Pareto. Em todas as abordagens multiobjetivo aqui consideradas, melhores valores de 
entropia, melhora e $p d m$ foram obtidos em comparação com a abordagem monoobjetivo.

Altos valores de $p d m$ e baixos valores de melhora são resultado de valores de avaliação mais próximos do código genético padrão. No caso da entropia, as soluções mais entrópicas geradas pelas abordagens multiobjetivo assemelham-se mais ao CGP, além de serem biologicamente mais plausíveis. A abordagem multiobjetivo também descarta a necessidade de utilizar a codificação restritiva, não sendo necessário restringir o espaço de busca. Na abordagem monoobjetivo, as soluções geradas possuem muitos códons associados a poucos aminoácidos, valores de $M_{s t}$ bem baixos considerando a polaridade (única propriedade otimizada).

O melhor $p d m$ foi obtido na abordagem de Pareto com dois objetivos, sendo eles polaridade e hidropatia. O valor obtido foi de 98,98\%, enquanto que o melhor valor obtido em (Santos e Monteagudo, 2011) foi de 89\%. Além disso, as soluções obtidas na abordagem de Pareto não dominam o CGP, o que pode indicar tanto que o CGP é um (dos) ótimo(s) global(is), quanto que o NSGA-II não foi capaz de obter soluções melhores.

Os valores de entropia das abordagens multiobjetivo também foram altos, mostrando que os códigos hipotéticos obtidos encontram-se mais próximos do CGC também em termos de estrutura. Outro ponto importante é que nenhuma das abordagens gerou códigos com organizações iguais ao CGP, sugerindo a necessidade de buscar outras características para otimizar e/ou estudar a otimalidade do código padrão e/ou combinar com outras hipóteses, por exemplo, a hipótese da cooevolução, na qual o CGP inicialmente codificava poucos aminoácidos precursores através de um código de duas letras.

Os resultados obtidos durante o desenvolvimento deste trabalho foram publicados em: (de Oliveira et al., 2015; de Oliveira e Tinós, 2012; de Oliveira e Tinós, 2014a,b). Atualmente, um novo artigo está em desenvolvimento. 


\section{APÊNDICE A}

\section{Abordagem de Pareto e por pesos considerando uma}

função de robustez baseada em entropia

As simulações apresentadas neste apêndice foram realizadas com a codificação não restritiva (Ver Seção 3.1.2). Os resultados obtidos foram publicados em (de Oliveira e Tinós, 2014a).

A codificação não restritiva não limita o número de códons associados a um aminoácido, de forma que esse número varia livremente. Intuitivamente, considerando os aminoácidos que são mais importantes na minimização da Eq. 2.1, que calcula o $M_{s}$, serão aqueles com menores distâncias médias para todos os demais, ou seja, aqueles com valores intermediários de $M_{s}$. As distâncias médias entre dois aminoácidos, ou seja, não levando em consideração que pode ser necessário mais de uma substituição em um códon para trocar um aminoácido, são apresentados na Tabela 4.4. É possível observar que Alanina, Glicina e Serina tem as menores distâncias, o que significa que eles podem mudar para qualquer outro aminoácido 
com menor custo $\left(M_{s}\right)$. Dessa maneira, códigos genéticos hipotéticos com grande número de códons associados a Alanina, Glicina e Serina apresentam melhores valores da função de avaliação dada pela Eq. 2.1.

A Figura A.1 mostra a distribuição de frequências para o melhor código genético obtido pelo AG para a codificação não restritiva e usando a Eq. 2.1. É possível observar que o código apresentado na Figura A.1 tem uma frequência não uniforme, sendo que a maioria dos aminoácidos é codificada somente por um códon, diferentemente do código genético padrão.

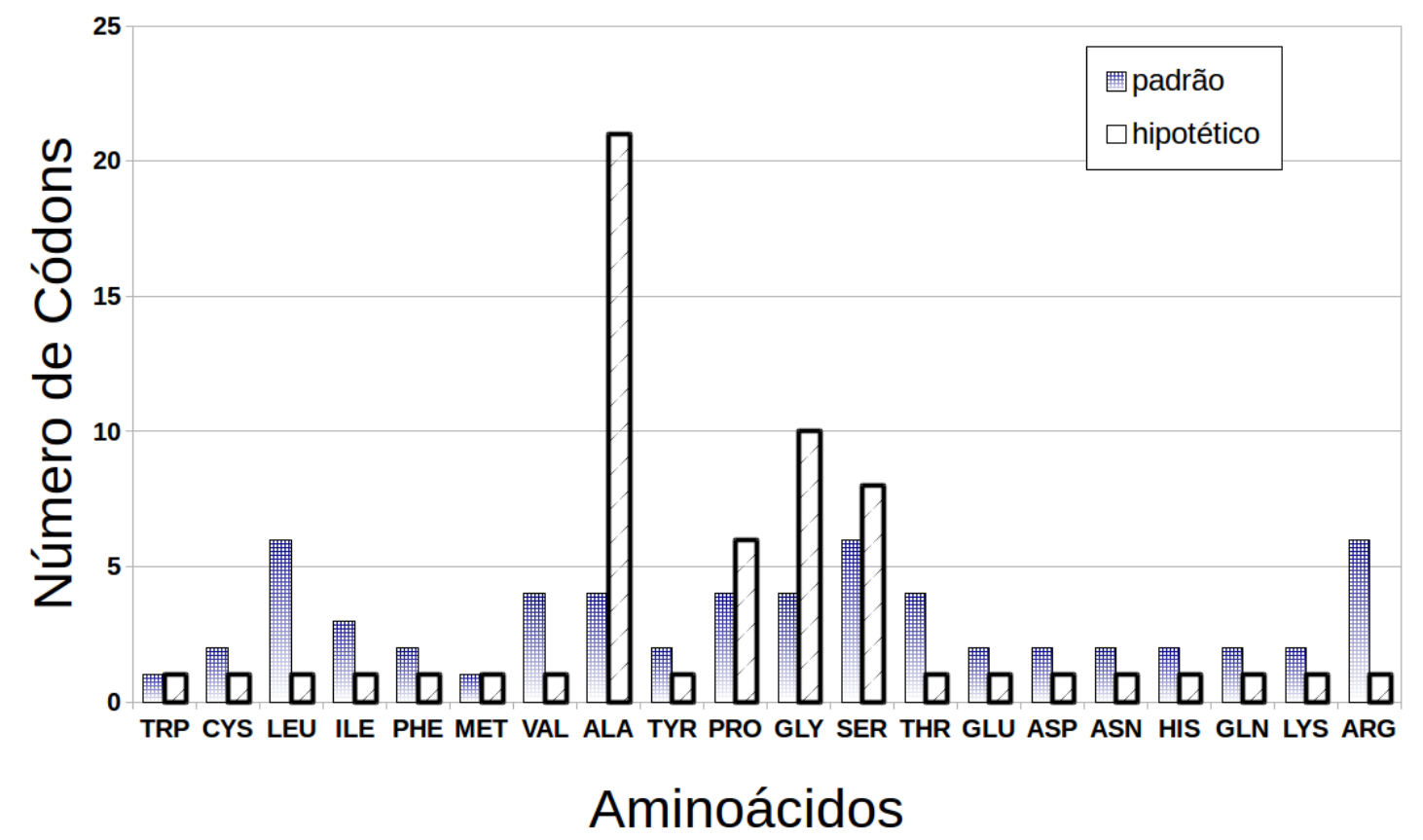

Figura A.1: Frequências de códons associados a aminoácidos para o melhor indivíduo em comparação com o código genético padrão.

Baseado no problema de aumento de frequência de códons da codificação não restritiva, propôs-se adicionar um novo termo baseado em entropia ao $M_{s}$ na função de avaliação do AG.

A existência de um maior número de códons capazes de codificar um aminoácido torna mais fácil incorporar um aminoácido a uma proteína, a medida que existem mais maneiras de mudar o códon atual para obter outro que corresponda a novos aminoácidos. Dessa forma, a distância entre os aminoácidos, em termos de mudanças necessárias para substituir um por outro, decresce a medida que a distribuição se torna uniforme. Quando a entropia é maximizada, possíveis mudanças de um códon para outro ocorrem sem custo excessivo, o que é certamente útil para a evolução biológica.

Para mostrar como distribuições uniformes de frequências de códons podem ser uteis nesse problema, um simples experimento foi executado. Um AG foi utilizado para otimizar a seguinte função de fitness: 


$$
f(y)=\|\mathbf{d}-\mathbf{y}\|
$$

onde $\mathbf{d}$ é o vetor de inteiros desejado e y é o fenótipo do indivíduo. Nesse experimento, cada indivíduo do AG é composto por um vetor binário, o qual é o genótipo do indivíduo. Cada 5 bits ou posições do genótipo codificam um elemento do vetor $\mathbf{y}$ (cada elemento do vetor $\mathbf{y}$ é um inteiro). O genótipo é convertido em fenótipo y por meio de uma tabela de conversão, que mapeia cada 5 bits em um valor. $\mathrm{O}$ vetor $\mathbf{d}$ foi aleatoriamente gerado no começo da simulação. Os vetores d e y são compostos por valores entre 1 e 10 e tabela de conversão combina todos as possibilidades de 5 bits, que são 32, nesses valores. Desse modo, é possível ter mais de um elemento de 5 bits associado com o mesmo valor. Três tabelas de conversão com diferentes distribuições foram usadas: a primeira foi uniforme, a segunda tinha um valor mais frequente e a terceira, dois valores mais frequentes. Os parâmetros utilizados foram uma população de 100 indivíduos, 60\% de crossover, 1\% de mutação e 10000 gerações. A Figura A.2 apresenta o comportamento do fitness para as três distribuições da tabela.

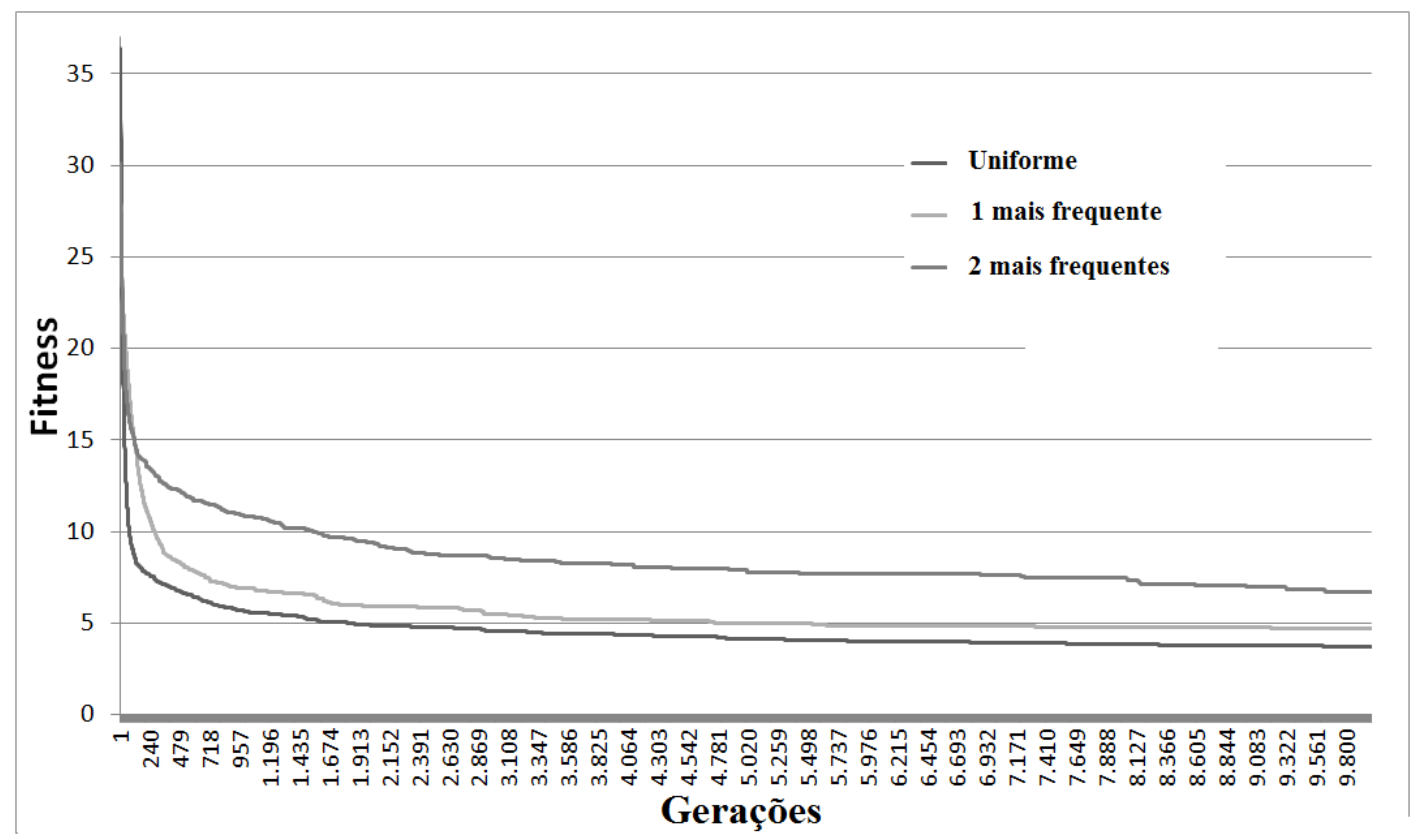

Figura A.2: Valor de avaliação do melhor individuo para 10 execuções do AG e diferentes tabelas de conversão.

Como pode ser observado, o fitness ou avaliação decresce mais rápido quando a tabela de conversão uniforme é utilizada. Esse resultado pode ser explicado pelo fato de que é mais fácil para o AG mudar um elemento de 5 bits do genótipo para alcançar a solução desejada quando a distribuição da tabela de conversão é uniforme e consequentemente a distância entre os elementos é menor. Uma forma de avaliar a uniformidade da distribuição e, como consequência, a distância média entre os aminoácidos (ou seja, o número de mudanças nos códons de um aminoácido para os códons de outro aminoácido), é computar a entropia da distribuição. De fato, nos resultados apresentados na Figura A.2, altas entropias significam convergência rápida para o algoritmo (nas execuções, a distribuição uniforme obteve a maior 
entropia). Entretanto, uma entropia mais alta em geral significa baixa robustez contra erros. Desse modo, uma função de avaliação multi-objetivo foi proposta na próxima seção.

\section{A.1 Função de avaliação baseada na entropia}

A função de avaliação baseada na entropia para o $i$-ésimo (código genético) é dada por:

$$
f(i)=a \times M_{s}(i)+(1-a) \times \frac{1}{S(i)}
$$

sendo, $a \in[0,1]$ é um número real e $S(i)$ é a entropia do indivíduo $i$ dada por:

$$
S(i)=-\sum_{k} p(i, k) \times \log p(i, k)
$$

onde $p(i, k)$ é a frequência relativa do $k$-ésimo aminoácido em um código genético do $i$-ésimo individuo. O termo $M_{s}$ é computado usando Eq. 2.1. É importante ressaltar que foram usados valores normalizados de $M_{s}$ e de entropia.

É possível observar que a Eq. 2.1 é reproduzida quando a é igual a 1,0 na Eq. A.4. Quando $a$ é igual a 0,0, somente a entropia é considerada como função de avaliação e os melhores códigos são aqueles onde todos os aminoácidos são codificados quase que pelo mesmo número de códons.

\section{A.2 Abordagem por pesos considerando entropia}

Nesta abordagem, a função de avaliação (de Oliveira e Tinós, 2012) de cada individuo é composta por um termo baseado em robustez, considerando polaridade e um termo baseado em entropia, da seguinte forma:

$$
f(i)=a M_{s}(i)+(1-a) \frac{1}{S(i)}
$$

onde $M_{s}(i)$ e $S(i)$ são respectivamente a média quadrática da variação de uma propriedade dos aminoácidos (Ver 2.6.1) e a entropia para o código genético correspondente ao $i$-ésimo indivíduo da população e $a$ é o peso correspondente a importância de cada objetivo na função de avaliação. Os valores de $M_{s}(i)$ e $S(i)$ são utilizados normalizados. Quando $a=1$, somente a robustez é minimizada. Por outro lado, somente a entropia é maximizada quando $a=0$.

Foram realizadas simulações considerando $M_{s}$ e $M_{s t}$. Nos experimentos no qual o $M_{s t}$ foi utilizado, a função de avaliação é dada por:

$$
f(i)=a M_{s t}(i)+(1-a) \frac{1}{S(i)}
$$




\section{A.3 Abordagem de Pareto}

O principal problema da abordagem por pesos é conseguir determinar bons valores para $a$. Na abordagem de Pareto os objetivos são avaliados independentemente, ou seja, é necessário definir artificialmente um peso $a$. Na abordagem de Pareto, aqui empregada, o algoritmo NSGA-II (Deb et al., 2002) foi implementado, conforme descrito em 7.

\section{A.4 Avaliação dos resultados}

A fim de comparar os resultados obtidos com o CGP, utilizou-se as medidas:

- $p d m$ (Porcentagem de distância de minimização) (Ver Seção 2.6.3);

- Melhora (Ver Seção 2.6.3);

- Valores de avaliação ou fitness (Ver Seção 2.6.3);

- Representação gráfica da fronteira de Pareto (Ver Seção 2.6.3);

- Número de coincidências (Ver Seção 2.6.3);

\section{A.5 Resultados e Discussão}

Os parâmetros utilizados na simulação foram: taxa de mutação de 0,01; taxa de swap de 0,5 e taxa de torneio de 3\% do tamanha da população. A Seção A.5.1 apresenta os resultados obtidos com a função baseada em entropia no experimento com pesos, enquanto que a Seção A.5.2 apresenta os resultados utilizando a abordagem de Pareto.

\section{A.5.1 Abordagem 1: ponderada baseada em entropia}

Um experimento inicial foi realizado para definir os pesos para a Eq. A.4. Baseado nesses resultados, simulações foram realizados com 10 sementes aleatórias do AG para cada valor de $a$ em um intervalo entre 0,4 e 1,0. Os resultados apresentados a seguir consideram $M_{s}$ ou $M_{s t}$ como primeiro objetivo conforme descrito pela Eq. A.3 ou Eq. A.5.

Os valores de $p d m$ médio e mais altos para as 10 sementes são apresentados na Tabela A.1. O melhor $p d m$ obtido foi $75,04 \%$ e a melhor média foi $73,56 \%$ para as simulações com $M_{s}$, ambos com $a=0.7$. Na abordagem monoobjetivo apresentada em (Santos e Monteagudo, 2010), o melhor pdm para a codificação não restritiva foi de $67 \%$ e a melhora foi de $66 \%$.

Os valores de $p d m$ e melhora obtidos para a função de avaliação baseada na entropia com $a=0.7$ foram melhores que os valores obtidos na simulação sem entropia. Além disso, esses valores são ainda melhores que os reportados por Santos e Monteagudo em (Santos e Monteagudo, 2010) para a codificação restritiva ( $p d m$ de $71 \%$ ). 
Tabela A.1: Valores de pdm e melhora no experimento com a abordagem 1, utilizando $M_{s}$.

\begin{tabular}{c|c|c|c|c}
\hline \hline$a$ & $p d m$ (melhor) & $p d m$ (médio) & melhora (melhor) & melhora (média) \\
\hline \hline 0,4 & 69,853 & 71,091 & 6,765 & 7,182 \\
\hline 0,5 & 73,654 & 72,298 & 8,489 & 9,096 \\
\hline 0,6 & 74,956 & 73,179 & 10,986 & 12,058 \\
\hline 0,7 & 75,038 & 73,561 & 15,011 & 16,224 \\
\hline 0,8 & 74,117 & 72,789 & 21,771 & 23,314 \\
\hline 0,9 & 70,964 & 70,499 & 36,155 & 36,978 \\
\hline 1,0 & 69,853 & 68,478 & 57,063 & 60,876 \\
\hline \hline
\end{tabular}

Tabela A.2: Valores de pdm e melhora no experimento com a abordagem 1, utilizando $M_{s t}$.

\begin{tabular}{c|c|c|c|c}
\hline \hline$a$ & $p d m$ (melhor) & $p d m$ (média) & melhora (melhor) & melhora (média) \\
\hline \hline 0,4 & 85,032 & 80,431 & 4,345 & 6,020 \\
\hline 0,5 & 87,007 & 83,158 & 5,413 & 7,353 \\
\hline 0,6 & 85,227 & 84,282 & 9,022 & 9,711 \\
\hline 0,7 & 90,557 & 86,054 & 7,843 & 12,221 \\
\hline 0,8 & 91,459 & 86,994 & 10,503 & 16,858 \\
\hline 0,9 & 88,271 & 86,962 & 24,218 & 27,346 \\
\hline 1,0 & 87,320 & 86,149 & 52,100 & 57,725 \\
\hline \hline
\end{tabular}

A Tabela A.2 apresenta os resultados para a simulação utilizando $M_{s}$. Nesta simulação, os valor de $p d m$ para $a=0,8$ é melhor do que os resultados com a função de avaliação padrão $(a=1,0)$ e os valores de melhora são também melhores para a função de avaliação que utiliza a entropia com $a=0,8$. Em (Santos e Monteagudo, 2010), os valores de melhora foram 33\%, usando a codificação restritiva e $66 \%$ com a codificação não restritiva. Dessa forma, usando a abordagem baseada em entropia e a codificação não restritiva valores de melhora mais baixos (melhores) foram obtidos (10,503\%). Quando a é igual a 0,8, o valor de $p d m$ foi de $91,459 \%$, enquanto que, quando a entropia não é considerada no experimento com o único objetivo apresentado em (Santos e Monteagudo, 2010) o valor do $p d m$ foi de $85 \%$.

A Tabela A.2 apresenta os resultados para o experimento com $M_{s t}$. Neste experimento, o valor de $p d m$ para $a=0.8$ (experimento com entropia) é melhor do que para $a=1.0$ (experimento sem entropia).

Em (Santos e Monteagudo, 2010), o valor de melhora obtido foi de 33\% considerando a codificação restritiva e de $60 \%$ para a codificação não restritiva. Neste sentido, usando a entropia e a codificação não restritiva o valor de melhora obtido foi de 10.50\%. Quando a é igual 0.8 , o valor de $p d m$ obtido foi de $91,459 \%$, enquanto que quando a entropia não é considerada o valor é de 85\% (Santos e Monteagudo, 2010).

Pode-se observar que, ao considerar os erros de tradução em função da base $\left(M_{s t}\right)$, melhores resultados são alcançados. Outros autores já constataram que $M_{s t}$ é mais apropriado para avaliar os códigos, tanto nas abordagens estatísticas, quanto nas por engenharia 
(Freeland e Hurst, 1998; Santos e Monteagudo, 2010). Além disso, em ambos os experimentos, a utilização de dois objetivos ( $M_{s t}$ e entropia) para avaliar os indivíduos resultou em um melhor desempenho do que quando apenas um objetivo foi utilizado, mesmo quando comparado com os resultados obtidos por um único objetivo com a codificação restritiva, como apresentado em (Santos e Monteagudo, 2010).

A codificação restritiva utiliza as informações dos grupos de códons do do código genético padrão para criar os códigos genéticos hipotéticos. As figuras A.3 e A.4 mostram as distribuições das frequências de códons associados aos aminoácidos nos códigos com melhor $p d m$, respectivamente, encontradas nos experimentos com $M_{s}$ e $M_{s t}$. Quando comparada com a distribuição do experimento com uma função de avaliação considerando apenas a robustez (Figura A.1), pode-se observar que no experimento onde a entropia foi considerada as distribuições são mais uniformes, os códigos gerados são mais próximos da distribuição do código genético padrão.

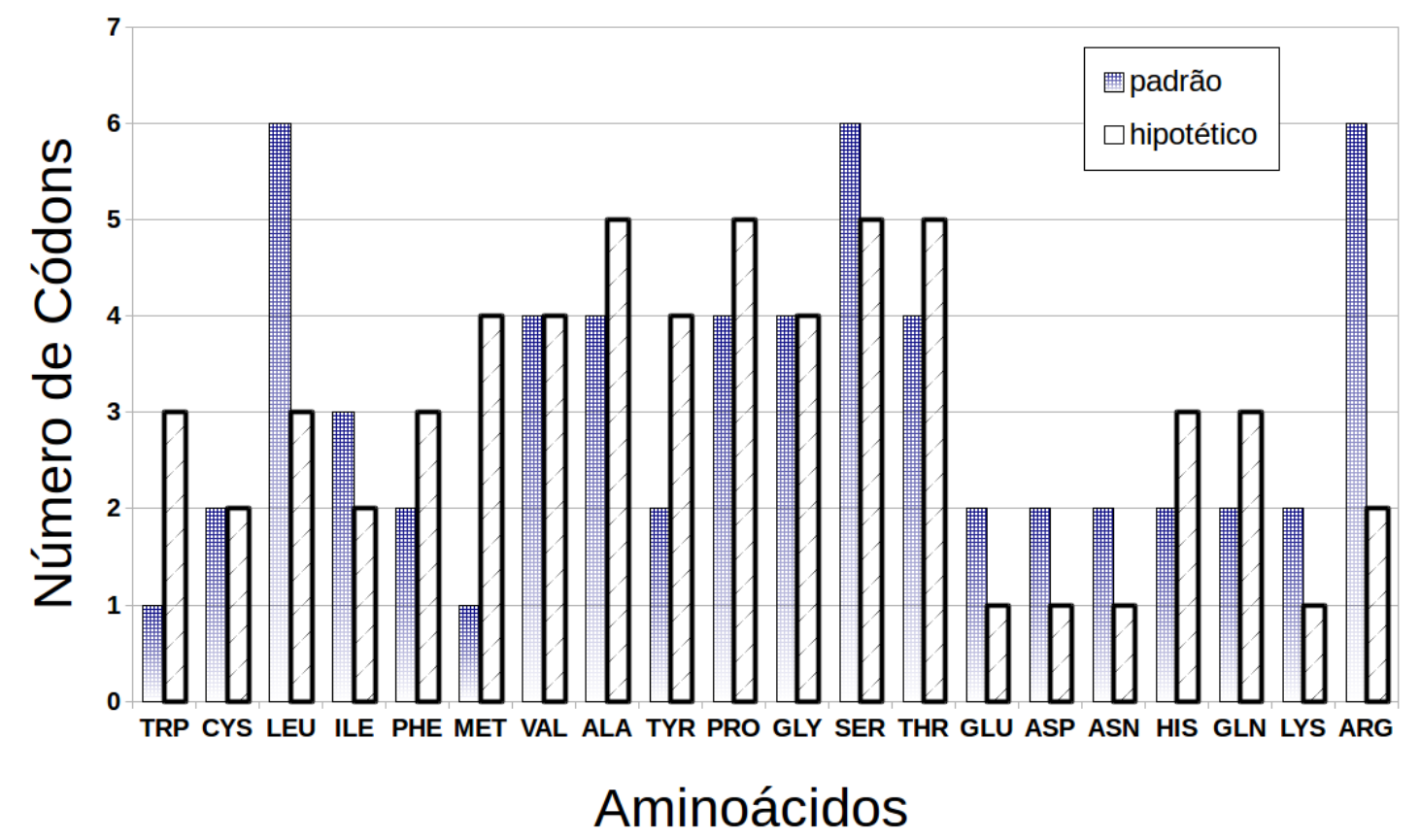

Figura A.3: Frequências de códons associados a aminoácidos no código genético padrão e no melhor código hipotético obtido no experimento com a abordagem 1 e com a $=0.7$ usando $M_{s}$. 


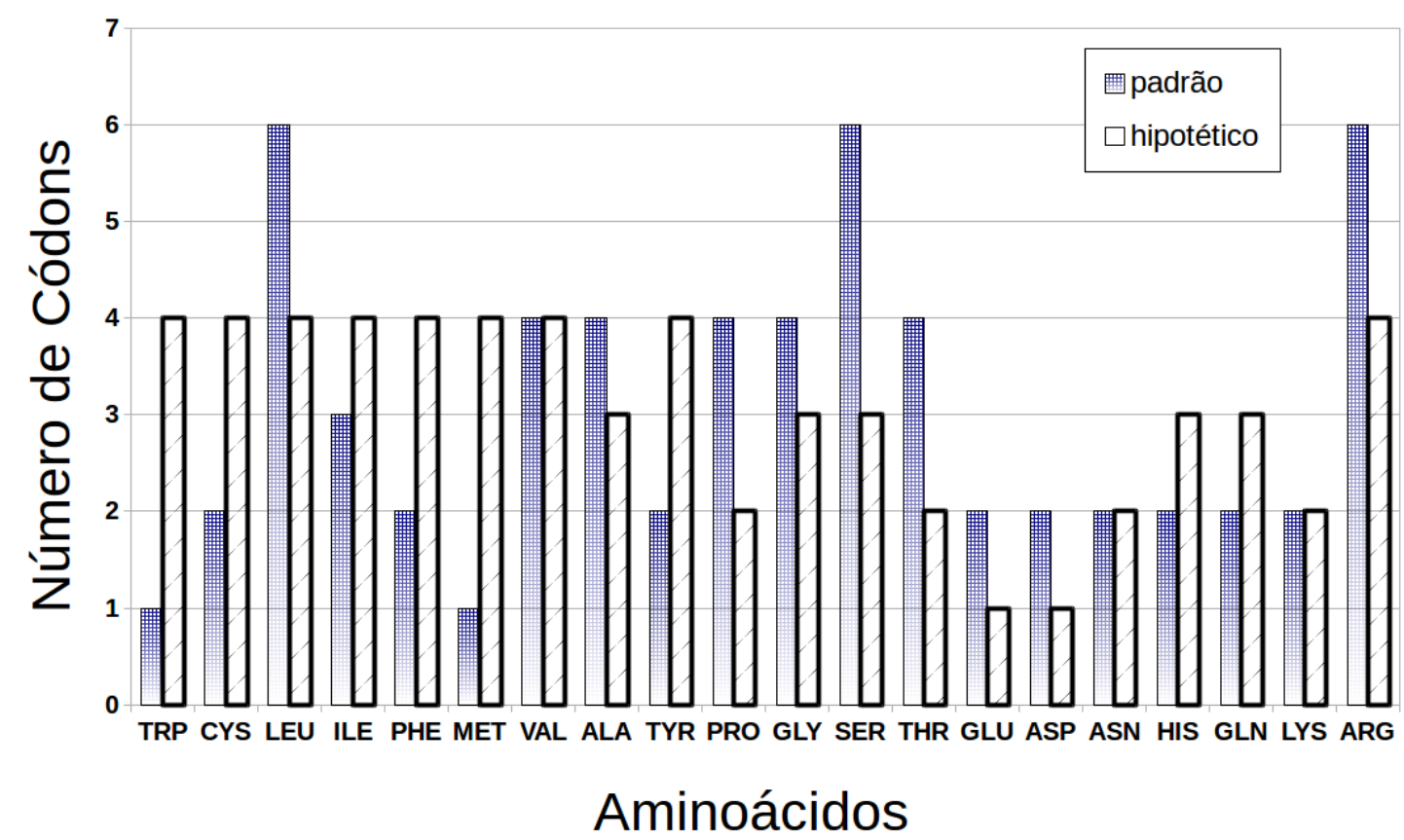

Figura A.4: Frequências de códons associados a aminoácidos no código genético padrão e no melhor código hipotético obtido no experimento com a abordagem 1 e com a $=0.8$ usando $M_{s t}$.

\section{A.5.2 Abordagem 2: Pareto baseada em entropia}

Nesta seção são apresentados os valores obtidos pelo experimento com a abordagem de Pareto. O algoritmo empregado foi o NSGA-II, conforme descrito na Seção 7.1. O algoritmo de otimização foi utilizado considerando $M_{s}$ (ou $M_{s t}$ ) como primeiro objetivo e a entropia com segundo objetivo.

A Tabela A.3 mostra os resultados obtidos no experimento com $M_{s}$. São apresentados os valores dos dois objetivos para as soluções não dominadas, os valores de $p d m$ e melhora e a dominância que indica se a solução domina o código genético padrão. A Tabela e a Figura apresentam os mesmos resultados porém considerando o experimento com $M_{s t}$.

Os melhores valores de $p d m$ obtidos foram 97,605\% e 97,676\% respectivamente para o experimento com $M_{s}$ e $M_{s t}$. Contudo, a melhora obtida no experimento com $M_{s}$ foi negativa indicando que o valor de $M_{s}$ da solução foi pior (mais baixo) do que o valor obtido para o código genético padrão. Assim como na abordagem 1, os resultados obtidos considerando o $M_{s t}$ foram melhores que aqueles considerando o $M_{s}$. Comparando as abordagens, a abordagem 1, de Pareto obteve os códigos hipotéticos mais próximos ao código padrão. O melhor valor de $p d m(97,676 \%)$ obtido aqui é também melhor que os resultados reportado na literatura para a codificação restritiva (Santos e Monteagudo, 2010).

As figuras A.5 e A.6 mostra a distribuição de frequências dos códons com o melhor pdm obtidos pela abordagem 2, considerando $M_{s}$ e $M_{s t}$. 
Tabela A.3: Resultados da avaliação dos objetivos 1 e 2, pdm e melhora para as soluções não dominadas e dominância em relação ao código padrão, considerando $M_{s}$.

\begin{tabular}{c|c|c|c|c|c}
\hline \hline solução & $\begin{array}{c}\text { Objetivo 1 } \\
M_{s}\end{array}$ & $\begin{array}{c}\text { Objetivo 2 } \\
\text { entropia }\end{array}$ & dominância & $p d m$ & melhora \\
\hline \hline 1 & 5,004 & 0,338 & Sim & 97,315 & 3,648 \\
\hline 2 & 3,678 & 0,341 & Sim & 81,916 & 29,190 \\
\hline 3 & 4,014 & 0,340 & Sim & 85,340 & 22,714 \\
\hline 4 & 3,421 & 0,343 & Sim & 79,483 & 34,131 \\
\hline 5 & 4,015 & 0,339 & Sim & 85,349 & 22,698 \\
\hline 6 & 3,524 & 0,342 & Sim & 80,439 & 32,154 \\
\hline 7 & 3,366 & 0,345 & Sim & 78,982 & 35,187 \\
\hline 8 & 3,452 & 0,342 & Sim & 79,768 & 33,536 \\
\hline 9 & 3,284 & 0,345 & Sim & 78,241 & 36,772 \\
\hline 10 & 4,206 & 0,339 & Sim & 87,432 & 19,008 \\
\hline 11 & 3,841 & 0,341 & Sim & 83,544 & 26,045 \\
\hline 12 & 6,906 & 0,336 & Não & 75,067 & $-32,968$ \\
\hline 13 & 4,733 & 0,339 & Sim & 93,708 & 8,878 \\
\hline 14 & 5,358 & 0,337 & Não & 97,605 & $-3,166$ \\
\hline 15 & 7,005 & 0,336 & Não & 73,623 & $-34,877$ \\
\hline 16 & 6,729 & 0,337 & Não & 77,638 & $-29,569$ \\
\hline 17 & 6,587 & 0,337 & Não & 79,702 & $-26,839$ \\
\hline \hline
\end{tabular}

Tabela A.4: Resultados da avaliação dos objetivos 1 e 2, pdm e melhora para as soluções não dominadas e dominância em relação ao código padrão, considerando $M_{s t}$.

\begin{tabular}{c|c|c|c|c|c}
\hline \hline solução & $\begin{array}{c}\text { Objetivo 1 } \\
M_{s t}\end{array}$ & $\begin{array}{c}\text { Objetivo 2 } \\
\text { entropia }\end{array}$ & dominância & $p d m$ & melhora \\
\hline 1 & 1,803 & 0,341 & Sim & 91,950 & 31,418 \\
\hline 2 & 1,902 & 0,338 & Sim & 92,852 & 27,625 \\
\hline 3 & 1,858 & 0,339 & Sim & 92,445 & 29,326 \\
\hline 4 & 1,665 & 0,343 & Sim & 90,733 & 36,654 \\
\hline 5 & 2,805 & 0,336 & Não & 98,124 & $-6,734$ \\
\hline 6 & 3,875 & 0,335 & Não & 86,783 & $-47,432$ \\
\hline 7 & 1,636 & 0,345 & Sim & 90,480 & 37,757 \\
\hline 8 & 1,646 & 0,345 & Sim & 90,570 & 37,365 \\
\hline 9 & 1,823 & 0,339 & Sim & 92,134 & 30,638 \\
\hline 10 & 2,404 & 0,337 & Sim & 97,676 & 8,539 \\
\hline 11 & 2,113 & 0,337 & Sim & 94,816 & 19,620 \\
\hline 12 & 2,124 & 0,337 & Sim & 94,929 & 19,171 \\
\hline 13 & 2,030 & 0,338 & Sim & 94,033 & 22,773 \\
\hline \hline
\end{tabular}




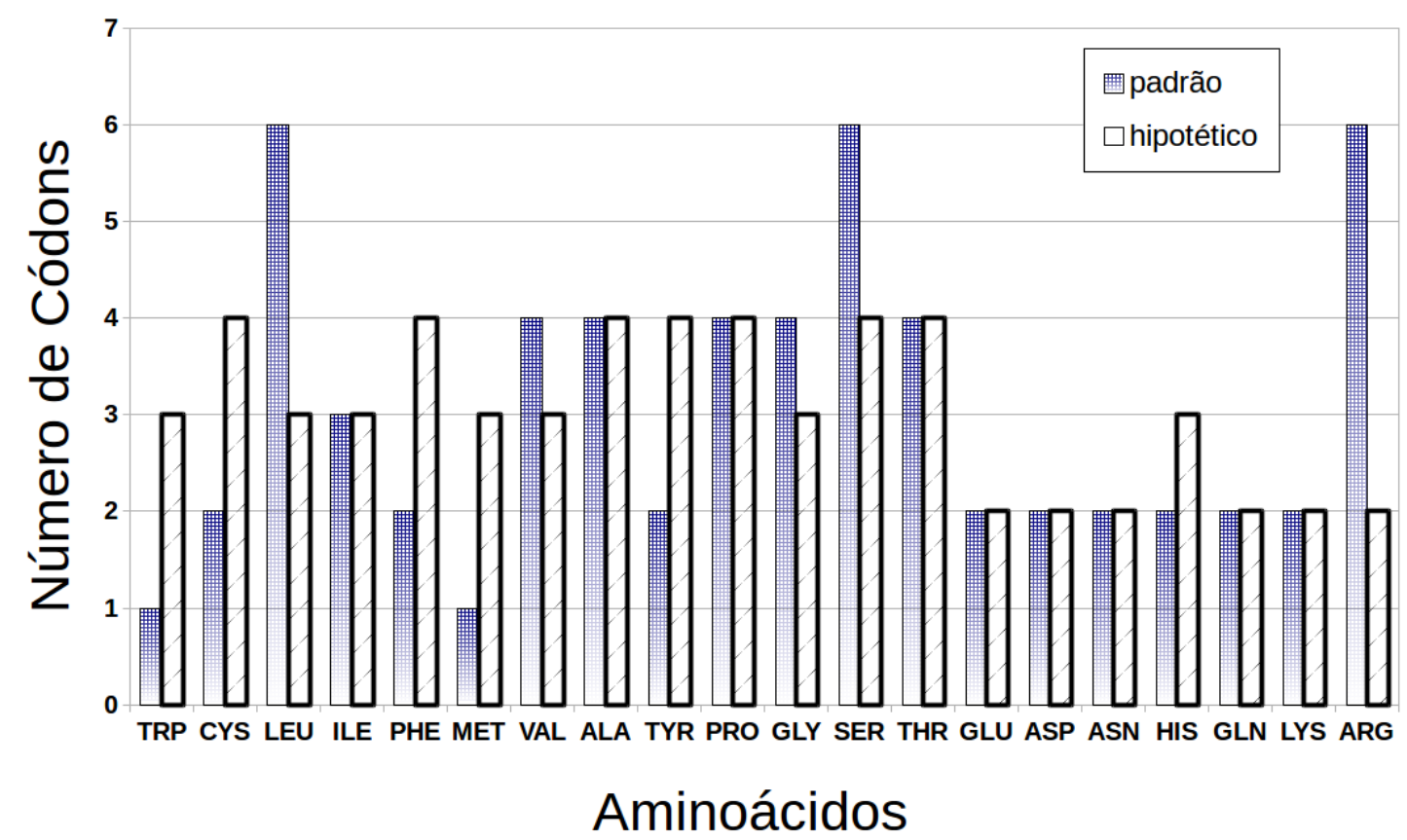

Figura A.5: Frequências de códons associados a aminoácidos no código genético padrão e no melhor código hipotético não dominado com a abordagem 1 e usando $M_{s}$.

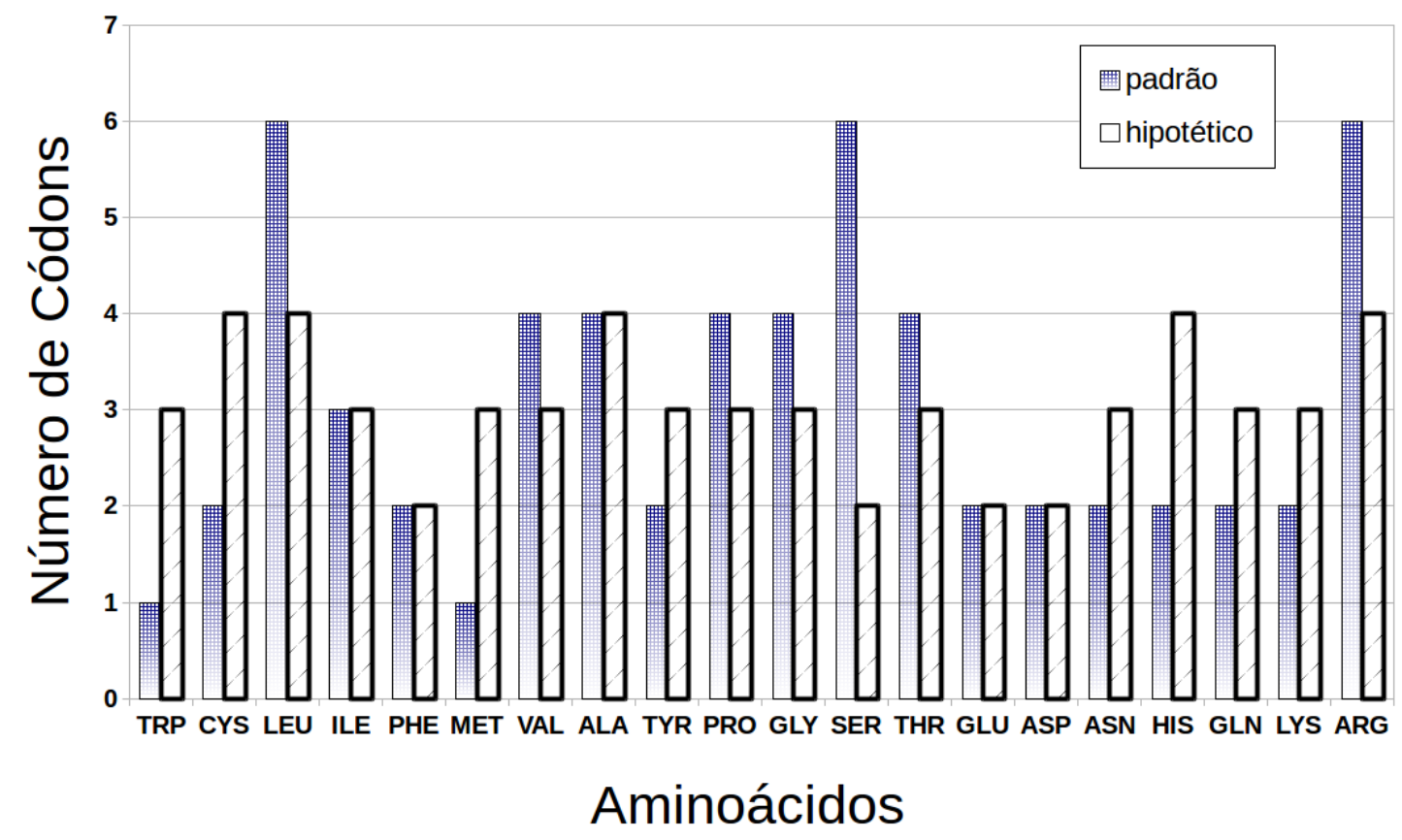

Figura A.6: Frequências de códons associados a aminoácidos no código genético padrão e no melhor código hipotético não dominado com a abordagem 1 e usando $M_{s t}$.

A Tabela A.5 mostra a média e o número máximo de coincidências para ambas as abordagens. Os melhores valores médios foram obtidos para o experimento $\operatorname{com} M_{s} \operatorname{com} a=0.7$, enquanto que os melhores valores máximos foram obtidos pela abordagem 2. Contudo, poucas coincidências foram obtidas em ambas as abordagens, apesar de ambas alcançarem valores 
Tabela A.5: Número de coindências para os experimentos com $M_{s}$ e $M_{s}$ para abordagem 1 (ponderada) e 2 (Pareto).

\begin{tabular}{c|c|c|c}
\hline \hline Experimento & Média & Máximo & desvio \\
\hline \hline Abordagem $1 \operatorname{com} M_{s}$ e $a=0,7$ & 4,80 & 8 & 2,394 \\
\hline Abordagem $1 \operatorname{com} M_{s}$ e $a=1,0$ & 3,00 & 7 & 2,357 \\
\hline Abordagem $2 \operatorname{com~} M_{s}$ & 2,47 & 4 & 1,179 \\
\hline Abordagem 1 com $M_{s t}$ e $a=0,8$ & 2,30 & 4 & 1,494 \\
\hline Abordagem 1 com $M_{s t}$ e $a=1,0$ & 3,10 & 11 & 3,725 \\
\hline Abordagem $2 \operatorname{com~} M_{s t}$ & 4,23 & 7 & 1,921 \\
\hline \hline
\end{tabular}

de avaliação próximos ao código padrão.

A Tabela A.6 mostra o código genético padrão e os melhores códigos obtidos por ambas as abordagens (códigos de maior $p d m$ ). É possível observar que os códigos hipotéticos não são muito similares ao código padrão.

\section{A.6 Considerações finais}

Nos resultados aqui apresentados, duas abordagens multiobjetivo baseadas em entropia foram investigadas para o estudo da adaptabilidade do código genético. Nos códigos com altos valores de entropia, o número médio de mudanças necessárias para trocar um aminoácido por outro é menor, e certamente benéfico para o processo evolutivo que resultou no CGP.

Em ambas as abordagens testadas, a robustez é usada como primeiro objetivo e o termo baseado em entropia é usado como segundo objetivo. A primeira abordagem emprega um GA com pesos para cada objetivo e a segunda utilizada o algoritmo NSGA-II

Ambas as abordagens geram códigos hipotéticos com valores de $p d m$ e melhora melhores do que que os códigos obtidos usando a funçao de avaliação padrão com somente um objetivo (robustez) empregada na literatura, mesmo quando a codificação restritiva foi utilizada. Melhores valores de $p d m$ e melhora indicam que o s códigos hipotéticos aqui obtidos estão mais próximos ao código padrão em termos de fitness. Quando as abordagens multiobjetivo foram comparadas, os melhores resultados foram obtidos pela abordagem de Pareto. Considerando os valores de $p d m$ o mlehor obtido pela abordagem de Pareto foi de $97,676 \%$ contra 91.459\% da abordagem ponderada e $85 \%$ para a abordagem monoobjetivo apresentada em (Santos e Monteagudo, 2010) com a codificação restritiva.

Os resultados indicam que não é necessário utilizar uma codificação restritiva para reduzir o espaço de busca, como tem sido feito na literatura, mas a direção deve ser no sentido de concentrar esforços para a melhora da função de avaliação dos códigos. O pequeno número de coincidências obtido em ambos os experimentos mostra essa necessidade. 
Tabela A.6: Código genético padrão e os código hipotéticos de maior valor de pdm em ambas as abordagens.

\begin{tabular}{|c|c|c|c|c|c|}
\hline codon & código padrão & ponderada $M_{s}$ & ponderada $M_{s t}$ & Pareto $M_{s}$ & Pareto $M_{s t}$ \\
\hline 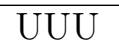 & $\overline{\mathrm{F}}$ & $\overline{\mathrm{S}}$ & $\overline{\mathrm{V}}$ & $\overline{\mathrm{I}}$ & $\overline{\mathrm{I}}$ \\
\hline UUC & F & A & V & $\mathrm{Y}$ & I \\
\hline UUA & $\bar{L}$ & $\mathrm{H}$ & $\mathrm{M}$ & V & $\mathrm{P}$ \\
\hline UUG & $\mathrm{L}$ & Q & $\mathrm{Y}$ & V & $\mathrm{F}$ \\
\hline UCU & $\mathrm{S}$ & $\mathrm{K}$ & $\mathrm{F}$ & $\mathrm{T}$ & $\mathrm{F}$ \\
\hline UCC & $\mathrm{S}$ & $\mathrm{R}$ & $\mathrm{F}$ & $\mathrm{C}$ & $\mathrm{C}$ \\
\hline UCA & $\mathrm{S}$ & $\mathrm{D}$ & $\mathrm{C}$ & W & $\mathrm{V}$ \\
\hline UCG & $\mathrm{S}$ & $\mathrm{E}$ & $\mathrm{I}$ & $\mathrm{C}$ & I \\
\hline UAU & $\mathrm{Y}$ & $\mathrm{T}$ & $\mathrm{D}$ & $\mathrm{H}$ & $\mathrm{C}$ \\
\hline $\mathrm{UAC}$ & $\mathrm{Y}$ & $\bar{Y}$ & $\mathrm{E}$ & $\mathrm{A}$ & $\mathrm{F}$ \\
\hline UGU & $\mathrm{C}$ & S & $\mathrm{H}$ & K & $\mathrm{F}$ \\
\hline UGC & $\mathrm{C}$ & $\mathrm{T}$ & $\mathrm{H}$ & $\mathrm{R}$ & W \\
\hline UGG & $\mathrm{W}$ & Q & S & $\mathrm{N}$ & $\mathrm{L}$ \\
\hline CUU & $\mathrm{L}$ & $\mathrm{A}$ & $\mathrm{V}$ & $\mathrm{F}$ & $\mathrm{A}$ \\
\hline CUC & $\mathrm{L}$ & $\mathrm{P}$ & $\mathrm{V}$ & $\mathrm{M}$ & $\bar{Y}$ \\
\hline CUA & $\mathrm{L}$ & $\mathrm{A}$ & $\mathrm{Y}$ & $\mathrm{P}$ & G \\
\hline CUG & $\mathrm{L}$ & G & $\mathrm{Y}$ & I & $\bar{M}$ \\
\hline $\mathrm{CCU}$ & $\mathrm{P}$ & $\mathrm{H}$ & $\mathrm{F}$ & $\mathrm{L}$ & V \\
\hline $\mathrm{CCC}$ & $\mathrm{P}$ & G & $\mathrm{F}$ & $\mathrm{L}$ & $\bar{Y}$ \\
\hline CCA & $\mathrm{P}$ & $\mathrm{R}$ & $\mathrm{L}$ & V & $\mathrm{S}$ \\
\hline $\mathrm{CCG}$ & $\mathrm{P}$ & $\mathrm{N}$ & I & W & $\mathrm{C}$ \\
\hline $\mathrm{CAU}$ & $\mathrm{H}$ & $\mathrm{V}$ & $\mathrm{K}$ & $\mathrm{Q}$ & $\mathrm{S}$ \\
\hline CAC & $\mathrm{H}$ & W & $\mathrm{K}$ & G & $\mathrm{Y}$ \\
\hline CAA & $\mathrm{Q}$ & $\mathrm{Y}$ & $\mathrm{N}$ & $\mathrm{H}$ & $\bar{K}$ \\
\hline CAG & Q & $\mathrm{P}$ & $\mathrm{N}$ & Q & G \\
\hline $\mathrm{CGU}$ & $\mathrm{R}$ & $\mathrm{T}$ & G & $\mathrm{K}$ & $\mathrm{P}$ \\
\hline CGC & $\mathrm{R}$ & V & G & $\mathrm{D}$ & $\mathrm{T}$ \\
\hline CGA & $\mathrm{R}$ & $\mathrm{T}$ & G & $\mathrm{E}$ & Q \\
\hline CGG & $\mathrm{R}$ & S & S & $\mathrm{E}$ & V \\
\hline AUU & I & $Y$ & $\mathrm{M}$ & $Y$ & S \\
\hline AUC & I & W & $\mathrm{M}$ & $\mathrm{P}$ & $\bar{T}$ \\
\hline AUA & I & V & W & $\mathrm{T}$ & $\mathrm{N}$ \\
\hline $\mathrm{AUG}$ & $\mathrm{M}$ & $\mathrm{P}$ & $\mathrm{W}$ & $\mathrm{P}$ & $\mathrm{T}$ \\
\hline $\mathrm{ACU}$ & $\mathrm{T}$ & $\mathrm{S}$ & $\mathrm{L}$ & I & $\mathrm{S}$ \\
\hline $\mathrm{ACC}$ & $\mathrm{T}$ & A & I & $\mathrm{C}$ & G \\
\hline ACA & $\mathrm{T}$ & G & $\mathrm{C}$ & $\mathrm{Y}$ & $\mathrm{K}$ \\
\hline $\mathrm{ACG}$ & $\mathrm{T}$ & $\mathrm{H}$ & $\mathrm{L}$ & $\mathrm{M}$ & $\mathrm{P}$ \\
\hline $\mathrm{AAU}$ & $\mathrm{N}$ & $\mathrm{L}$ & $\mathrm{R}$ & G & $\mathrm{H}$ \\
\hline $\mathrm{AAC}$ & $\mathrm{N}$ & C & $\mathrm{R}$ & S & $\mathrm{N}$ \\
\hline AAA & $\bar{K}$ & $\mathrm{~L}$ & $\mathrm{Q}$ & $\bar{A}$ & $\bar{D}$ \\
\hline $\mathrm{AAG}$ & $\mathrm{K}$ & $\mathrm{M}$ & Q & G & $\mathrm{R}$ \\
\hline $\mathrm{AGU}$ & S & M & A & $\mathrm{N}$ & $\mathrm{H}$ \\
\hline $\mathrm{AGC}$ & S & I & A & $\mathrm{H}$ & $\mathrm{E}$ \\
\hline AGA & $\mathrm{R}$ & $\mathrm{F}$ & $\mathrm{P}$ & $\mathrm{R}$ & $\mathrm{E}$ \\
\hline $\mathrm{AGG}$ & $\mathrm{R}$ & $\mathrm{P}$ & $\mathrm{T}$ & $\mathrm{K}$ & $\mathrm{D}$ \\
\hline GUU & V & $\mathrm{Y}$ & $\mathrm{M}$ & W & $\mathrm{L}$ \\
\hline GUC & $\mathrm{V}$ & W & $\mathrm{Y}$ & $\mathrm{M}$ & $\mathrm{M}$ \\
\hline GUA & V & $\mathrm{V}$ & W & A & Q \\
\hline GUG & V & $\mathrm{T}$ & W & $\mathrm{T}$ & $\mathrm{Y}$ \\
\hline GCU & A & $\mathrm{S}$ & I & $\mathrm{L}$ & $\mathrm{C}$ \\
\hline
\end{tabular}




\section{APÊNDICE B}

\section{Apêndice: Abordagem de Pareto considerando a codificação restritiva}

A seguir, serão apresentados os resultados obtidos pela abordagem de Pareto com a codificação restritiva. O algoritmo utilizado foi o NSGA-II (ver de Pareto 7). A metodologia utilizada nos experimentos aqui apresentados foi a mesma utilizada nos experimentos do Capítulo 7), exceto pelo fato de que aqui a codificação empregada foi a restritiva. Desse modo os detalhes do algoritmo não serão repetidos aqui. Apenas dois objetivos foram utilizados sendo o primeiro deles o erro médio quadrático considerando a polaridade e o segundo, o erro considerando a hidropatia ou o volume molecular. A etapa de trabalho aqui apresentada foi publicada em (de Oliveira et al., 2015). Os experimentos foram realizados considerando o $M_{s}$ e o $M_{s t}$. 
Tabela B.1: Resultados de avaliação para os objetivos ( $M_{t}$ considerando polaridade $(P)$ e hidropatia $(H))$, pdm e melhora para as soluções não dominadas obtidas pelo NSGA-II. Os valores de $M_{s}$ para o código padrão são 5,19 para a polaridade e 9,39 para a hidropatia.

\begin{tabular}{c|c|c|c|c|c}
\hline & Objetivo 1 & Objetivo 2 & & & \\
solução & $\mathrm{P}$ & $\mathrm{H}$ & dominância & $p d m P R(\%)$ & $p d m H(\%)$ \\
\hline 1 & 3,735 & 5,897 & Sim & 73,975 & 51,847 \\
\hline 2 & 3,820 & 5,781 & Sim & 75,117 & 51,028 \\
\hline 3 & 4,386 & 5,721 & Sim & 83,720 & 50,617 \\
\hline 4 & 3,927 & 5,747 & Sim & 76,610 & 50,796 \\
\hline 5 & 3,835 & 5,767 & Sim & 75,328 & 50,933 \\
\hline 6 & 4,561 & 5,415 & Sim & 86,793 & 48,616 \\
\hline 7 & 3,540 & 6,622 & Sim & 71,479 & 57,607 \\
\hline \hline
\end{tabular}

\section{B.1 Abordagem de Pareto utilizando dois objetivos: Po- laridade e Volume Molecular}

A Tabela B.1 mostra os resultados para as soluções não dominadas utilizando o $M_{s}$ e considerando as propriedades: polaridade e hidropatia. Os valores apresentados nas colunas 2 e 3 são também apresentados na Figura B.1. Os valores de $p d m$ e a distância euclidiana entre o código padrão e o hipotético obtido também são apresentados. O melhor valor de $p d m$ considerando a polaridade foi de $86.79 \%$, enquanto que o mehor valor de $p d m$ considerando a hidropatia foi de $57.61 \%$.

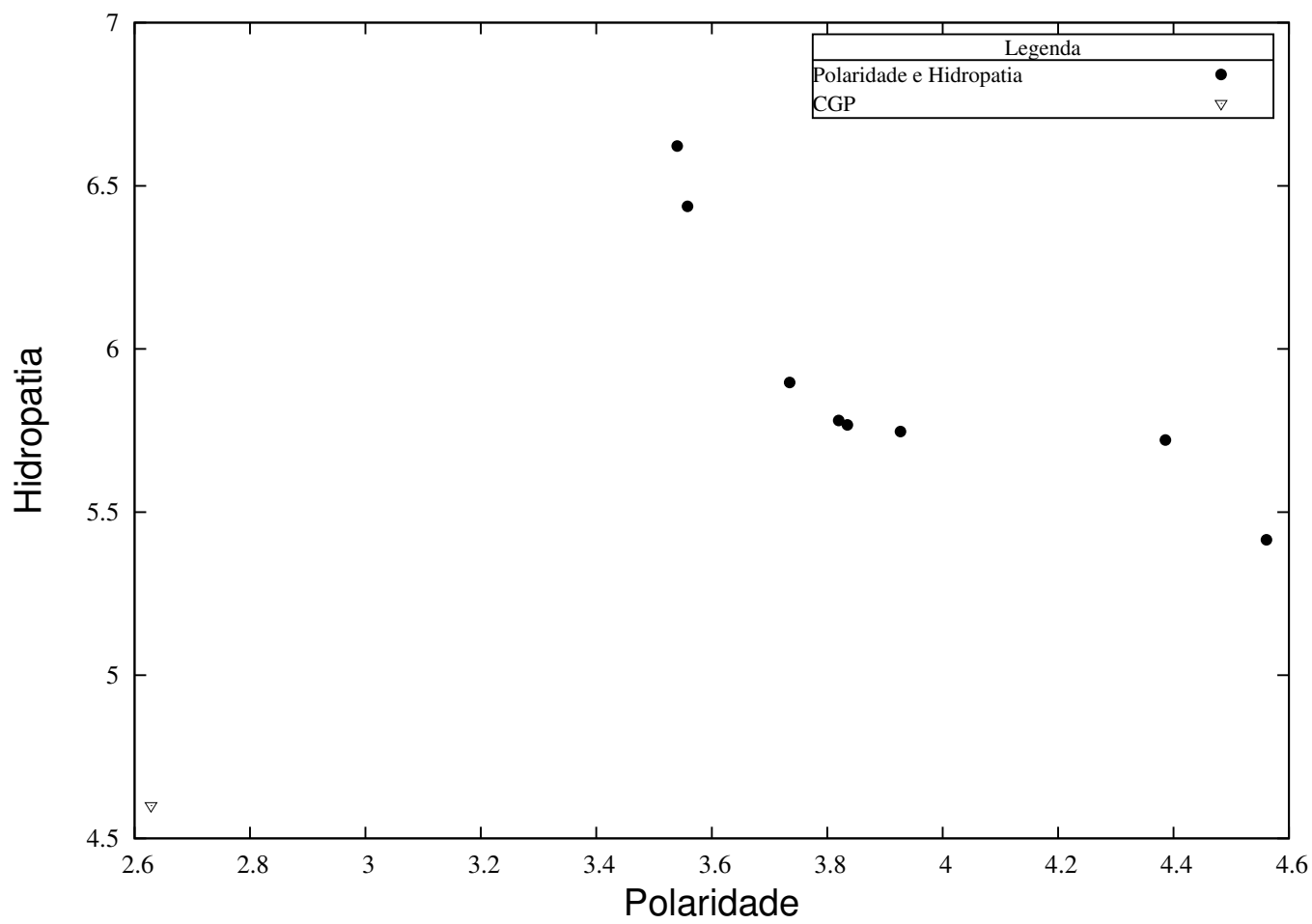

Figura B.1: Fronteira de Pareto para o experimento utilizando polaridade e hidropatia com a codificação restritiva. 
Tabela B.2: Resultados de avaliação para os objetivos ( $M_{\text {st }}$ considerando polaridade e hidropatia), pdm e melhora para as soluções não dominadas obtidas pelo NSGA-II. Os valores de $M_{\text {st }}$ para o código padrão são 2,63 para a polaridade e 4,6 para a hidropatia.

\begin{tabular}{c|c|c|c|c|c|c}
\hline & Objetivo 1 & Objetivo 2 & & & & \\
solução & $\mathrm{P}$ & $\mathrm{H}$ & dist. & dominância & $p d m P R(\%)$ & $p d m H(\%)$ \\
\hline 1 & 2,29 & 2,04 & 0,31 & Sim & 93,73 & 69,84 \\
\hline 2 & 2,25 & 2,05 & 0,31 & Sim & 92,90 & 69,97 \\
\hline 3 & 1,75 & 2,30 & 0,30 & Sim & 85,13 & 72,04 \\
\hline 4 & 1,63 & 2,48 & 0,29 & Sim & 83,38 & 73,65 \\
\hline
\end{tabular}

A Figura B.1 apresenta a fronteira de Pareto obtida pelo algoritmo NSGA-II. Os valores de $M_{s}$ podem ser observados para as soluções da fronteira, assim como para o código genético padrão. É possível observar que o código gerado pela abordagem monoobjetivo tem um valor baixo de $M_{s}$ para a polaridade e um valor alto para a hidropatia, que não está sendo otimizada.

A Tabela B.2 e a Figura B.2 msotram os resultados para o experimento com $M_{s t}$, i.e., considerando pesos em função da posição da base do códon e possíveis erros da tradução. Todas as soluções obtidas dominam o código genético padrão.

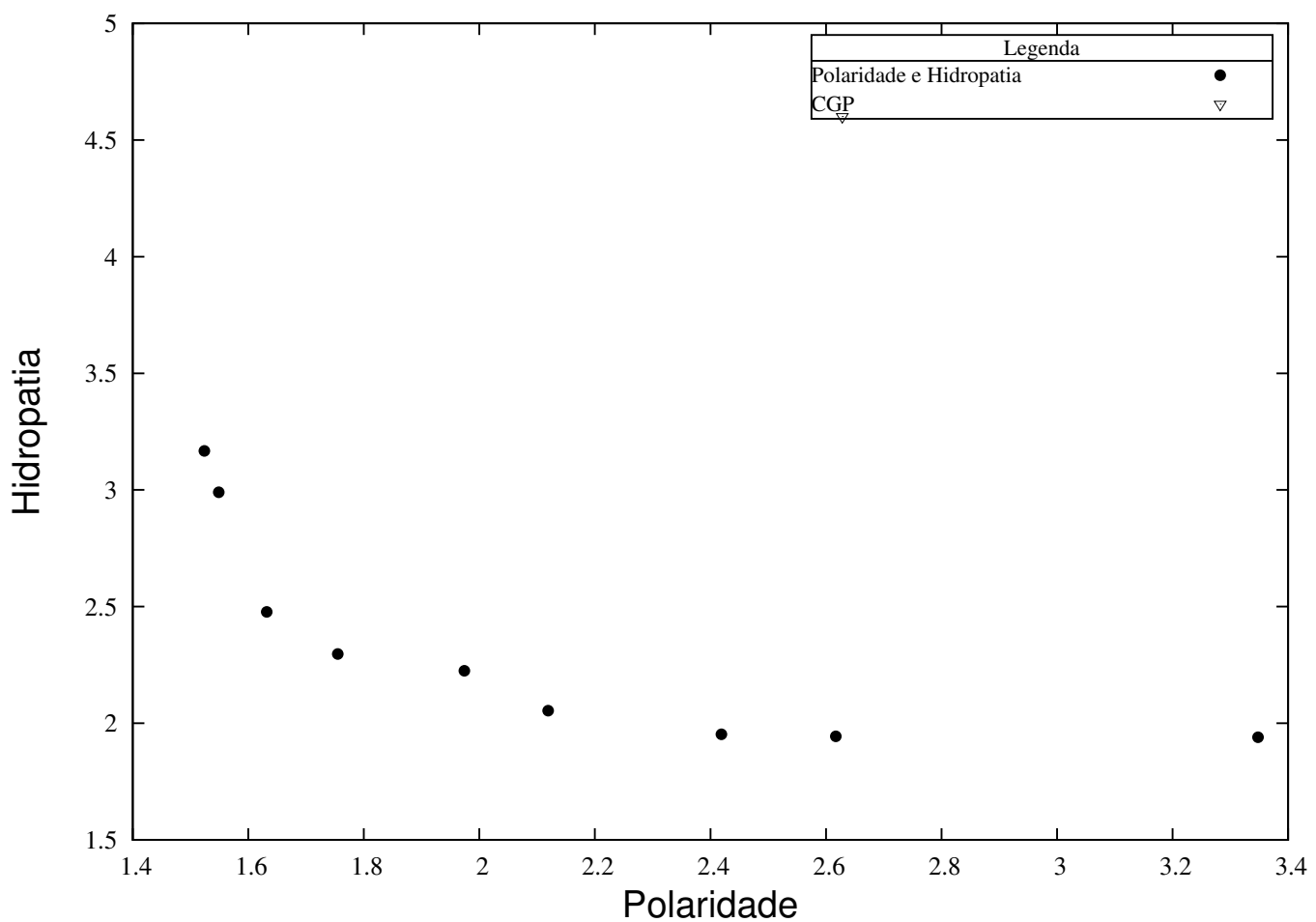

Figura B.2: Fronteira de Pareto para o experimento utilizando polaridade e hidropatia com a codificação restritiva e $M_{s t}$.

O melhor valor de $p d m$ obtido considerando a polaridade foi $93,73 \%$, enquanto que para a hidropatia foi de $73,65 \%$. Ambos os valores foram melhores que aqueles obtidos no experimento com $M_{s}$, mostrando que a consideração de erros no processo de tradução e a ponderação em função da posição da base é uma forma melhor de avaliar os códigos hipo- 
Tabela B.3: Resultados de avaliação para os objetivos $\left(M_{s}\right.$ considerando polaridade e o volume molecular), pdm e melhora para as soluções não dominadas obtidas pelo NSGA-II. Os valores de $M_{s}$ para o código padrão são 5,19 para a polaridade e 2266,13 para o volume.

\begin{tabular}{c|c|c|c|c|c}
\hline solução & $\begin{array}{c}\text { Objetivo 1 } \\
\mathrm{P}\end{array}$ & $\begin{array}{c}\text { Objetivo 2 } \\
\text { VM }\end{array}$ & domina & $p d m P R(\%)$ & $p d m V M(\%)$ \\
\hline 1 & 5,380 & 1550 & Não & - & - \\
\hline 2 & 4,493 & 1907,460 & Sim & 85,587 & 58,945 \\
\hline 3 & 9,628 & 1206,300 & Não & - & - \\
\hline 4 & 4,480 & 1961,500 & Sim & 85,345 & 62,832 \\
\hline 5 & 9,673 & 1198,390 & Não & - & \\
\hline 6 & 4,587 & 1784,450 & Sim & 87,280 & $51,670,832$ \\
\hline 7 & 4,111 & 2562,610 & Não & - & - \\
\hline 8 & 7,617 & 1299,320 & Não & - & - \\
\hline 9 & 4,693 & 1759,040 & Sim & 89,272 & 34,753 \\
\hline 10 & 4,745 & 1687,680 & Sim & 90,284 & 50,385 \\
\hline 11 & 5,565 & 1404,140 & Não & 89,272 & 50,403 \\
\hline 12 & 6,099 & 1303,940 & Não & 90,284 & 47,097 \\
\hline 13 & 8,599 & 1278,680 & Não & - & - \\
\hline 14 & 4,927 & 1557,320 & Sim & 94,012 & 42,080 \\
\hline
\end{tabular}

téticos, possibilitando a obtenção de códigos mais próximos ao código genético padrão, O melhor valor de $p d m$ obtido aqui, também foi mais alto do que o valor calculado com $M_{s t}$ para a polaridade reportado em (Santos e Monteagudo, 2011), que foi de $84 \%$.

\section{B.1.1 Abordagem de Pareto utilizando dois objetivos: Polaridade e Volume Molecular}

A Tabela B.3 e a Figura B.3 mostram os resultados utilizando $M_{s}$ para a polaridade e volume molecular, enquanto que a Tabela B.4 e a Figura B.4 mostram o mesmo experimento para o $M_{s t}$, Os valores de $M_{s}$ calculados para o código padrão foram: 5,19 para a polaridade e 2266,13 para o volume molecular. Quando o $M_{s t}$ foi empregado os valores foram 2,63 para a polaridade e 1766,77 para o volume molecular.

Para o experimento considerando $M_{s}, 8$ das 14 soluções otidas pelo AG não dominam o código genético padrão. O melhor valor de $p d m$ obtido foi de $94,012 \%$ para a polaridade e de $62,832 \%$ para o volume molecular. No experimento considerando $M_{s t}, 7$ das 11 soluções obtidas pelo AG não dominam o código genético padrão. Os melhores valores de $p d m$ obtidos foram $86,214 \%$ para a polaridade e $48,897 \%$ para o volume molecular. 
Tabela B.4: Resultados de avaliação para os objetivos ( $M_{s t}$ considerando polaridade e o volume molecular), pdm e melhora para as soluções não dominadas obtidas pelo NSGA-II. Os valores de $M_{\text {st }}$ para o código padrão são 2,63 para a polaridade e 1766,7 para o volume.

\begin{tabular}{c|c|c|c|c|c}
\hline solução & $\begin{array}{c}\text { Objetivo 1 } \\
\mathrm{P}\end{array}$ & $\begin{array}{c}\text { Objetivo 2 } \\
\text { VM }\end{array}$ & domina & $p d m P R(\%)$ & $p d m V M(\%)$ \\
\hline 1 & 3.884 & 632,507 & Não & - & - \\
\hline 2 & 1.829 & 802,054 & Sim & 86.207 & 33.018 \\
\hline 3 & 1.829 & 797,364 & Sim & 86.214 & 32.911 \\
\hline 4 & 1.821 & 1269,770 & Sim & 86.086 & 48.897 \\
\hline 5 & 3.241 & 732,760 & Não & - & - \\
\hline 6 & 3.348 & 726,481 & Não & - & - \\
\hline 7 & 1.828 & 881,415 & Sim & 86.192 & 34.944 \\
\hline 8 & 4.001 & 628,784 & Não & - & - \\
\hline 9 & 4.288 & 624,356 & Não & - & - \\
\hline 10 & 4.866 & 551,263 & Não & - & - \\
\hline 11 & 4.631 & 584,045 & Não & - & - \\
\hline
\end{tabular}

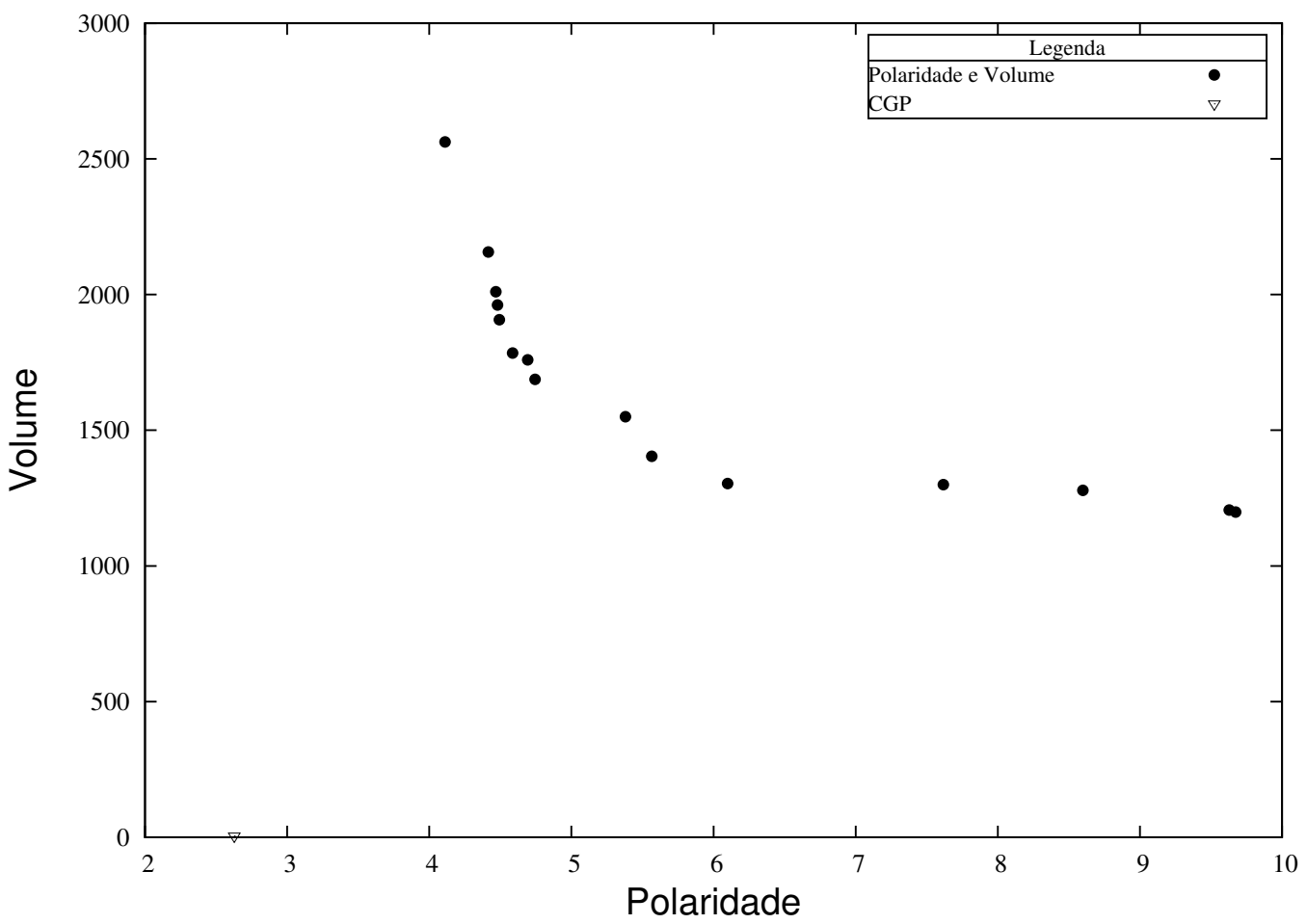

Figura B.3: Fronteira de Pareto para o experimento utilizando polaridade e hidropatia com a codificação restritiva. 
Tabela B.5: Numero de códigos aleatórios melhores que o padrão. Foram gerados 10 milhões de códigos.

\begin{tabular}{c|c|c|c}
\hline \hline & PR & HI & MV \\
\hline \hline Número de códigos $\left(M_{s}\right)$ & 0 & 9 & 7466 \\
\hline Número de códigos $\left(M_{s t}\right)$ & 0 & 0 & 20 \\
\hline \hline
\end{tabular}

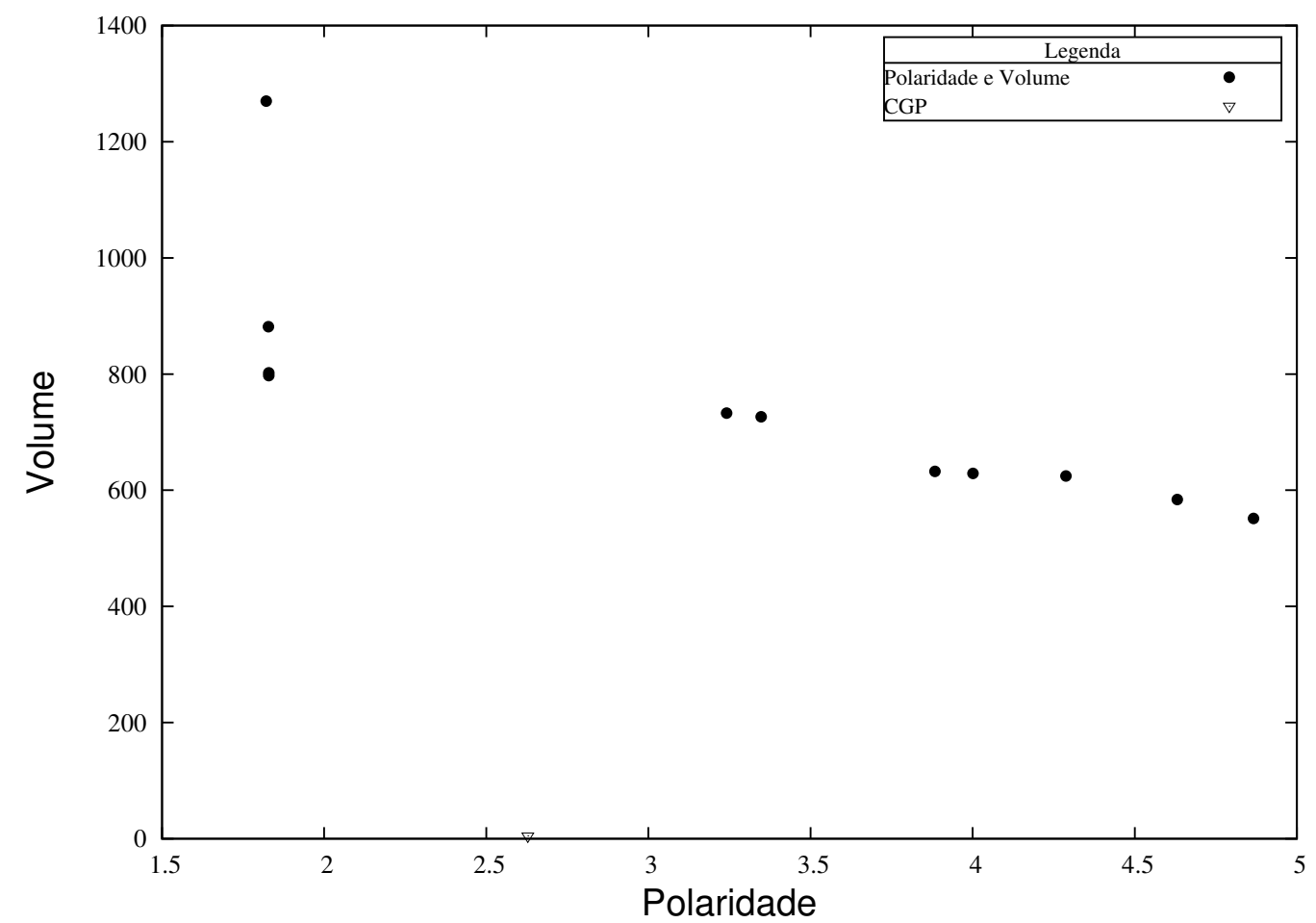

Figura B.4: Fronteira de Pareto para o experimento utilizando polaridade e volume com a codificação restritiva e $M_{s t}$.

\section{B.2 Abordagem estatística}

A fim de comparar os resultados obtidos pela abordagem por engenharia, experimentos foram realizados também com a abordagem estatística. A Tabela B.5 mostra o número de códigos aleatórios gerados que são melhores que o código genético padrão. Os objetivos foram analisados individualmente. Os resultados também confirmam que o uso de pesos e a consideração de erros na tradução resultam em um melhor maneira de avaliar os códigos, uma vez que se torna mais difícil obter códigos aleatórios melhores que o código padrão (quando a polaridade é considerada). Em alguns experimentos, nenhum código aleatório melhor que o padrão foi obtido. Uma limitação da abordagem estatística é para obter códigos melhores que o padrão, o número de códigos aleatórios a serem gerados precisa ser alto. Já na abordagem por engenharia, é possível obter códigos melhores mais facilmente e com menor número de códigos aleatórios.

De qualquer maneira a distribuição de códigos aleatórios pode ser útil para mostrar que 
os melhores códigos obtidos no experimento com o NSGA-II, comparando-os com códigos aleatórios.

\section{B.3 Conclusões}

Na etapa de trabalho apresentada aqui, a abordagem de Pareto foi empregada com a codificação restritiva. Dois objetivos foram utilizados, sendo o primeiro deles a polaridade e o segundo foi a hidropatia ou o volume molecular.

Quando comparados aos resultados da abordagem monoobjetivo com codificação restritiva descritos na literatura, a abordagem multiobjetivo produziu os melhores resultados em termos de $p d m$. O melhor valor de $p d m$ obtido para a polaridade foi de $94,012 \%$ (no experimento com hidropatia) e 90,284\% experimento com volume molecular, contra $84 \%$ obtido pela abordagem monoobjetivo apresentada em (Santos e Monteagudo, 2010). Em outras palavras, os códigos hipotéticos obtidos pelo algoritmo de otimização multiobjetivo tem valor de avaliação mais próximo do código padrão. Quando o volume molecular foi usado, mais soluções não dominam o código padrão.

Outro ponto a ser ressaltado é que os códigos hipotéticos obtidos com o algoritmo multiobjetivo tem um número maior de coincidências com o código padrão do que os obtidos com a abordagem monoobjetivo, porém esse número ainda é pequeno. Maiores detalhes da análise dos resultados obtidos podem ser vistos em (de Oliveira et al., 2015). 


\section{Bibliografia}

Abrantes (2011) Paulo C Abrantes. Filosofia da biologia. Artmed. Citado na pág. 6, 8

Alberts et al. (2010) Bruce Alberts, Alexander Johnson, Julian Lewis, Martin Raff, Keith Roberts e Peter Walter. Biologia molecular da célula. Artmed. Citado na pág. 6, 8

Alff-Steinberger (1969) C Alff-Steinberger. The genetic code and error transmission. Proceedings of the National Academy of Sciences, 64(2):584-591. Citado na pág. 3

Ardell e Sella (2001) David H Ardell e Guy Sella. On the evolution of redundancy in genetic codes. Journal of Molecular Evolution, 53(4-5):269-281. Citado na pág. 13

Bowler (2000) Peter Bowler. The Mendelian revolution: the emergence of hereditarian concepts in modern science and society. A\&C Black. Citado na pág. 10

Branden et al. (1991) C. Branden, J. Tooze et al. Introduction to protein structure, volume 17. Garland Publishing New York. Citado na pág. 6

Buhrman et al. (2011) Harry Buhrman, Peter TS Van der Gulik, Steven M Kelk, Wouter M Koolen e Leen Stougie. Some mathematical refinements concerning error minimization in the genetic code. Computational Biology and Bioinformatics, IEEE/ACM Transactions on, 8(5):1358-1372. Citado na pág. 3

Butler et al. (2009) Thomas Butler, Nigel Goldenfeld, Damien Mathew e Zaida LutheySchulten. Extreme genetic code optimality from a molecular dynamics calculation of amino acid polar requirement. Physical review E, 79(6):060901. Citado na pág. 14

Coello (1999) C.A.C. Coello. List of references on evolutionary multiobjective optimization. http://www.lania.mx/ ccoello/EMOO/EMOObib.html, 1999. Citado na pág. 28

Crick (1968) F. H. Crick. The origin of the genetic code. Journal of Molecular Biology, 38 (3):367-379. Citado na pág. 1, 2, 5, 8

Crow et al. (1970) James F Crow, Motoo Kimura et al. An introduction to population genetics theory. An introduction to population genetics theory. Citado na pág. 11 
de Oliveira et al. (2015) Lariza L de Oliveira, Paulo SL de Oliveira e Renato Tinós. A multiobjective approach to the genetic code adaptability problem. BMC bioinformatics, 16(1):52. Citado na pág. $63,76,82$

de Oliveira e Tinós (2012) Lariza Laura de Oliveira e Renato Tinós. Entropy-based evaluation function for the investigation of genetic code adaptability. Em $B C B$ '12: Proceedings of the ACM Conference on Bioinformatics, Computational Biology and Biomedicine, páginas 558-560. ACM. ISBN 978-1-4503-1670-5. doi: http://doi.acm.org/10.1145/2382936. 2383020. Citado na pág. 25, 63, 67

de Oliveira e Tinós (2014a) Lariza Laura de Oliveira e Renato Tinós. Entropy-based evaluation function in a multi-objective approach for the investigation of the genetic code robustness. Memetic Computing, 6(3):157-170. Citado na pág. 17, 25, 63, 64

de Oliveira e Tinós (2014b) Lariza Laura de Oliveira e Renato Tinós. Using base position errors in an entropy-based evaluation function for the study of genetic code adaptability. Em Nature Inspired Cooperative Strategies for Optimization (NICSO 2013), volume 512 of Studies in Computational Intelligence, páginas 99-111. Springer International Publishing. doi: 10.1007/978-3-319-01692-4_8. Citado na pág. 63

Deb et al. (2002) K. Deb, A. Pratap, S. Agarwal e T. Meyarivan. A fast and elitist multiobjective genetic algorithm: Nsga-ii. Evolutionary Computation, IEEE Transactions on, 6(2):182-197. Citado na pág. 27, 43, 68

Di Giulio (2005) M. Di Giulio. The origin of the genetic code: theories and their relationships, a review. Biosystems, 80(2):175-184. Citado na pág. 2, 5

Di Giulio (1989) M. Di Giulio. The extension reached by the minimization of the polarity distances during the evolution of the genetic code. Journal of Molecular evolution, 29(4): 288-293. Citado na pág. 2, 5, 13, 16, 18, 39

Di Giulio et al. (1994) M. Di Giulio, M.R. Capobianco e M. Medugno. On the optimization of the physicochemical distances between amino acids in the evolution of the genetic code. Journal of Theoretical Biology, 168(1):43-51. Citado na pág. 13

Dunnill (1966) Peter Dunnill. Triplet nucleotide-amino-acid pairing; a stereo-chemical basis for the division between protein and non-protein amino-acids. Nature, 210:12671268. Citado na pág. 11

El-Ghazali (2009) Talbi El-Ghazali. Metaheuristics: from design to implementation. Jonh Wiley and Sons Inc., Chichester. Citado na pág. 27

Epstein (1966) Charles J Epstein. Role of the amino-acidcode'and of selection for conformation in the evolution of proteins. Nature, 210:25-28. Citado na pág. 11

Freeland e Hurst (1998) S. J. Freeland e L. D. Hurst. The genetic code is one in a million. Journal of Molecular Evolution, 47(3):238-248. Citado na pág. 2, 5, 13, 15, 16, 70

Freitas (2004) Alex A Freitas. A critical review of multi-objective optimization in data mining: a position paper. ACM SIGKDD Explorations Newsletter, 6(2):77-86. Citado na pág. 40

Gamow (1954) George Gamow. Possible relation between deoxyribonucleic acid and protein structures. Citado na pág. 11 
Gilis et al. (2001) Dimitri Gilis, Serge Massar, Nicolas J Cerf, Marianne Rooman et al. Optimality of the genetic code with respect to protein stability and amino-acid frequencies. Genome Biol, 2(11):49-1. Citado na pág. 13

Goldberg e Wittes (1966) Alfred L Goldberg e Robert E Wittes. Genetic code: aspects of organization. Science, 153(3734):420-424. Citado na pág. 11

Goldberg (1989) D.E. Goldberg. Genetic algorithms in search, optimization, and machine learning. Addison-wesley. ISBN 0201157675. Citado na pág. 21

Goldman (1993) Nick Goldman. Further results on error minimization in the genetic code. Journal of molecular evolution, 37(6):662-664. Citado na pág. 13, 18

Grantham (1974) R Grantham. Amino acid difference formula to help explain protein evolution. Science, 185(4154):862-864. Citado na pág. xiv, 14, 15

Haig e Hurst (1991) D. Haig e L. D. Hurst. A quantitative measure of error minimization in the genetic code. Journal of Molecular Evolution, 33(5):412-417. Citado na pág. xiv, 2, 13, $15,18,39$

Hartl et al. (1997) Daniel L Hartl, Andrew G Clark e Andrew G Clark. Principles of population genetics, volume 116. Sinauer associates Sunderland. Citado na pág. 10

Haupt e Haupt (1998) R. L. Haupt e S. E. Haupt. Practical genetic algorithms. John Wiley \& Sons, Inc. ISBN 047-1188735. Citado na pág. 20, 21

Hornos e Hornos (1993) José Eduardo M Hornos e Yvone MM Hornos. Algebraic model for the evolution of the genetic code. Physical Review Letters, 71(26):4401-4404. Citado na pág. 19

Judson e Haydon (1999) Olivia P Judson e Daniel Haydon. The genetic code: what is it good for? an analysis of the effects of selection pressures on genetic codes. Journal of Molecular Evolution, 49(5):539-550. Citado na pág. 18, 19

Kimura (1984) Motoo Kimura. The neutral theory of molecular evolution. Cambridge University Press. Citado na pág. 11

Klug et al. (2010) William S Klug, Michael R Cummings, Charlotte A Spencer e Michael A Palladino. Conceitos de genética. Artmed. Citado na pág. 9

Knight et al. (1999) R. D. Knight, S. J. Freeland e L. F. Landweber. Selection, history and chemistry: the three faces of the genetic code. Trends in Biochemical Sciences, 24(6): 241-247. Citado na pág. 2, 3

Knight et al. (2001) Robin D Knight, Stephen J Freeland e Laura F Landweber. Rewiring the keyboard: evolvability of the genetic code. Nature Reviews Genetics, 2(1):49-58. Citado na pág. 2

Konak et al. (2006) A. Konak, D.W. Coit e A.E. Smith. Multi-objective optimization using genetic algorithms: A tutorial. Reliability Engineering \& System Safety, 91(9):992-1007. Citado na pág. 28

Koonin e Novozhilov (2009) Eugene V Koonin e Artem S Novozhilov. Origin and evolution of the genetic code: the universal enigma. IUBMB life, 61(2):99-111. Citado na pág. 2 
Kyte e Doolittle (1982) Jack Kyte e Russell F Doolittle. A simple method for displaying the hydropathic character of a protein. Journal of molecular biology, 157(1):105-132. Citado na pág. xiv, 14,15

Leach (2001) A. R. Leach. Molecular Modelling: Principles and Applications. Pearson Education Ema, 2nd edition ed. Citado na pág. 7

Lehninger et al. (2005) A. L. Lehninger, D. L. Nelson e M. M. Cox. Lehninger Principles of Biochemistry. W. H. Freeman, 4th ed. Citado na pág. xi, 1, 2, 7, 8, 9, 12, 13, 15

Lodish et al. (2007) H. Lodish, A. Berk, S. Lawrence Zipursky, Chris A. Kaiser, M. Krieger, M. P. Scott, A. Bretscher, H. Ploegh e P. Matsudaira. Molecular Cell Biology. W. H. Freeman, 6th ed. Citado na pág. 6, 15

Luenberger e Ye (2008) D.G. Luenberger e Y. Ye. Linear and nonlinear programming. Springer Verlag. ISBN 0387745025. Citado na pág. 21

Maddox (1994) John Maddox. The genetic code by numbers. Nature, 367(6459):111. Citado na pág. 2,19

Mitchell (1996) M. Mitchell. An Introduction To Genetic Algorithms. Mit Press. ISBN 0-262-13316-4. Citado na pág. 20, 21

Monteagudo e Santos (2007) Ángel Monteagudo e José Santos. Simulated evolution of the adaptability of the genetic code using genetic algorithms. Em Bio-inspired Modeling of Cognitive Tasks, páginas 478-487. Springer. Citado na pág. 2, 19

Novozhilov et al. (2007) Artem S Novozhilov, Yuri I Wolf e Eugene V Koonin. Evolution of the genetic code: partial optimization of a random code for robustness to translation error in a rugged fitness landscape. Biology Direct, 2(24):1-24. Citado na pág. 11

Parker (1989) J. Parker. Errors and alternatives in reading the universal genetic code. Microbiology and Molecular Biology Reviews, 53(3):273. Citado na pág. 2, 15

Parsopoulos e Vrahatis (2002) K.E. Parsopoulos e M.N. Vrahatis. Particle swarm optimization method in multiobjective problems. Em Proceedings of the 2002 ACM symposium on Applied computing, páginas 603-607. ACM. Citado na pág. 28

Pelc e Welton (1966) SR Pelc e MG Welton. Stereochemical relationship between coding triplets and amino-acids. Nature, 209(5026):868-870. Citado na pág. 11

Santos e Monteagudo (2010) J. Santos e Á. Monteagudo. Study of the genetic code adaptability by means of a genetic algorithm. Journal of Theoretical Biology, 264(3): 854-865. Citado na pág. 3, 13, 14, 16, 19, 24, 25, 29, 30, 39, 40, 47, 68, 69, 70, 71, 74, 82

Santos e Monteagudo (2011) J. Santos e Á. Monteagudo. Simulated evolution applied to study the genetic code optimality using a model of codon reassignments. BMC Bioinformatics, 12(1):56. Citado na pág. 63,79

Santos e Monteagudo (2009) José Santos e Ángel Monteagudo. Genetic code optimality studied by means of simulated evolution and within the coevolution theory of the canonical code organization. Natural Computing, 8(4):719-738. Citado na pág. 13, 17 
Schoenauer e Clote (1997) S. Schoenauer e P. Clote. How optimal is the genetic code. Em Computer Science and Biology, Proceedings of the German Conference on Bioinformatics ( $\left.G C B^{\prime} 97\right)$, páginas $65-67$. Citado na pág. 2

Sonneborn (1965) TM Sonneborn. Degeneracy of the genetic code: extent, nature, and genetic implications. Evolving genes and proteins. Academic Press, New York, páginas 377-397. Citado na pág. 11

Suman e Kumar (2005) B. Suman e P. Kumar. A survey of simulated annealing as a tool for single and multiobjective optimization. Journal of the operational research society, 57 (10):1143-1160. Citado na pág. 28

Szathmáry e Zintzaras (1992) Eörs Szathmáry e Elias Zintzaras. A statistical test of hypotheses on the organization and origin of the genetic code. Journal of molecular evolution, 35(3):185-189. Citado na pág. 18

Vetsigian et al. (2006) Kalin Vetsigian, Carl Woese e Nigel Goldenfeld. Collective evolution and the genetic code. Proceedings of the National Academy of Sciences, 103(28):1069610701. Citado na pág. 2

Woese (1965) C. R. Woese. On the evolution of the genetic code. Proceedings of the National Academy of Sciences of the United States of America, 54(6):1546-1552. Citado na pág. xiv, 2, 5, 14, 15, 18, 39

Wong (1975) J Tze-Fei Wong. A co-evolution theory of the genetic code. Proceedings of the National Academy of Sciences of the United States of America, 72(5):1909. Citado na pág. 11

Wong (2005) J Tze-Fei Wong. Coevolution theory of the genetic code at age thirty. BioEssays, 27(4):416-425. Citado na pág. 12

Zaha et al. (2014) Arnaldo Zaha, Henrique Bunselmeyer Ferreira e Luciane MP Passaglia. Biologia Molecular Básica-5. Artmed Editora. Citado na pág. 10 